\title{
Missing Selectivity of Targeted $4 \beta-$ Phorbol Prodrugs Expected to be Potential Chemotherapeutics
}

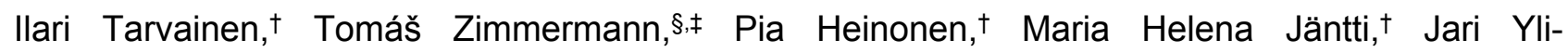
Kauhaluoma, \| Virpi Talman,,$^{\dagger,}{ }^{\perp}$ Henrik Franzyk, ${ }^{\S}$ Raimo K Tuominen, ${ }^{\dagger}$ Søren Brøgger Christensen $\S^{*}$ Ilari Tarvainen, ${ }^{\dagger}$ Tomáš Zimmermann,, ,ł Pia J Heinonen, ${ }^{\dagger}$ Maria $\mathrm{H}$ Jäntti, ${ }^{\dagger}$ Jari Yli-Kauhaluoma,\| Virpi Talman, ${ }^{\dagger}{ }^{\perp}$ Henrik Franzyk, ${ }^{\S}$ Raimo K Tuominen, ${ }^{\dagger}$ Søren Brøgger Christensen $\aleph^{\star}$

† Drug Research Program, Division of Pharmacology and Pharmacotherapy, Faculty of Pharmacy, University of Helsinki, Helsinki, Finland

$\S$ Department of Drug Design and Pharmacology, Faculty of Health and Medical Sciences, University of Copenhagen, Jagtvej 162, DK-2100, Copenhagen, Denmark

‡ Department of Chemistry of Natural Compounds, Faculty of Food and Biochemical Technology, University of Chemistry and Technology, Prague, Czech Republic

\| Drug Research Program, Division of Pharmaceutical Chemistry and Technology, Faculty of Pharmacy, University of Helsinki, Helsinki, Finland

${ }^{\perp}$ National Heart and Lung Institute, Imperial College London, London, United Kingdom

Contents:

Syntheses of compounds $\mathbf{2}-\mathbf{6}$

pages $\mathrm{S} 2-\mathrm{S} 6$

Fig. S1 Displacement assay

page $\mathrm{S} 10$

Fig. S2 Nummerical cell death

pages $\mathrm{S} 12$

Fig. S3. PKC $\alpha,-\delta$ and PSMA expression in 22Rv1 cell line

page $\mathrm{S} 16$

Fig. S4 Blot images of PKC, PSMA and GADH expression

page $\mathrm{S} 17$

Fig. S5 Blot images of ERK phosphorylation after exposure to drugs

Fig. S7 - S10 Spectra of compound 3

page $\mathrm{S} 19$

Fig. S11 - S14 Spectra of compound 2

pages $\mathrm{S} 27-\mathrm{S} 30$

Fig. S15 - S18 Spectra of compound 5

pages $\mathrm{S} 32-\mathrm{S} 35$

Fig. S19 - S22 Spectra of compound 4

pages $\mathrm{S} 38-\mathrm{S} 41$

Fig. S23 - S26 Spectra of compound 6

pages $\mathrm{S} 44-\mathrm{S} 47$

pages $\mathrm{S} 50-\mathrm{S} 53$

Fig. S27 Structures of thapsigargin and prodrugs and peptides

page $\mathrm{S} 54$

Table S1 Displacement assay

page $\mathrm{S} 10$

Table S2 LDH data

pages $\mathrm{S} 13-\mathrm{S} 14$

Table S3 PKC and PSMA expression

page $\mathrm{S} 18$

Table S4 MTT numerical data

page S19-S21

Table S5 MTT numerical data

page S21

Scheme S6

page $S 22$ 


\section{S1: Syntheses of Compounds 2 - 6}

\section{S1.1: Synthesis of Cytotoxin 2}

By using solid-phase synthesis for the conjugation several protection-deprotection steps were avoided. First 12-Aminododecanoic acid was loaded onto a 2-chlorotrityl chloride (2-CTC) resin, and upon removal of the fluorenylmethyloxycarbonyl (Fmoc) group Boc-Leu-OH was attached. The resulting resin-bound Boc-Leu-12-aminododecanoic acid was released from the resin under mildly acidic conditions, and was then coupled to 9 by Steglich esterification using 1-ethyl-3-(3dimethylaminopropyl)carbodiimide (EDC) and 4-(N,N-dimethylamino)pyridine (DMAP) to give compound 2 (Scheme 1).
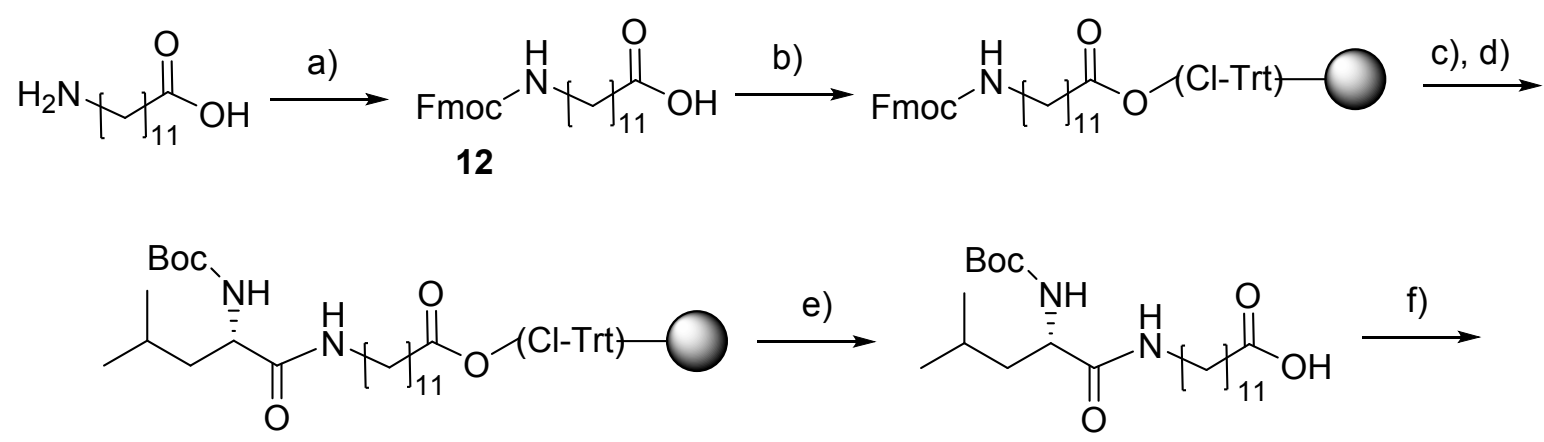

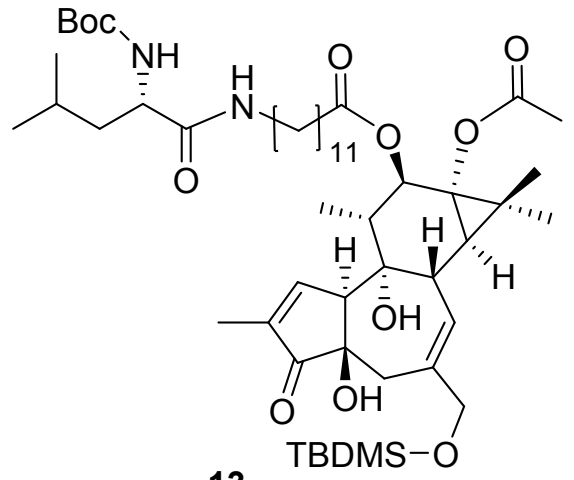

13

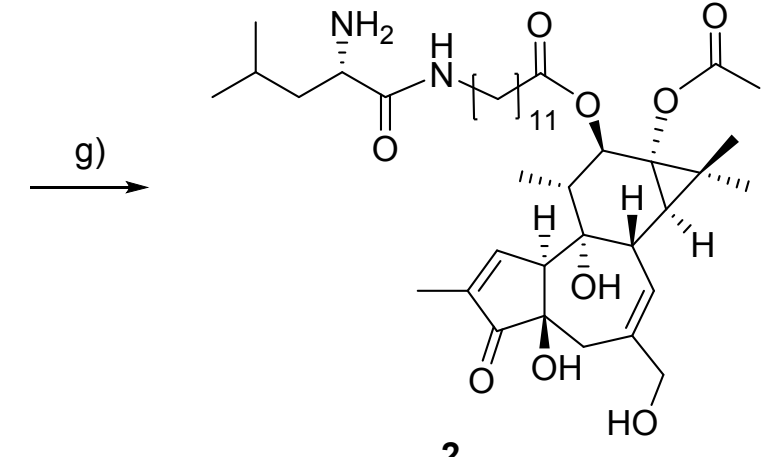

Scheme S1. Synthesis of compound 2. Reagents and conditions: (a) Fmoc-OSu, $\mathrm{NaHCO}_{3}, \mathrm{H}_{2} \mathrm{O}$-acetone (1:1), $23^{\circ} \mathrm{C}$, $20 \mathrm{~h}$ (43\%); (b) 2-CTC resin, DIPEA, $23^{\circ} \mathrm{C}, 3 \mathrm{~h}$; (c) $20 \%$ Piperidine in DMF, $23{ }^{\circ} \mathrm{C}, 2 \times 20 \mathrm{~min}$; (d) Boc-Leu-OH, PyBOP, DIPEA, DMF, $4 \mathrm{~h}, 23{ }^{\circ} \mathrm{C}$; (e) $20 \% \mathrm{HFIP}$ in DCM, $23{ }^{\circ} \mathrm{C}, 3 \times 30 \mathrm{~min}$; (f) EDC, DMAP, compound $9,23{ }^{\circ} \mathrm{C}(86 \%), 15 \mathrm{~h}$, DCM-THF (1:1); (g) $23^{\circ} \mathrm{C}, 3 \mathrm{~h}$, TFA-DCM (1:1) (30\%). 


\section{S1.2: Synthesis of Intermediate 3}

Fmoc-Asp- $\alpha-O t B u$ was coupled to resin-bound 12-aminododecanoic acid, and the resulting Fmoc$\beta$-Asp(OtBu)-N-12-aminododecanoic acid was released from the resin. In order to avoid undesired DMAP-catalyzed removal of the Fmoc protecting group during synthesis of 14 Fmoc- $\beta-A s p(O t B u)-$ 12-aminododecanoic acid was esterified with 9 by using a minimum amount of DMAP. The Boc and TBDMS groups were removed simultaneously with TFA, while the Fmoc group was deprotected with diethylamine in DCM to provide target compound 3 (Scheme 2).

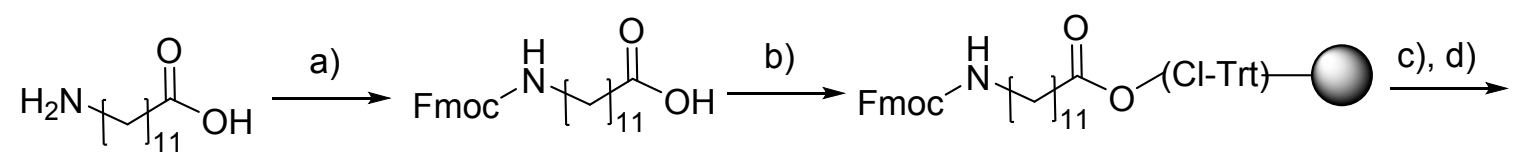

12

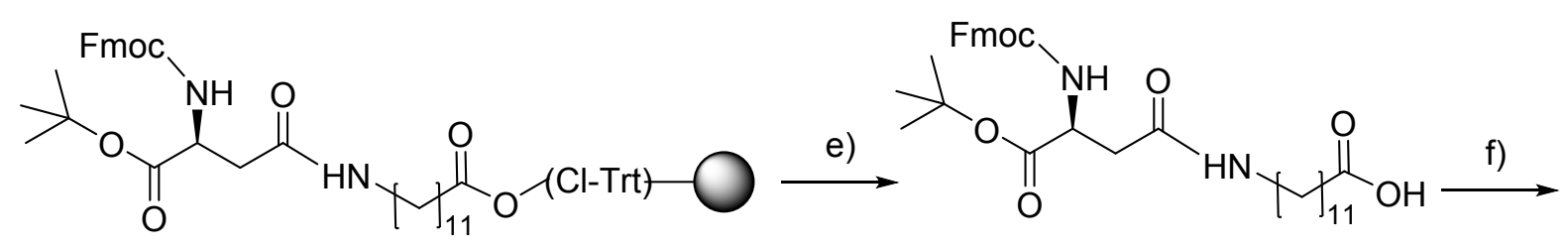

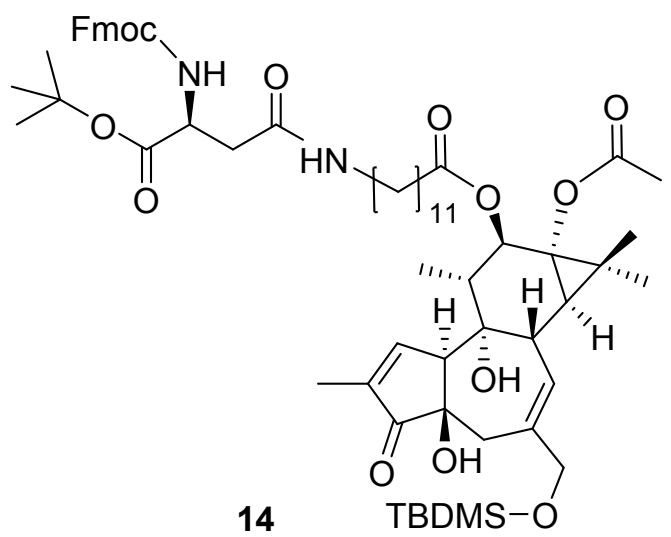

g), h)

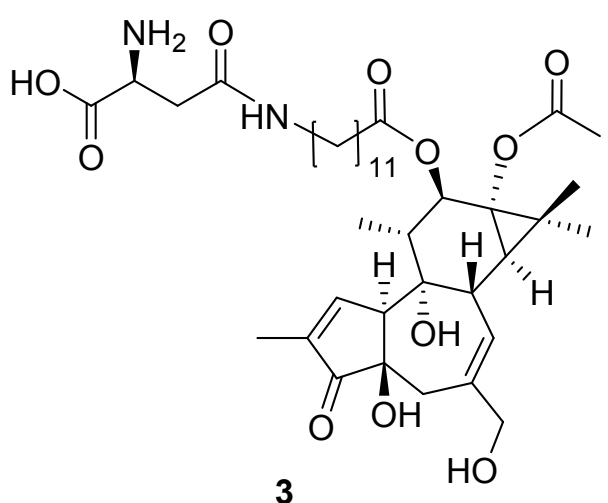

Scheme S2. Synthesis of compound 3. Reagents and conditions: (a) Fmoc-OSu, $\mathrm{NaHCO}_{3}, \mathrm{H}_{2} \mathrm{O}-$ Acetone (1:1), $23^{\circ} \mathrm{C}$, $20 \mathrm{~h}(43 \%)$, 12-Aminododecanoic acid; (b) 2-CTC resin, DIPEA, $23^{\circ} \mathrm{C}, 3 \mathrm{~h}$; (c) $20 \%$ Piperidine in DMF, $23{ }^{\circ} \mathrm{C}, 2 \times 20 \mathrm{~min}$; (d) Fmoc-Asp-OtBu, PyBOP, DIPEA, DMF, $4 \mathrm{~h}, 23{ }^{\circ} \mathrm{C}$; (e) $20 \% \mathrm{HFIP}$ in DCM, $23{ }^{\circ} \mathrm{C}$, $3 \times 30 \mathrm{~min}$; (f) EDC, $10 \mathrm{~mol} \%$ DMAP, compound $9,23^{\circ} \mathrm{C}, 25 \mathrm{~h}$, DCM-THF (1:1) (42\%); (g) $23^{\circ} \mathrm{C}, 1 \mathrm{~h}$, TFA-DCM (1:1); (h) $23{ }^{\circ} \mathrm{C}, 1 \mathrm{~h}, 20 \% \mathrm{Et}_{2} \mathrm{NH}$ in DCM (62\%). 


\section{S1.3: Synthesis of prodrug 4}

The peptide sequences Gly-Lys-Ala-Phe-Arg-Arg-Leu and His-Ser-Ser-Lys-Leu-Gln-Leu were assembled on an Fmoc-Leu-preloaded 2-chlorotrityl resin by using a CEM Liberty Blue ${ }^{\mathrm{TM}}$ automated microwave (MW) peptide synthesizer. The protected resin-bound peptide Gly-Lys-AlaPhe-Arg-Arg-Leu was end-capped by acetylation. After washing the capped and protected peptide was released from the resin, and then the peptide was coupled in solution to 8 . Finally, the protecting groups were removed with TFA to give prodrug 4 (Scheme 3 ).<smiles>CC(C)CC(N=P)C(=O)OCC#CCOc1ccccc1</smiles>

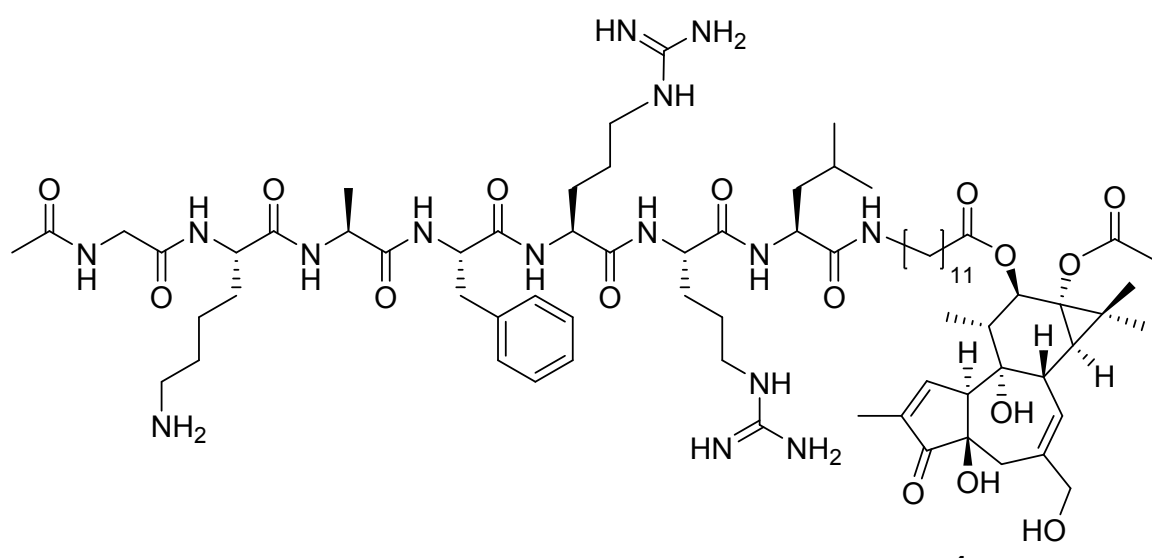

Scheme S3. Synthesis of phorbol prodrug 4 (substrate for hK2). (a) SPPS of protected Gly-Lys-Ala-Phe-Arg-Arg-Leu on a MW peptide synthesizer; (b) NMP-DIPEA-Ac $2 \mathrm{O}(3: 2: 1), 23{ }^{\circ} \mathrm{C}, 2 \times 10 \mathrm{~min}$ (c) $20 \% \mathrm{HFIP}$ in DCM, $23^{\circ} \mathrm{C}, 3 \times 30 \mathrm{~min}$; (d) 12-O-(12-Aminododecanoyl)-13-O-acetyl-4ß-phorbol (8), PyBOP, DIPEA, $40{ }^{\circ} \mathrm{C}, 26 \mathrm{~h}$; (e) TFA-DCM (2:1), $\mathrm{H}_{2} \mathrm{O}$ (few drops), $23^{\circ} \mathrm{C}, 80 \mathrm{~min}$. 


\section{S1.4: Synthesis of Prodrug 5}

Upon MW-assisted assembly the protected resin-bound peptide His-Ser-Ser-Lys-Leu-GIn-Leu was modified with a urea moiety by reaction with morpholine-4-carbonyl chloride to give the protected peptide of prodrug 5. After release from the resin the end-capped protected peptide was coupled in solution with 8. Acid-labile protecting groups were removed with TFA to give prodrug 5 (Scheme 4).<smiles>CCNC(=O)CC[C@H](NC(=O)[C@H](CC(C)C)NC(=O)[C@H](CC(C)C)NC(=O)[C@H](CCCCN)NC(=O)[C@H](COC(C)(C)C)NC(=O)[C@H](COC(C)(C)C)NC(=O)[C@H](Cc1cnn(C(C)(C)C)c1)NC(=O)N1CCOCC1)C(=O)O</smiles>

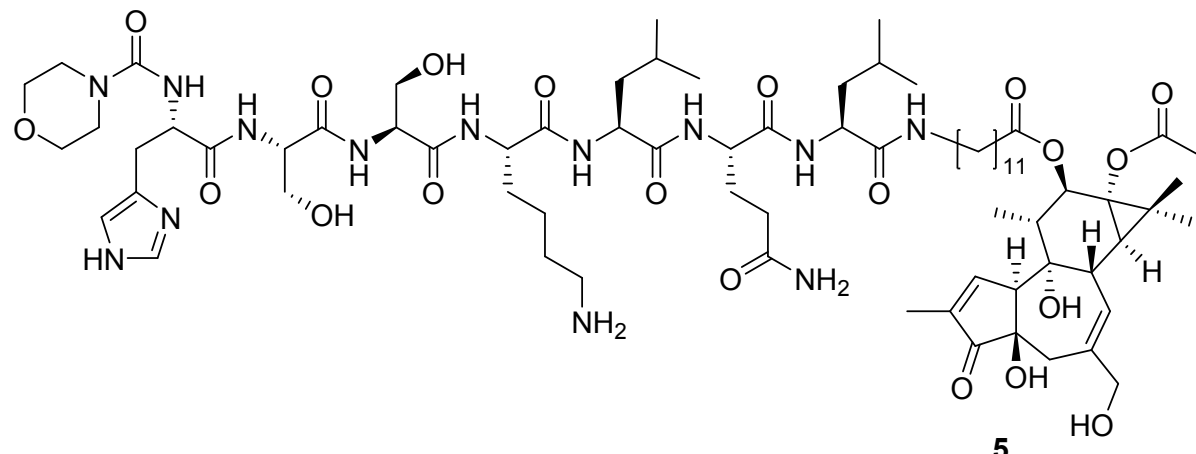

Scheme S4. Synthesis of phorbol prodrug 5 (substrate for PSA). (a) SPPS of protected His-Ser-Ser-Lys-Leu-GIn-Leu on a MW peptide synthesizer; (b) Morpholine-4-carbonyl chloride-Et ${ }_{3} \mathrm{~N}-\mathrm{NMP}(1: 4: 15), 40{ }^{\circ} \mathrm{C}, 3 \mathrm{~h}$; (c) $20 \% \mathrm{HFIP}$ in DCM, 23 ${ }^{\circ} \mathrm{C}, 3 \times 30 \mathrm{~min}$; (d) 12-O-(12-aminododecanoyl)-13-O-acetyl-4ß-phorbol (8), PyBOP, DIPEA, $23{ }^{\circ} \mathrm{C}, 21 \mathrm{~h}$; (e) TFA-DCM (1:1), $\mathrm{H}_{2} \mathrm{O}$ (few drops), $23^{\circ} \mathrm{C}, 1 \mathrm{~h}(13 \%)$. 


\section{S1.5: Synthesis of prodrug 6}

Synthesis of protected $\gamma$-Glu-y-Glu-y-Glu- - -Glu- $\alpha-A s p$ is depicted in Scheme 5 . Since sterical hindrance was expected to be an issue in the on-resin coupling with $\mathbf{8}$, a downloading of the CTC resin was performed, and the synthesis was carried out manually. Fmoc-Glu-OtBu was loaded onto the CTC resin, and the resulting loading was estimated before continuing the SPPS. The preloaded resin was placed into a syringe fitted with a polypropylene filter, and three additional $\gamma$ Glu residues were attached, followed by coupling of Boc-Asp(All)-OH. The orthogonal protection scheme enabled selective removal of the allyl protecting group. Gratifying, the on-resin coupling of $\mathbf{8}$ to the peptide proceeded satisfactorily. After side-chain deprotection and cleavage from the resin with TFA 6 was obtained (Scheme 5).

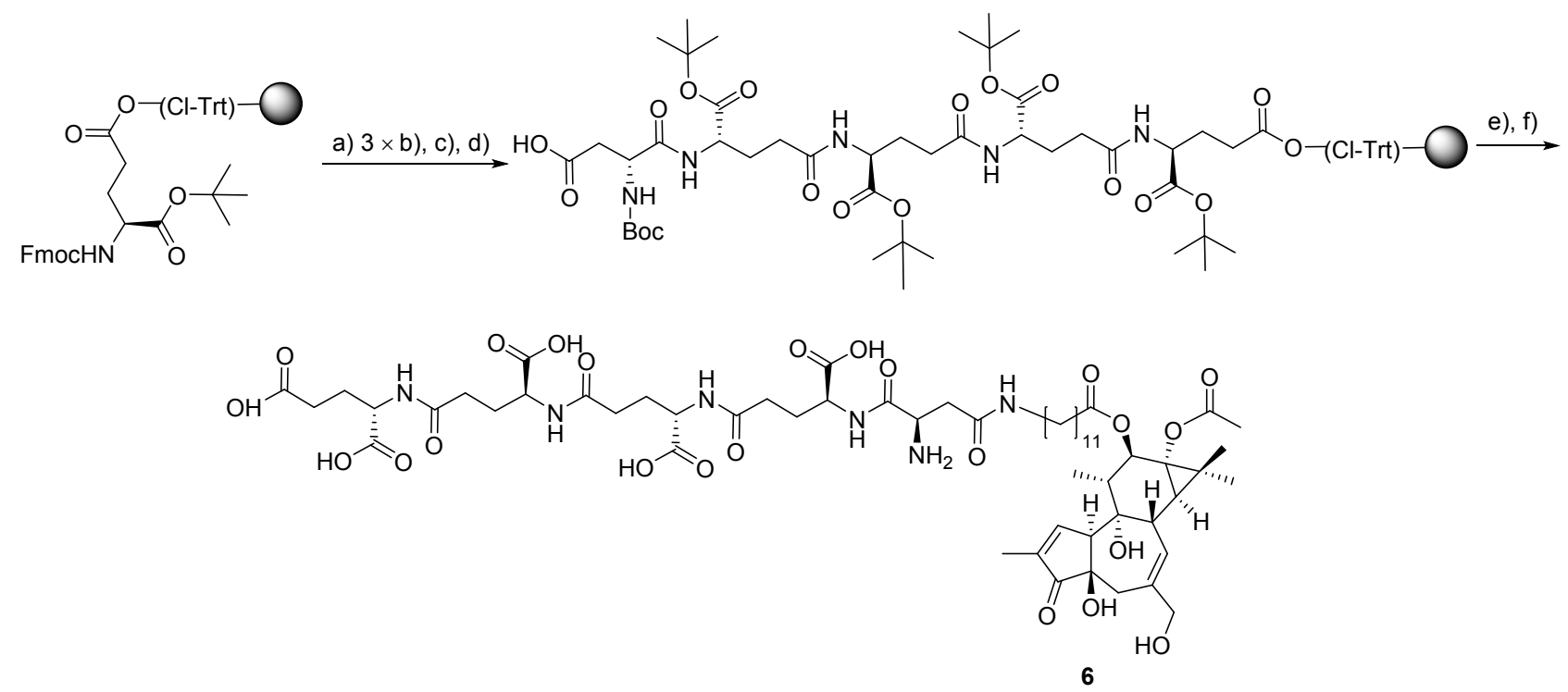

Scheme S5. Synthesis of phorbol prodrug 6 (substrate for PSMA). Reagents and conditions: (a) 20\% Piperidine in DMF, (b) Fmoc-Glu-OtBu, PyBOP, DIPEA, DMF, $23{ }^{\circ} \mathrm{C}, 16 \mathrm{~h}$, followed by $20 \%$ piperidine in DMSO; (c) Boc-Asp(All)-OH, PyBOP, DIPEA, DMF, $23^{\circ} \mathrm{C}, 18 \mathrm{~h}$; (d) $\mathrm{Me}_{2} \mathrm{~N} \cdot \mathrm{BH}_{3}, \mathrm{Pd}\left(\mathrm{PPh}_{3}\right)_{4}$ in $\mathrm{DCM}, 23^{\circ} \mathrm{C}, 6 \mathrm{~h}$; (e) 12-O-(12-Aminododecanoyl)-13-Oacetyl-4ß-phorbol (8), PyBOP, DIPEA, DCM, $23^{\circ} \mathrm{C}, 18 \mathrm{~h}$; (f) TFA-DCM (1:1), $\mathrm{H}_{2} \mathrm{O}$ (few drops), $1 \mathrm{~h}(21 \%)$. 


\section{S2: Experimental section}

S2.1. Starting material, reagents, cells and solvents

$4 \beta-P h o r b o l ~(7)$ was obtained from seeds of Croton tiglium purchased from Herbalveda UK, East Harrow Middlesex by extraction and solvolysis 1 while $\mathrm{O}-8$-(Leu- $\mathrm{N}$-12-aminododecanoyl-)-8-Odebutanoyl-thapsigargin (Tg2), O-8-( $\beta$-Asp- $N$-12-aminododecanoyl)-8-O-debutanoyl-thapsigargin (Tg3), O-8-(Boc-N-12-aminododecanoyl)-8-O-debutanoyl-thapsigargin (Tg1) were available in our lab. Mipsagargin (Tg6) was prepared as already reported ${ }^{1}$ All Fmoc-protected standard amino acids, 2-(1H-benzotriazol-1-yl)-1,1,3,3-tetramethyluronium hexafluorophosphate (HBTU), N,Ndiisopropylethylamine (DIPEA), 1,1,1,3,3,3-hexafluoro-2-propanol (HFIP), 1-ethyl-3-(3dimethylaminopropyl)carbodiimide (EDC), benzotriazol-1-yl-oxytripyrrolidinophosphonium hexafluorophosphate (PyBOP) and 2-chlorotrityl chloride (CTC) resin (loading: 1.0-1.6 mmol/g) were purchased from Iris Biotech $\mathrm{GmbH}$ (Marktredwitz, Germany). Borane dimethylamino complex, 3-(4,5-dimethylthiazol-2-yl)-2,5-diphenyltetrazolium bromide (MTT), phorbol 12-myristate 13-acetate (PMA) phosphatidyl-L-serine (PS; product number: P6641), bovine immunoglobulin G (lgG), the pan-PKC inhibitor Gö6983 and $\mathrm{Pd}\left(\mathrm{PPh}_{3}\right)_{4}$ were purchased from Sigma-Aldrich. BocAsp(All)-OH and Fmoc-Glu-OtBu were purchased from Bachem AG (Bubendorf, Switzerland). All solvents and deprotection and cleavage reagents were of synthesis grade purchased from Iris Biotech GmbH (Marktredwitz, Germany). Solvents for column chromatography, HPLC, HRMS and HR-MALDI-TOF were of HPLC grade purchased from VWR International. [20-3H]Phorbol-12,13dibutyrate $\left(\left[{ }^{3} \mathrm{H}\right] \mathrm{PDBu}\right)(20 \mathrm{Ci} / \mathrm{mmol})$ was acquired from American Radiolabeled Chemicals Inc. (St. Louis, MO, USA). LNCaP22Rv1, DU145, and PC3 cells were from ATCC (Manassas, VA, USA) (HTB-81; CRL-2505; CRL-1740 and CRL-1435). Protease inhibitors (Complete Protease Inhibitor Cocktail Tablets) were from Roche (Mannheim, Germany), and the Optiphase SuperMix liquid scintillant was from PerkinElmer (Groningen, The Netherlands). Croton tiglium seeds were purchased from Herbalveda UK, East Harrow Middlesex, UK.

\section{S2.2. Solid-phase peptide synthesis (SPPS)}

Protected peptide P3 (for numbering see Supplementary data) was synthesized by manual SPPS by using a 2-Cl-Trt resin preloaded with Fmoc-Glu-OtBu. Peptides P1 and P2 were assembled on a 2-CTC resin preloaded with Fmoc-Leu-OH by using a Liberty Blue ${ }^{\mathrm{TM}}$ automated microwave peptide synthesizer (CEM Corp., Matthews, NC, USA) following an Fmoc/tBu protocol. In all cases, a 2-CTC resin (loading: 1.0-1.6 mmol/g) was used as the solid phase. Couplings were performed by using $0.2 \mathrm{M}$ solutions of $\mathrm{N}^{\alpha}$-Fmoc-protected amino acid building blocks ( 5 equiv; with acid-labile $t \mathrm{Bu} / \mathrm{Trt} / \mathrm{Boc} / \mathrm{Pbf}$ as side-chain protecting groups) in DMF in combination with a $0.5 \mathrm{M}$ solution of HBTU (5.0 equiv) as a coupling reagent and a $2 \mathrm{M}$ solution of DIPEA in NMP as the 
activator base. Fmoc deprotection was performed with a $20 \%$ solution of piperidine in DMF. Peptide Gly-Lys-Ala-Phe-Arg-Arg-Leu was synthesized by using double couplings (each for 15 min) at $45{ }^{\circ} \mathrm{C}$ and triple couplings of Arg. Peptide His-Ser-Ser-Lys-Leu-GIn-Leu was synthesized by using single couplings for $15 \mathrm{~min}$ at $45^{\circ} \mathrm{C}$. Fmoc removal was performed by repeated treatment with a $20 \%$ solution of piperidine in DMF at $45{ }^{\circ} \mathrm{C}$ for $30 \mathrm{~s}$ and $180 \mathrm{~s}$. Protected products were cleaved from the resin with a $20 \%$ solution of HFIP in DCM. Subsequently the protecting groups were removed with TFA added a few drops of $\mathrm{H}_{2} \mathrm{O}$ in DCM.

\section{S2.3. Compound purification and characterization}

\section{S2.3.1. HPLC}

Water used for analytical and preparative HPLC was filtered through a $0.22 \mu \mathrm{m}$ Millipore membrane filter. All final products were purified by reversed phase preparative HPLC on a Phenomenex Luna C18(2) column (250 mm $\times 21.2 \mathrm{~mm} ; 5 \mu \mathrm{m}$ particle size) on a Shimadzu Prominence system by using an aqueous MeCN gradient with 0.1\% TFA added (eluent A: 5:95 $\mathrm{MeCN}-\mathrm{H}_{2} \mathrm{O}+0.1 \%$ TFA, eluent $\mathrm{B}$ : 95:5 $\mathrm{MeCN}-\mathrm{H}_{2} \mathrm{O}+0.1 \%$ TFA). Elution was performed with linear gradients during $20 \mathrm{~min}$ at a flow rate of $20 \mathrm{~mL} / \mathrm{min}$ with UV detection at $\lambda=220 \mathrm{~nm}$. Purity was determined by analytical HPLC on a Phenomenex Luna C18(2) HTS column $(100 \mathrm{~mm} \times 3.0$ $\mathrm{mm} ; 2.5 \mu \mathrm{m}$ particle size) using a Shimadzu Prominence and Shimadzu Nexera system with the same eluents as used for preparative HPLC and a flow rate of $0.5 \mathrm{~mL} / \mathrm{min}$. All tested compounds had a purity of at least $95 \%$.

\section{S2.3.2. NMR spectroscopy}

${ }^{1} \mathrm{H}$ and ${ }^{13} \mathrm{C}$ NMR spectra were recorded on a $600 \mathrm{MHz}$ Bruker Avance III HD spectrometer equipped with a cryogenically cooled $5 \mathrm{~mm}$ dual probe or on a $400 \mathrm{MHz}$ Bruker Ascend spectrometer. Samples were dissolved in methanol- $d_{4}$ (Cambridge Isotope Laboratories, Tewksbury, USA) and analyzed at $300 \mathrm{~K}$. The residual solvent peak was used as internal reference (methanol- $d_{4}: \delta_{\mathrm{C}}=49.00 ; \delta_{\mathrm{H}}=3.31$ ). Coupling constants ( $\mathrm{J}$ values) are given in hertz $(\mathrm{Hz})$. Multiplicities are reported as follows: singlet $(\mathrm{s})$, doublet $(\mathrm{d})$, triplet $(\mathrm{t})$, quartet $(\mathrm{q})$, quintet (quin) and multiplet $(m)$. NMR signals are assigned according to the standard numbering of the phorbol skeleton as displayed in Fig. 1 for PMA (1).

\section{S2.3.3. Mass spectrometry}

High-resolution mass spectra were recorded on a Bruker MicroTOF-Q LC mass spectrometer equipped with an electrospray ionization source or on a Quadropole MS detector or via MALDITOF on a Bruker SolariX XR in MALDI mode. The analyses were performed in positive ionization mode to give peaks of $[\mathrm{M}+\mathrm{nH}]^{\mathrm{n}+}$. 


\section{S2.4. Biological assays}

\section{S2.4.1. Cell culture}

LNCaP, 22Rv1 and DU145 were cultured in RPMI1640 medium (Cat \#1060120, MP Biomedicals, Santa Ana, CA, USA), PC3 cells in Ham's F12K (Kaighn's modification, Cat \#21127022; Gibco, Thermo Fisher Scientific, Waltham, MA, USA) medium which were supplemented with $10 \%$ foetal bovine serum, $100 \mathrm{U} \cdot \mathrm{mL}^{-1}$ penicillin, and $100 \mu \mathrm{g} \cdot \mathrm{mL}^{-1}$ streptomycin (all from Gibco). Cell cultures were maintained in a humidified incubator with $5 \% \mathrm{CO}_{2}$ at $37{ }^{\circ} \mathrm{C}$. All experiments were done in the above-described cell culture media.

\section{S2.4.2. Displacement assay}

Recombinant human PKCa protein was produced in baculovirus-infected Sf9 cells as described previously ${ }^{2}$. The cells were harvested two days after infection, washed with phosphate-buffered

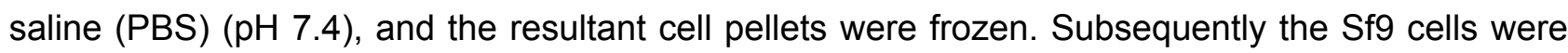
suspended in buffer containing $25 \mathrm{mM}$ Tris- $\mathrm{HCl}(\mathrm{pH} 7.5), 0.5 \mathrm{mM}$ EGTA, 0.1\% Triton X-100, and protease inhibitors to prepare a crude cell lysate. Following a 30-min incubation on ice, the lysate was centrifuged at $16,000 \mathrm{~g}$ for $15 \mathrm{~min}$ at $4{ }^{\circ} \mathrm{C}$ and the supernatant representing the soluble fraction was collected. The protein content of the supernatant was determined with a Bradford assay. ${ }^{3}$ The ability of the compounds to compete in binding to the regulatory domain of PKCa with tritium-labelled phorbol ester $\left[{ }^{3} \mathrm{H}\right] \mathrm{PDBu}$ was determined according to ${ }^{4}$. Protein $(20 \mu \mathrm{g} / \mathrm{well})$ from the supernatant was incubated with different concentrations of the test compounds and $25 \mathrm{nM}$ of $\left[{ }^{3} \mathrm{H}\right] \mathrm{PDBu}$ for $10 \mathrm{~min}$ at room temperature in a 96-well Durapore filter plate (Millipore, cat. no. MSHVN4B50, Carrigtwohill, Ireland) in a total volume of $125 \mu \mathrm{L}$. The final concentrations in the assay were: $20 \mathrm{mM}$ Tris- $\mathrm{HCl}$ ( $\mathrm{pH} 7.5$ ), $40 \mu \mathrm{M} \mathrm{CaCl}_{2}, 10 \mathrm{mM} \mathrm{MgCl}_{2}, 400 \mu \mathrm{g} / \mathrm{mL}$ bovine IgG, $25 \mathrm{nM}$ $\left[{ }^{3} \mathrm{H}\right] \mathrm{PDBu}$, and $0.1 \mathrm{mg} / \mathrm{mL}$ phosphatidyl-L-serine (1,2-diacyl-sn-glycero-3-phospho-L-serine). Proteins were then precipitated by the addition of $125 \mu \mathrm{L}$ of cold $20 \%$ poly(ethylene glycol) 6000 . After 15 min of incubation on a plate shaker at room temperature the filters were washed six times using a vacuum manifold with buffer containing $20 \mathrm{mM}$ Tris- $\mathrm{HCl}(\mathrm{pH} 7.5), 100 \mu \mathrm{M} \mathrm{CaCl}_{2}$ and $5 \mathrm{mM}$ $\mathrm{MgCl}_{2}$. The plates were dried and $25 \mu \mathrm{L}$ of Optiphase SuperMix liquid scintillant was added to each well. Radioactivity was measured using Wallac Microbeta Trilux microplate liquid scintillation counter (PerkinEImer, Waltham, MA, USA) after an equilibration period of three hours. All tested compounds were dissolved in DMSO and diluted with the buffer to give the same final DMSO concentration in the binding assay $(4 \%)$ in each well. PMA $(1 \mu \mathrm{M})$ was used as a positive control to obtain maximum displacement in all assays. Since nonspecific binding was always $\approx 5 \%$, only the total binding was measured. The results were calculated as a percentage of DMSO control from the same plate. 


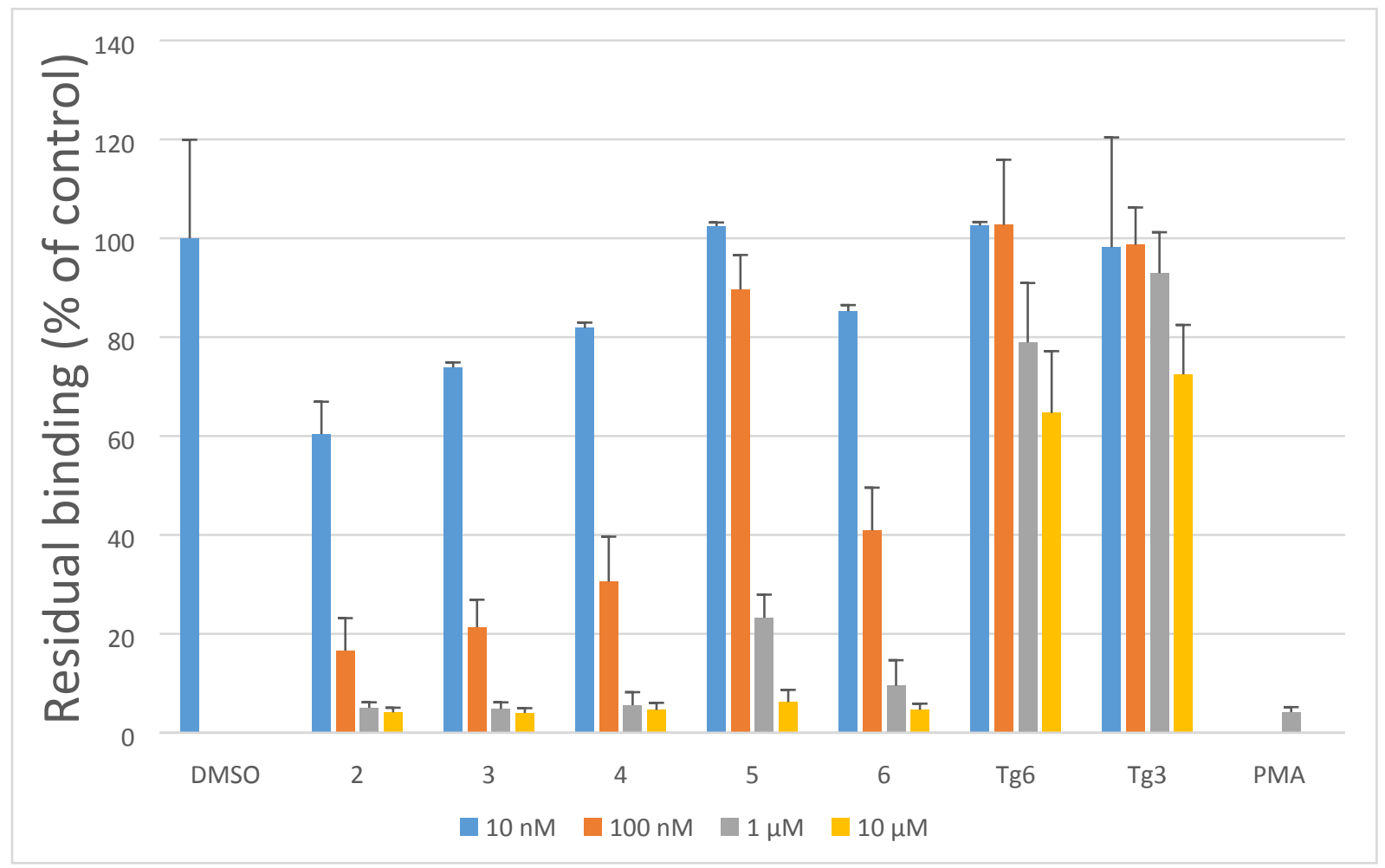

Fig. S1 Displacement assay data presented as mean $+\mathrm{SEM}(\mathrm{N}=3)$ of residual $\left[{ }^{3} \mathrm{H}\right] \mathrm{PDBu}$ binding $(\%$ of control).

Table S1 Displacement assay numerical data presented as averages from three individual experiments and three parallel wells in each experiment (\% of control).

\begin{tabular}{|c|c|c|c|c|c|c|c|c|c|c|}
\hline & & Ctrl & 2 & 3 & 4 & 5 & 6 & Tg3 & $\operatorname{Tg} 6$ & PMA \\
\hline & $10 \mathrm{nM}$ & 100.00 & 60.38 & 73.87 & 81.85 & 102.44 & 85.23 & 102.55 & 98.18 & \\
\hline \multirow{3}{*}{ AVG } & $100 \mathrm{nM}$ & & 16.60 & 21.35 & 30.57 & 89.61 & 40.90 & 102.70 & 98.68 & \\
\hline & $1 \mu \mathrm{M}$ & & 5.04 & 4.80 & 5.57 & 23.24 & 9.49 & 78.94 & 92.92 & 4.17 \\
\hline & $10 \mu \mathrm{M}$ & & 4.11 & 3.97 & 4.59 & 6.19 & 4.65 & 64.65 & 72.47 & \\
\hline \multirow{4}{*}{ SEM } & $10 \mathrm{nM}$ & 19.91 & 6.56 & 1.01 & 1.10 & 0.74 & 1.25 & 0.74 & 22.21 & \multirow{4}{*}{1.02} \\
\hline & $100 \mathrm{nM}$ & & 6.57 & 5.55 & 9.09 & 7.01 & 8.66 & 13.17 & 7.54 & \\
\hline & $1 \mu \mathrm{M}$ & & 1.11 & 1.34 & 2.64 & 4.68 & 5.18 & 12.00 & 8.30 & \\
\hline & $10 \mu \mathrm{M}$ & & 0.96 & 1.00 & 1.45 & 2.47 & 1.23 & 12.52 & 10.00 & \\
\hline
\end{tabular}




\section{S2.4.3. Cell viability assays}

Cell viability was determined using mitochondrial oxidoreductase activity assay [3-(4,5dimethylthiazol-2-yl)-2,5-diphenyltetrazolium bromide (MTT)]. Lactate dehydrogenase (LDH) test was used to measure the amount of LDH released from cells with compromised cell membrane integrity. The PSA/PSMA-positive LNCaP and 22Rv1 and PSA/PSMA-negative DU145 and PC3 human PC cells were plated on 96-well plates at 6000-8000 cells per well in serum-supplemented media and exposed to the compounds for $72 \mathrm{~h}$, after which the LDH assay was carried out using $50 \mu \mathrm{L}$ samples of cell culture media and the MTT assay with the cells. For the LDH assay, $50 \mu \mathrm{L}$ of $\mathrm{LDH}$ substrate solution (1.3 mM $\beta$-nicotinamide adenine dinucleotide, $660 \mu \mathrm{M}$ iodonitrotetrazolium, $54 \mathrm{mM} \mathrm{L}(+)$-lactic acid, $280 \mu \mathrm{M}$ phenazine methosulfate (all from Sigma-Aldrich) in $0.2 \mathrm{M} \mathrm{Tris/HCl}$, $\mathrm{pH}$ 8.2) was added to the media samples. After a 30-min incubation at room temperature the reaction was stopped by adding $50 \mu \mathrm{L}$ of a $1 \mathrm{M}$ solution of acetic acid in water. The absorbance was measured at $490 \mathrm{~nm}$. Background absorbance was measured from the wells without cells. Untreated cells were used as controls for spontaneous LDH release, and maximal LDH release was determined from cells lysed with $0.9 \%$ Triton X-100. In the MTT assay, solution was added to the cells at $0.5 \mathrm{mg} / \mathrm{mL}$. The cells were incubated in cell culture conditions for $2 \mathrm{~h}$, after which cell culture media was aspirated and replaced with $200 \mu \mathrm{L}$ DMSO. The absorbance was then measured at $550 \mathrm{~nm}$ with absorbance at $650 \mathrm{~nm}$ subtracted as background. Some of the cells were first pre-incubated with the PKC inhibitor Gö6983 for $10 \mathrm{~min}$ and then exposed to compounds $(20 \mu \mathrm{M})$ for $72 \mathrm{~h}$. 

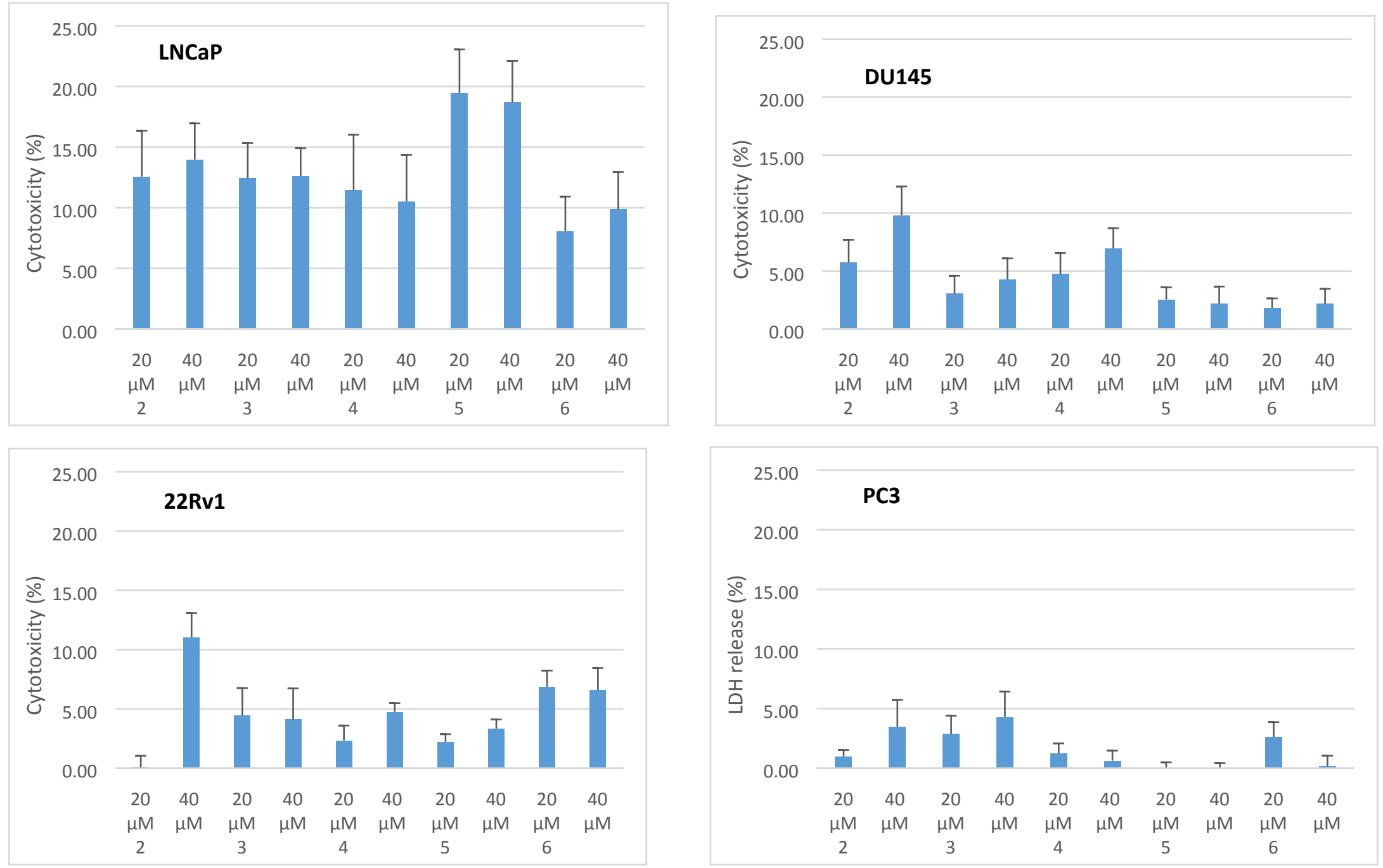

Fig. S2 Necrotic cell death in different cell types after $72 \mathrm{~h}$ exposure to the test compounds, measured by LDH assay. Results are presented as mean + SEM $(n=3)$. 
Table S2 Numerical LDH data from three individual experiments and three parallel wells in each experiment.

\begin{tabular}{|c|c|c|c|c|c|c|c|c|c|c|}
\hline \multirow[t]{2}{*}{ LNCaP } & & \multicolumn{2}{|l|}{2} & \multicolumn{2}{|l|}{3} & \multicolumn{2}{|l|}{4} & \multicolumn{2}{|l|}{5} & \multirow[b]{2}{*}{$40 \mu \mathrm{M}$} \\
\hline & $20 \mu \mathrm{M}$ & $40 \mu \mathrm{M}$ & $20 \mu \mathrm{M}$ & $40 \mu \mathrm{M}$ & $20 \mu \mathrm{M}$ & $40 \mu \mathrm{M}$ & $20 \mu \mathrm{M}$ & $40 \mu \mathrm{M}$ & $20 \mu \mathrm{M}$ & \\
\hline & 9.05 & 17.30 & 11.34 & 13.37 & 18.91 & 17.02 & 18.13 & 18.36 & 16.01 & 16.89 \\
\hline & 8.99 & 10.68 & 20.43 & 18.75 & 17.93 & 15.88 & 18.28 & 17.43 & 13.80 & 16.66 \\
\hline & 8.59 & 10.21 & 15.76 & 15.21 & 17.62 & 13.71 & 18.51 & 18.23 & 12.46 & 17.20 \\
\hline & 6.58 & 8.09 & 12.35 & 7.82 & 15.14 & 13.71 & 25.52 & 26.51 & 2.82 & 5.04 \\
\hline & 7.63 & 9.29 & 7.59 & 9.66 & 15.52 & 14.57 & 29.01 & 25.35 & 3.54 & 6.24 \\
\hline & 8.58 & 10.38 & 7.14 & 10.88 & 14.78 & 14.46 & 26.56 & 25.54 & 3.28 & 6.04 \\
\hline & 21.86 & 19.97 & -1.03 & -0.48 & 1.29 & 1.49 & 12.80 & 12.13 & 8.14 & 6.79 \\
\hline & 21.49 & 19.70 & 0.73 & 1.42 & 0.19 & 2.76 & 14.78 & 12.99 & 7.45 & 7.52 \\
\hline & 20.40 & 20.19 & -0.22 & 1.09 & 1.64 & 1.13 & 11.63 & 11.79 & 5.21 & 6.53 \\
\hline AVG & 12.57 & 13.98 & 12.43 & 12.62 & 11.45 & 10.53 & 19.47 & 18.70 & 8.08 & 9.88 \\
\hline STDEV & 6.56 & 5.16 & 5.05 & 3.99 & 7.93 & 6.64 & 6.22 & 5.89 & 4.93 & 5.32 \\
\hline SEM & 3.79 & 2.98 & 2.92 & 2.30 & 4.58 & 3.84 & 3.59 & 3.40 & 2.85 & 3.07 \\
\hline v1 & & 2 & & 3 & & 4 & & 5 & & 6 \\
\hline & $20 \mu \mathrm{M}$ & $40 \mu \mathrm{M}$ & $20 \mu \mathrm{M}$ & $40 \mu \mathrm{M}$ & $20 \mu \mathrm{M}$ & $40 \mu \mathrm{M}$ & $20 \mu \mathrm{M}$ & $40 \mu \mathrm{M}$ & $20 \mu \mathrm{M}$ & $40 \mu \mathrm{M}$ \\
\hline & -1.54 & 7.57 & 1.09 & 0.68 & -0.55 & 3.79 & 1.25 & 1.04 & 4.32 & 3.40 \\
\hline & 0.10 & 9.47 & 3.06 & 1.89 & -1.07 & 3.03 & 1.42 & 1.98 & 4.62 & 3.42 \\
\hline & -1.21 & 10.75 & 2.75 & 3.02 & 0.54 & 4.85 & 1.53 & 2.12 & 4.92 & 4.61 \\
\hline & -1.54 & 7.17 & 1.12 & 0.53 & 3.18 & 5.21 & 3.68 & 4.22 & 6.14 & 6.17 \\
\hline & -1.34 & 11.26 & 1.55 & 1.72 & 2.50 & 3.90 & 3.09 & 4.12 & 5.82 & 4.44 \\
\hline & -0.25 & 10.48 & 2.45 & 1.94 & 3.18 & 3.43 & 4.19 & 4.94 & 6.55 & 4.89 \\
\hline & 1.75 & 11.57 & 11.93 & 13.68 & 4.45 & 6.79 & 1.66 & 3.59 & 10.62 & 10.35 \\
\hline & 2.32 & 11.76 & 9.83 & 9.68 & 4.41 & 5.49 & 1.29 & 3.69 & 9.55 & 11.43 \\
\hline & 2.44 & 19.37 & 6.33 & 3.93 & 4.47 & 6.23 & 1.90 & 4.45 & 9.35 & 10.44 \\
\hline G & 0.08 & 11.04 & 4.45 & 4.12 & 2.35 & 4.75 & 2.22 & 3.35 & 6.88 & 6.57 \\
\hline DEV & 1.67 & 3.54 & 4.00 & 4.53 & 2.18 & 1.30 & 1.12 & 1.32 & 2.36 & 3.25 \\
\hline M & 0.97 & 2.04 & 2.31 & 2.61 & 1.26 & 0.75 & 0.65 & 0.76 & 1.36 & 1.87 \\
\hline
\end{tabular}




\begin{tabular}{|c|c|c|c|c|c|c|c|c|c|c|}
\hline \multirow[t]{2}{*}{ DU145 } & \multicolumn{3}{|c|}{2} & \multicolumn{2}{|l|}{3} & \multicolumn{2}{|l|}{4} & \multicolumn{2}{|l|}{5} & 6 \\
\hline & $20 \mu \mathrm{M}$ & $40 \mu \mathrm{M}$ & $20 \mu \mathrm{M}$ & $40 \mu \mathrm{M}$ & $20 \mu \mathrm{M}$ & $40 \mu \mathrm{M}$ & $20 \mu \mathrm{M}$ & $40 \mu \mathrm{M}$ & $20 \mu \mathrm{M}$ & $40 \mu \mathrm{M}$ \\
\hline & 3.60 & 5.79 & 1.05 & 0.99 & 3.03 & 1.81 & 5.20 & -0.46 & -0.50 & -1.15 \\
\hline & 3.70 & 8.31 & 3.01 & 4.25 & 7.14 & 8.04 & 4.82 & -0.85 & 2.40 & 2.25 \\
\hline & 6.64 & 9.92 & 3.89 & 4.44 & 6.43 & 10.52 & 3.72 & -0.75 & 2.11 & 2.66 \\
\hline & 10.53 & 14.61 & 7.80 & 8.90 & 8.11 & 9.71 & 1.89 & 3.37 & 3.92 & 4.54 \\
\hline & 9.80 & 15.26 & 3.73 & 6.72 & 7.28 & 9.16 & 1.35 & 5.50 & 3.05 & 4.35 \\
\hline & 9.34 & 15.04 & 6.06 & 8.22 & 7.36 & 8.46 & 3.69 & 5.83 & 3.00 & 5.19 \\
\hline & 1.80 & 4.28 & -0.76 & 0.21 & 0.61 & 5.48 & 0.81 & 2.94 & 0.95 & 0.41 \\
\hline & 2.62 & 5.36 & 0.89 & 1.81 & 0.24 & 3.05 & 0.73 & 2.38 & 0.74 & 1.52 \\
\hline & 3.68 & 9.71 & 1.69 & 3.06 & 2.45 & 6.41 & 0.70 & 1.88 & 0.71 & -0.27 \\
\hline AVG & 5.75 & 9.81 & 3.04 & 4.29 & 4.74 & 6.96 & 2.55 & 2.20 & 1.82 & 2.17 \\
\hline STDEV & 3.38 & 4.32 & 2.69 & 3.12 & 3.14 & 3.02 & 1.82 & 2.53 & 1.43 & 2.24 \\
\hline SEM & 1.95 & 2.49 & 1.55 & 1.80 & 1.81 & 1.74 & 1.05 & 1.46 & 0.82 & 1.29 \\
\hline \multirow[t]{11}{*}{ PC3 } & & 2 & & 3 & & 4 & & 5 & & 6 \\
\hline & $20 \mu \mathrm{M}$ & $40 \mu \mathrm{M}$ & $20 \mu \mathrm{M}$ & $40 \mu \mathrm{M}$ & $20 \mu \mathrm{M}$ & $40 \mu \mathrm{M}$ & $20 \mu \mathrm{M}$ & $40 \mu \mathrm{M}$ & $20 \mu \mathrm{M}$ & $40 \mu \mathrm{M}$ \\
\hline & -0.27 & -0.12 & 1.19 & 4.65 & 4.06 & 3.30 & 0.10 & -1.66 & 4.96 & -1.04 \\
\hline & 0.05 & 0.42 & 1.54 & 2.80 & 2.49 & 1.79 & 0.17 & -1.48 & 5.04 & -0.79 \\
\hline & 1.90 & 1.07 & 2.70 & 3.53 & 2.43 & 2.01 & 0.02 & -0.56 & 4.87 & -0.42 \\
\hline & 2.20 & 2.02 & 5.37 & 10.46 & 0.10 & -1.06 & 0.37 & 1.73 & 0.96 & 0.03 \\
\hline & 1.35 & 0.63 & 7.62 & 8.30 & 0.70 & 0.01 & -1.99 & -0.15 & -0.16 & -0.54 \\
\hline & 1.41 & 1.71 & 5.53 & 7.30 & 1.41 & -0.93 & -2.54 & -2.47 & -0.48 & -1.35 \\
\hline & 1.30 & 7.53 & 0.11 & 0.23 & 0.19 & 0.08 & 1.46 & 0.73 & 2.36 & 2.91 \\
\hline & -0.32 & 8.18 & 0.85 & 0.80 & -0.38 & -0.12 & 0.75 & 0.88 & 2.68 & 2.36 \\
\hline & 1.30 & 9.93 & 1.04 & 0.53 & 0.06 & 0.62 & -0.44 & -0.24 & 3.39 & 0.46 \\
\hline AVG & 0.99 & 3.49 & 2.88 & 4.29 & 1.23 & 0.63 & -0.23 & -0.36 & 2.62 & 0.18 \\
\hline STDEV & 0.93 & 3.90 & 2.63 & 3.69 & 1.49 & 1.45 & 1.27 & 1.35 & 2.16 & 1.50 \\
\hline SEM & 0.54 & 2.25 & 1.52 & 2.13 & 0.86 & 0.84 & 0.74 & 0.78 & 1.25 & 0.87 \\
\hline
\end{tabular}


S2.4.4. Determination of ERK1/2 Phosphorylation, PKC $\alpha$ and $-\delta$ and PSMA expression by Immunoblotting

The PSA/PSMA-positive 22Rv1 and PSA/PSMA-negative DU145 human PC cells were seeded onto 6 -well plates at a density of $4.0 \times 10^{5}$ cells/well. Then, $20-24 \mathrm{~h}$ after seeding, the medium was changed to serum free RPMI1640. After a 2-h serum starvation, the cells were treated with the test compounds for $30 \mathrm{~min}$, washed twice with ice-cold PBS, and harvested in ice-cold lysis buffer (1 mM EDTA, $150 \mathrm{mM} \mathrm{NaCl}, 0.25 \%$ NP-40, 1\% Triton X-100, $10 \mathrm{mM}$ Tris/ $\mathrm{HCl}, \mathrm{pH}$ 6.8) supplemented with protease and phosphatase inhibitors (Complete and PHOStop, respectively; Roche, Mannheim, Germany). Lysates were centrifuged (13,000 g, 4 min, $4{ }^{\circ} \mathrm{C}$ ) and the supernatants collected. Equal amounts of protein $(10 \mu \mathrm{g})$ were subjected to reducing SDS-PAGE and transferred to poly(vinylidene difluoride) membrane.

After blocking the membranes with $5 \%$ milk in $0.1 \%$ Tween 20 in Tris-buffered saline (TBST) for $1 \mathrm{~h}$ at room temperature the cells were incubated overnight at $4{ }^{\circ} \mathrm{C}$ in a shaker with primary antibodies against p44/42 MAPK (Erk1/2) (\#9102; 1:2000, Cell Signaling Technology, Danvers, MA, USA), phospho-p44/42 MAPK (Erk1/2) (\#9101; 1:2000, Cell Signaling Technology, Danvers, MA, USA) and GAPDH (sc47724, 1:2000, Santa Cruz Biotechnology, Dallas, TX, USA) in blocking buffer. For determining the PKC and PSMA protein levels in 22Rv1 cells, all primary antibodies were from Abcam PKCa (ab 32376), PKCठ (ab 182126) and PSMA (ab 76104) and were used as 1:1000 dilution. The experiments were repeated three times with two wells per condition in each experiment. The following day, the membranes were washed with TBST and incubated with blocking buffer containing HRP-linked secondary antibody (goat anti-rabbit, \#170-6515; Bio-Rad, CA, USA or antimouse IgG \#7076S; Cell Signaling Technology) for $1 \mathrm{~h}$ at RT. Secondary antibodies were detected with chemiluminescent substrate (SuperSignal West Pico, \#34080; Thermo Fisher) utilizing ChemiDoc XRS+ imaging System (Bio-Rad Laboratories, Hercules, CA, USA). Quantification was carried out by measuring the optical densities of the immunoreactive bands using ImageJ software (https://imagej.net/Downloads). The optical densities were always first normalized to GAPDH from the same sample and then to the corresponding control (cells treated with the vehicle only) on the same membrane. 

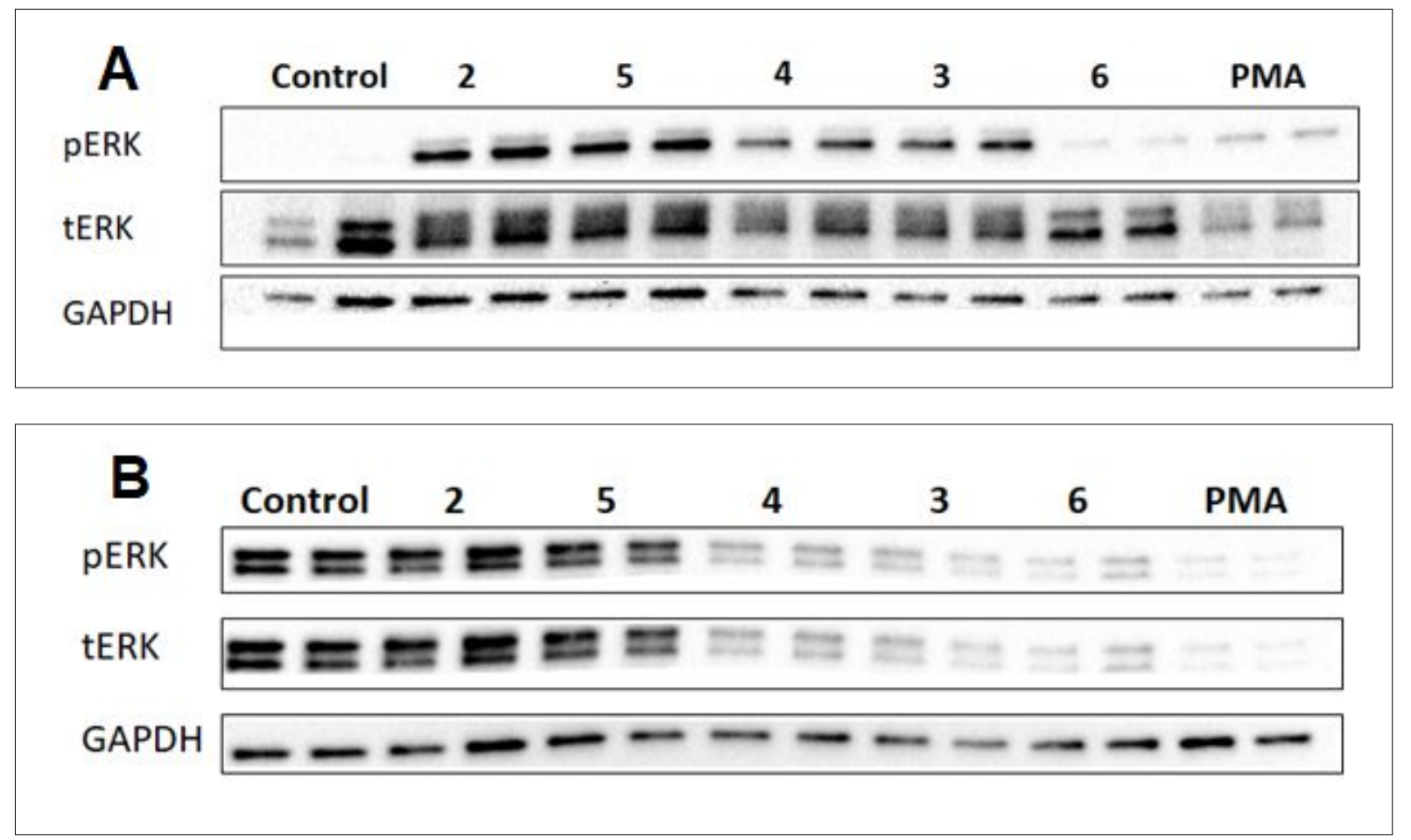

Fig. S3 Representative blot images from a single ERK phosphorylation experiment, with two parallel samples for each condition on 22Rv1 (A) and DU145 cells (B). 

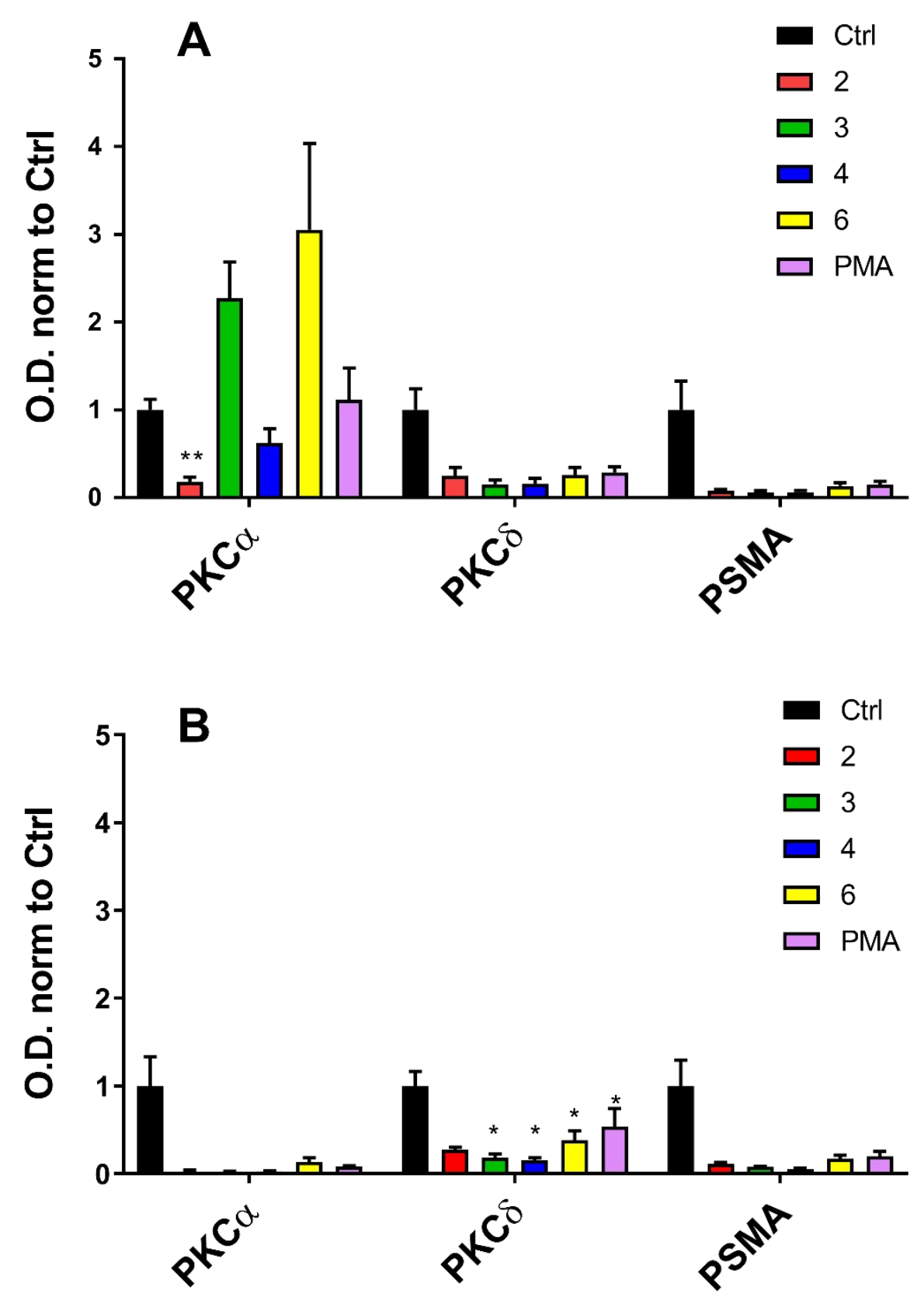

Fig. S4 PKC $\alpha,-\delta$ and PSMA expression in 22Rv1 cell line after $24 \mathrm{~h}(\mathrm{~A})$ and 72 $\mathrm{h}$ (B) exposure to the test compounds 2, 3, 4, 6 and PMA. Results are presented as mean $+\mathrm{SEM}\left(\mathrm{N}=3 ;{ }^{*} \mathrm{P}<0.05\right.$ vs ctrl, ${ }^{* *} \mathrm{P}<0.01$ Welch's t-test). 
Table S3 PKC $\alpha,-\delta$ and PSMA expression in 22Rv1 cell line after $24 \mathrm{~h}$ and $72 \mathrm{~h}$ exposure numerical data.

\begin{tabular}{|r|c|c|c|c|c|c|}
\hline $\mathbf{2 4} \mathbf{h}$ & PKC $\alpha$ & SEM & PKC $\delta$ & SEM & PSMA & SEM \\
\hline Ctrl & $\mathbf{1 . 0 0}$ & 0.12 & $\mathbf{1 . 0 0}$ & 0.24 & $\mathbf{1 . 0 0}$ & 0.32 \\
\hline 2 & $\mathbf{0 . 1 8}$ & 0.05 & $\mathbf{0 . 2 4}$ & 0.10 & $\mathbf{0 . 0 7}$ & 0.02 \\
\hline 3 & $\mathbf{2 . 2 7}$ & 0.41 & $\mathbf{0 . 1 5}$ & 0.05 & $\mathbf{0 . 0 6}$ & 0.02 \\
\hline 4 & $\mathbf{0 . 6 2}$ & 0.17 & $\mathbf{0 . 1 5}$ & 0.06 & $\mathbf{0 . 0 6}$ & 0.02 \\
\hline 6 & $\mathbf{3 . 0 5}$ & 0.98 & $\mathbf{0 . 2 6}$ & 0.09 & $\mathbf{0 . 1 3}$ & 0.04 \\
\hline PMA & $\mathbf{1 . 1 1}$ & 0.36 & $\mathbf{0 . 2 8}$ & 0.07 & $\mathbf{0 . 1 5}$ & 0.04 \\
\hline
\end{tabular}

\begin{tabular}{|r|r|r|r|r|r|r|}
\hline $\mathbf{7 2} \mathbf{h}$ & PKC & SEM & PKC & SEM & PSMA & SEM \\
\hline Ctrl & $\mathbf{1 . 0 0}$ & 0.34 & $\mathbf{1 . 0 0}$ & 0.17 & $\mathbf{1 . 0 0}$ & 0.30 \\
\hline 2 & $\mathbf{0 . 0 2}$ & 0.02 & $\mathbf{0 . 2 8}$ & 0.03 & $\mathbf{0 . 1 1}$ & 0.02 \\
\hline 3 & $\mathbf{0 . 0 2}$ & 0.01 & $\mathbf{0 . 1 9}$ & 0.04 & $\mathbf{0 . 0 8}$ & 0.01 \\
\hline 4 & $\mathbf{0 . 0 3}$ & 0.01 & $\mathbf{0 . 1 6}$ & 0.03 & $\mathbf{0 . 0 6}$ & 0.01 \\
\hline 6 & $\mathbf{0 . 1 4}$ & 0.05 & $\mathbf{0 . 3 8}$ & 0.11 & $\mathbf{0 . 1 7}$ & 0.05 \\
\hline PMA & $\mathbf{0 . 0 9}$ & 0.00 & $\mathbf{0 . 5 4}$ & 0.20 & $\mathbf{0 . 2 0}$ & 0.06 \\
\hline
\end{tabular}


Table S4 MTT assay numerical data presented as averages ( \pm SEM) from three individual experiments and three parallel wells in each experiment. (\% of control).

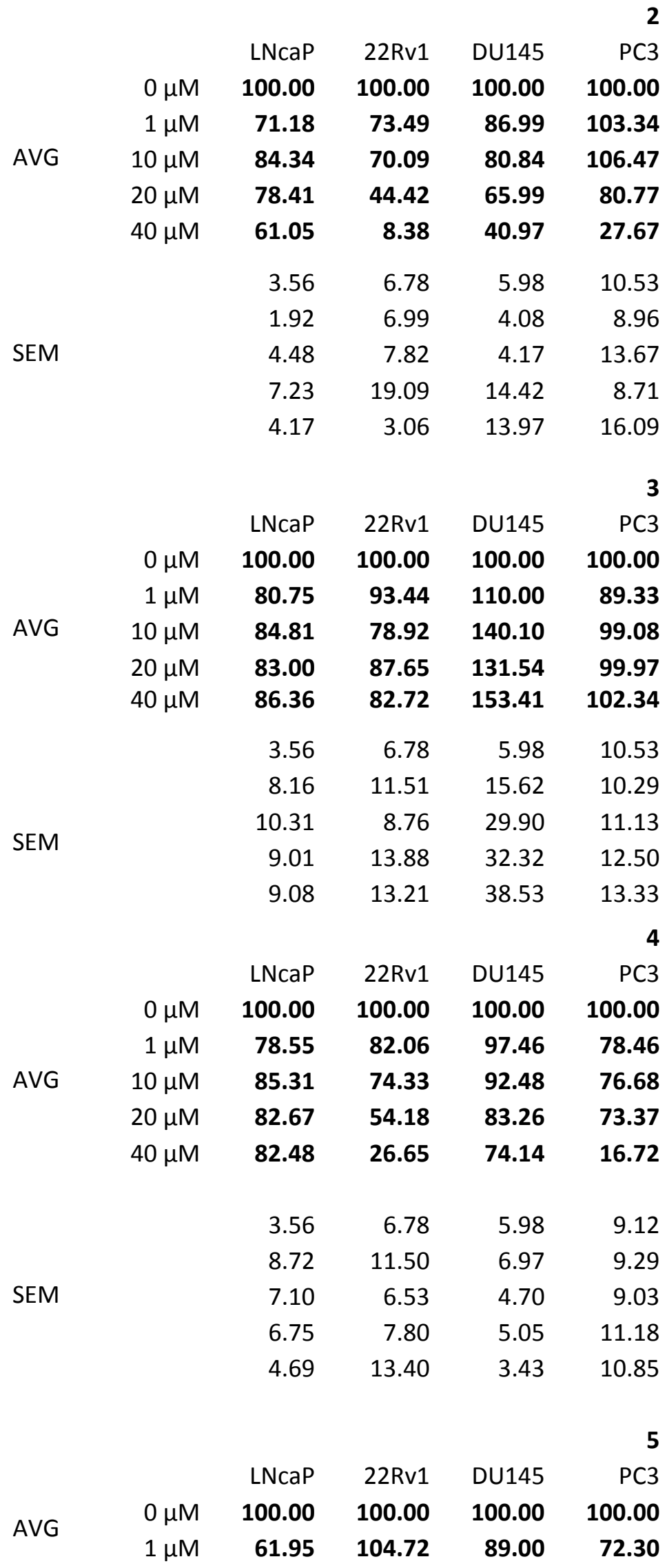




\begin{tabular}{|c|c|c|c|c|c|}
\hline & $10 \mu \mathrm{M}$ & 50.60 & 90.83 & 83.41 & 80.45 \\
\hline & $20 \mu \mathrm{M}$ & 40.50 & 87.51 & 85.04 & 84.41 \\
\hline & $40 \mu \mathrm{M}$ & 41.00 & 74.68 & 70.90 & 65.97 \\
\hline & & 3.56 & 6.78 & 5.98 & 10.53 \\
\hline & & 13.35 & 14.13 & 5.58 & 5.94 \\
\hline SEM & & 13.15 & 8.89 & 3.23 & 6.10 \\
\hline & & 2.48 & 9.17 & 8.81 & 8.07 \\
\hline & & 4.78 & 9.69 & 2.40 & 10.97 \\
\hline & & LNcaP & 22Rv1 & DU145 & PC3 \\
\hline & $0 \mu \mathrm{M}$ & 100.00 & 100.00 & 100.00 & 100.00 \\
\hline & $1 \mu \mathrm{M}$ & 91.24 & 96.04 & 104.25 & 91.66 \\
\hline AVG & $10 \mu \mathrm{M}$ & 70.40 & 64.47 & 77.88 & 77.85 \\
\hline & $20 \mu \mathrm{M}$ & 70.79 & 55.00 & 69.78 & 76.33 \\
\hline & $40 \mu \mathrm{M}$ & 65.84 & 50.29 & 63.31 & 12.91 \\
\hline & & 3.56 & 6.78 & 5.98 & 10.53 \\
\hline & & 7.03 & 8.04 & 16.02 & 6.59 \\
\hline SEM & & 4.79 & 13.71 & 17.84 & 8.47 \\
\hline & & 4.14 & 16.25 & 20.44 & 9.69 \\
\hline & & 4.82 & 19.33 & 21.61 & 2.01 \\
\hline & & & & & $\operatorname{Tg} 3$ \\
\hline & & LNcaP & 22Rv1 & DU145 & PC3 \\
\hline & $0 \mu \mathrm{M}$ & 100.00 & 100.00 & 100.00 & 100.00 \\
\hline & $1 \mu \mathrm{M}$ & 71.05 & 60.50 & 82.99 & 38.28 \\
\hline AVG & $10 \mu \mathrm{M}$ & 26.45 & 31.11 & 35.13 & 19.38 \\
\hline & $20 \mu \mathrm{M}$ & 10.56 & 28.56 & 31.75 & 18.16 \\
\hline & $40 \mu \mathrm{M}$ & 3.61 & 26.50 & 19.69 & 15.57 \\
\hline & & 3.56 & 6.78 & 5.98 & 10.53 \\
\hline & & 8.64 & 8.60 & 1.96 & 4.61 \\
\hline SEM & & 4.57 & 7.77 & 2.26 & 1.59 \\
\hline & & 3.27 & 7.04 & 1.76 & 3.66 \\
\hline & & 1.47 & 7.47 & 1.94 & 3.03 \\
\hline & & & & & Tg6 \\
\hline & & LNcaP & 22Rv1 & DU145 & PC3 \\
\hline & $0 \mu \mathrm{M}$ & 100.00 & 100.00 & 100.00 & 100.00 \\
\hline & $1 \mu \mathrm{M}$ & 94.64 & 97.97 & 96.92 & 94.45 \\
\hline AVG & $10 \mu \mathrm{M}$ & 71.19 & 69.27 & 86.42 & 67.89 \\
\hline & $20 \mu \mathrm{M}$ & 67.54 & 56.47 & 78.88 & 48.25 \\
\hline & $40 \mu \mathrm{M}$ & 35.45 & 40.39 & 67.07 & 32.44 \\
\hline
\end{tabular}




$\begin{array}{rrrrr} & 3.56 & 6.78 & 5.98 & 10.53 \\ \text { SEM } & 4.72 & 4.44 & 4.57 & 9.45 \\ & 4.69 & 6.69 & 3.95 & 10.73 \\ & 5.03 & 8.53 & 1.65 & 7.35 \\ & 15.89 & 9.28 & 4.01 & 3.87\end{array}$

Table S5 MTT assay numerical data presented as averages from three individual experiments and three parallel wells in each experiment without and with $1 \mu \mathrm{M}$ PKC inhibitor Gö6983 (\% of control).

\begin{tabular}{|c|c|c|c|c|c|}
\hline & & LNcaP & 22Rv1 & DU145 & PC3 \\
\hline \multirow{2}{*}{2} & $20 \mu \mathrm{M}$ & 78.41 & 44.42 & 65.99 & 80.77 \\
\hline & $20 \mu \mathrm{M}+$ Gö6983 & 90.02 & 36.69 & 78.84 & 114.92 \\
\hline \multirow{2}{*}{3} & $20 \mu \mathrm{M}$ & 83.00 & 87.65 & 136.56 & 99.97 \\
\hline & $20 \mu \mathrm{M}$ + Gö6983 & 92.56 & 121.47 & 111.94 & 110.45 \\
\hline \multirow{2}{*}{4} & $20 \mu \mathrm{M}$ & 82.67 & 54.18 & 83.26 & 73.37 \\
\hline & $20 \mu \mathrm{M}+$ Gö6983 & 101.91 & 69.75 & 97.71 & 95.70 \\
\hline \multirow{2}{*}{5} & $20 \mu \mathrm{M}$ & 40.50 & 87.51 & 85.04 & 84.41 \\
\hline & $20 \mu \mathrm{M}$ + Gö6983 & 74.31 & 111.03 & 96.37 & 105.99 \\
\hline \multirow{2}{*}{6} & $20 \mu \mathrm{M}$ & 70.79 & 55.00 & 69.78 & 76.33 \\
\hline & $20 \mu \mathrm{M}$ + Gö6983 & 94.18 & 61.22 & 66.31 & 102.79 \\
\hline \multirow{2}{*}{ Tg3 } & $20 \mu \mathrm{M}$ & 10.56 & 28.56 & 28.28 & 18.16 \\
\hline & $20 \mu \mathrm{M}$ + Gö6983 & 15.50 & 24.56 & 24.00 & 19.02 \\
\hline \multirow{2}{*}{ Tg6 } & $20 \mu \mathrm{M}$ & 67.54 & 56.47 & 74.70 & 48.25 \\
\hline & $20 \mu \mathrm{M}$ + Gö6983 & 55.04 & 53.68 & 76.24 & 53.08 \\
\hline \multirow{2}{*}{ PMA } & $100 \mathrm{nM}$ & 52.72 & 96.95 & 85.81 & 89.22 \\
\hline & 100 nM + Gö6983 & 93.65 & 108.46 & 103.73 & 79.41 \\
\hline Gö6983 & $1 \mu \mathrm{M}$ & 90.98 & 99.67 & 99.20 & 100.15 \\
\hline
\end{tabular}




\section{S2.5. Synthesis of phorbol derivatives}

\section{S2.5.1. Isolation of the starting material $4 \beta-$ phorbol (7)}

The starting $4 \beta$-phorbol (7) was obtained from seeds of $C$. tiglium by extraction, fractionation and solvolysis as reported. ${ }^{1}$ All NMR or HRMS data correspond to those already published. ${ }^{5}$

In Scheme S1 PMA (1) is depicted as a representative of phorbol esters. The isolated fraction consists of a number of phorbol esters acylated at $0-12$ and $0-13$ and in addition some also acylated at $0-20 .{ }^{1,6}$ Solvolysis of the mixture of phorbol esters provided $4 \beta$ phorbol (7) as previously described. ${ }^{1}$ Protection of the primary alcohol at C-20 and selective acetylation at $0-13$ gave intermediate 9 , which after esterification at $0-12$ with Boc-protected 12-Aminododecanoic acid and subsequent removal of the Boc group yielded starting material 8 (Scheme S6).

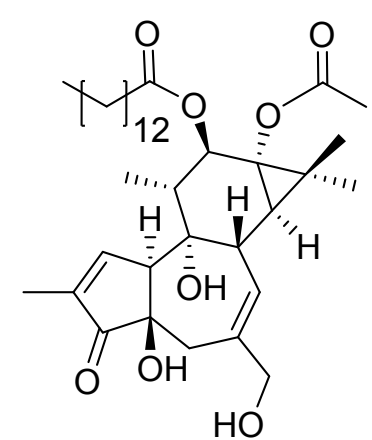

1

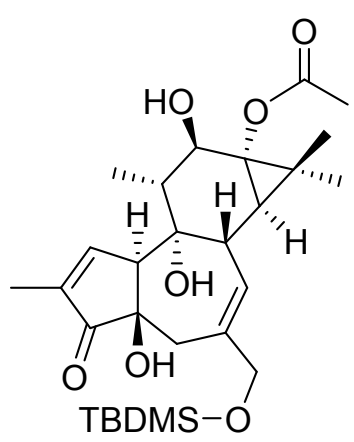

9
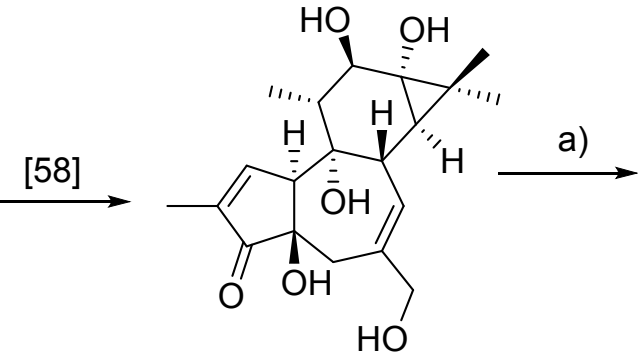

7

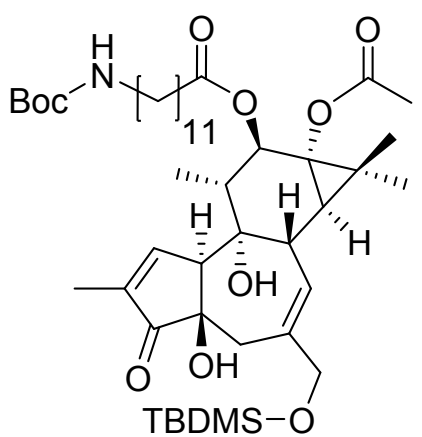

10

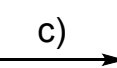

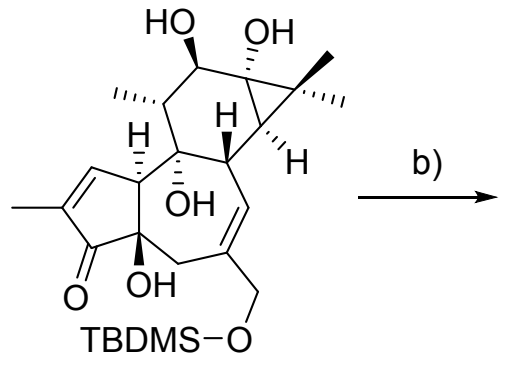

11
Scheme S6. Synthesis of 12-O-(12-Aminododecanoyl)-13-O-acetyl-4ß-phorbol 8. Reagents and conditions: (a) TBDMS-Cl, DMAP, imidazole, DMF, $23^{\circ} \mathrm{C}, 2 \mathrm{~h}(53 \%)$; (b) DMAP, $\mathrm{Et}_{3} \mathrm{~N}, 10 \% \mathrm{Ac}_{2} \mathrm{O}$ in DCM, $0{ }^{\circ} \mathrm{C}$ to $23{ }^{\circ} \mathrm{C}, 75 \mathrm{~min}$ (85\%); (c) Boc-12-aminododecanoic acid, DMAP, EDC, DCM, $23{ }^{\circ} \mathrm{C}, 20 \mathrm{~h}$ (94\%); (d) TFA-DCM (2:1), 30 min, 23 ${ }^{\circ} \mathrm{C}(91 \%)$. 


\section{S2.5.2. 20-O-TBDMS-4 $\beta$-phorbol (11)}

$4 \beta$-Phorbol (7; $1.19 \mathrm{~g} ; 3.27 \mathrm{mmol})$ was dissolved in DMF $(20 \mathrm{~mL})$, and while stirring on ice DMAP (80 mg; $0.65 \mathrm{mmol}$ ), imidazole (675 mg; $9.92 \mathrm{mmol}$ ) and TBDMSCl (739 mg; 4.90 $\mathrm{mmol}$ ) were added. The reaction mixture was left to warm up to $23^{\circ} \mathrm{C}$, and after additional 4 $\mathrm{h}$ more TBDMS (492 $\mathrm{mg} ; 3.27 \mathrm{mmol}$ ) was added to convert residual amounts of the starting $4 \beta$-phorbol. After additional $2 \mathrm{~h}$ the solvent was removed from the reaction mixture, and then the residue was fractionated on a silica column (eluted with DCM-MeOH 20:1) to give 11 as a white crystalline powder $(1.34 \mathrm{~g} ; 85 \%) .{ }^{1} \mathrm{H}$ NMR $\left(600 \mathrm{MHz}\right.$, methanol- $\left.d_{4}\right) \delta \mathrm{ppm} 7.62(\mathrm{dd}, J$ $=2.1,1.3 \mathrm{~Hz}, 1 \mathrm{H}, \mathrm{H}-1), 5.62(\mathrm{~d}, J=4.4 \mathrm{~Hz}, 1 \mathrm{H}, \mathrm{H}-7), 4.05(\mathrm{~d}, J=10.0 \mathrm{~Hz}, 1 \mathrm{H}, \mathrm{H}-12), 4.06$ (s, $2 \mathrm{H}, \mathrm{H}-20), 3.13$ (t, J = 5.5 Hz, $1 \mathrm{H}, \mathrm{H}-8), 3.09$ (t, $J=2.7 \mathrm{~Hz}, 1 \mathrm{H}, \mathrm{H}-10), 2.50$ (d, J = 19.1 $\left.\mathrm{Hz}, 1 \mathrm{H}, \mathrm{H}_{\mathrm{a}}-5\right), 2.45\left(\mathrm{~d}, J=19.1 \mathrm{~Hz}, 1 \mathrm{H}, \mathrm{H}_{\mathrm{a}}-5\right), 1.94-1.99(\mathrm{~m}, 1 \mathrm{H}, \mathrm{H}-11), 1.75(\mathrm{dd}, J=2.8$, $1.3 \mathrm{~Hz}, 3 \mathrm{H}, \mathrm{H}-19), 1.28$ (s, $3 \mathrm{H}, \mathrm{H}-16), 1.17$ (s, $3 \mathrm{H}, \mathrm{H}-17), 1.08$ (d, J = 6.6 Hz, $3 \mathrm{H}, \mathrm{H}-18$ ), $0.90\left(\mathrm{~s}, 9 \mathrm{H}\right.$, TBDMS $\left.3 \times \mathrm{CH}_{3}\right), 0.64(\mathrm{~d}, J=5.4 \mathrm{~Hz}, 1 \mathrm{H}, \mathrm{H}-14), 0.00\left(\mathrm{~s}, 3 \mathrm{H}, \mathrm{Si}-\mathrm{CH}_{3}\right),-0.01$ (s, $\left.3 \mathrm{H}, \mathrm{Si}-\mathrm{CH}_{3}\right) \cdot{ }^{13} \mathrm{C}$ NMR (150 MHz, methanol- $\left.d_{4}\right) \delta$ ppm 209.37 (1 C, C-3), 159.79 (1 C, C-1), 140.21 (1 C, C-6), 132.83 (1 C, C-2), 129.32 (1 C, C-7), 80.71 (1 C, C-12), 78.26 (1 C, C-9), 73.57 (1 C, C-4), 67.79 (1 C, C-20), 61.86 (1 C, C-13), 57.40 (1 C, C-10), 44.79 (1 C, C-11), 38.95 (1 C, C-8), 36.90 (1 C, C-5), 36.02 (1 C, C-14), 25.73 (1 C, C-15), 24.98 (3 C, TBDMS $\left.3 \times \mathrm{CH}_{3}\right) 22.71$ (1 C, C-17), $17.75\left(1 \mathrm{C}, \mathrm{Si}-\mathrm{C}-\left(\mathrm{CH}_{3}\right)_{3}\right) 16.44$ (1 C, C-16), 14.03 (1 C, C-18), 8.84 (1 C, C-19), $-6.55\left(2 \mathrm{C}, \mathrm{Si}-\left(\mathrm{CH}_{3}\right)_{2}\right)$.

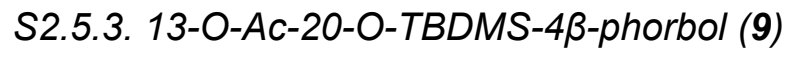

After dissolving 20-O-TBDMS-4 $\beta$-phorbol $(11 ; 412 \mathrm{mg} ; 0.86 \mathrm{mmol})$ in DCM $(1.5 \mathrm{~mL})$ and THF (1.5 mL), $\mathrm{Et}_{3} \mathrm{~N}(0.23 \mathrm{~mL} ; 1.72 \mathrm{mmol})$ and DMAP (11 mg; $\left.0.09 \mathrm{mmol}\right)$ were added, followed by slow addition of a $10 \%$ solution of $\mathrm{Ac}_{2} \mathrm{O}$ in $\mathrm{DCM}(0.9 \mathrm{~mL} ; 0.86 \mathrm{mmol})$ while stirring on ice. Shortly after addition of the $\mathrm{Ac}_{2} \mathrm{O}$ solution the ice bath was removed, and then the reaction mixture was allowed to warm to $23^{\circ} \mathrm{C}$ for $1.5 \mathrm{~h}$. The solvent was evaporated, the residue was dissolved in DCM and washed with brine and a saturated solution of $\mathrm{NH}_{4} \mathrm{Cl}$ in water. The organic phase was dried over $\mathrm{Na}_{2} \mathrm{SO}_{4}$, evaporated, and the resulting residue fractionated on silica gel (200 mL silica gel, eluting with heptane-EtOAc 2:1 and 3:2) to give 12,13-di-O-Ac20-O-TBDMS-4ß-phorbol (76 mg) and the desired product 9 as a yellow powder $(379 \mathrm{mg}$; 85\%). ${ }^{1} \mathrm{H}$ NMR (600 MHz, $\mathrm{CDCl}_{3}$ ) $\delta \mathrm{ppm} 7.57$ (dd, $\left.J=2.1,1.3 \mathrm{~Hz}, 1 \mathrm{H}, \mathrm{H}-1\right), 5.61$ (d, $J=4.4$ $\mathrm{Hz}, 1 \mathrm{H}, \mathrm{H}-7$ ), 4.0 (d, J = $10.0 \mathrm{~Hz}, 1 \mathrm{H}, \mathrm{H}-12), 4.02$ (s, $2 \mathrm{H}, \mathrm{H}-20), 3.15$ (t, J = $5.5 \mathrm{~Hz}, 1 \mathrm{H}, \mathrm{H}-$ 8), $3.13(\mathrm{t}, J=2.7 \mathrm{~Hz}, 1 \mathrm{H}, \mathrm{H}-10), 2.47\left(\mathrm{~d}, J=19.1 \mathrm{~Hz}, 1 \mathrm{H}, \mathrm{H}_{\mathrm{a}}-5\right), 2.37(\mathrm{~d}, J=19.1 \mathrm{~Hz}, 1 \mathrm{H}$, $\mathrm{H}_{\mathrm{b}}-5$ ), 2.13 (s, $3 \mathrm{H}, \mathrm{H}-2 \mathrm{Ac}$ ), 2.05-1.99 (m, $1 \mathrm{H}, \mathrm{H}-11$ ), 1.77 (dd, $J=2.8,1.3 \mathrm{~Hz}, 3 \mathrm{H}, \mathrm{H}-19$ ), 1.25 (s, $3 \mathrm{H}, \mathrm{H}-16), 1.22$ (s, $3 \mathrm{H}, \mathrm{H}-17), 1.04$ (d, $J=6.6 \mathrm{~Hz}, 3 \mathrm{H}, \mathrm{H}-18), 1.03$ (d, J = 5.4 Hz, 1 
$\mathrm{H}, \mathrm{H}-14), 0.90\left(\mathrm{~s}, 9 \mathrm{H}\right.$, TBDMS $\left.3 \times \mathrm{CH}_{3}\right), 0.07\left(\mathrm{~s}, 3 \mathrm{H}, \mathrm{Si}-\mathrm{CH}_{3}\right), 0.06\left(\mathrm{~s}, 3 \mathrm{H}, \mathrm{Si}-\mathrm{CH}_{3}\right) .{ }^{13} \mathrm{C} \mathrm{NMR}$ $\left(150 \mathrm{MHz}, \mathrm{CDCl}_{3}\right) \delta$ ppm 208.87 (1 C, C-3), 174.09 (1C, C-1 Ac), 160.30 (1 C, C-1), 140.66 (1 C, C-6), 132.95 (1 C, C-2), 127.51 (1 C, C-7), 78.26 (1 C, C-9), 77.48 (1 C, C-12), 73.53 (1 C, C-4), 68.33 (1 C, C-13) 67.86 (1 C, C-20), 56.90 (1 C, C-10), 44.90 (1 C, C-11), 39.02 (1 C, C-8), 38.35 (1 C, C-5), 35.42 (1 C, C-14), 26.68 (1 C, C-15), 25.94 (3 C, TBDMS $3 \times \mathrm{CH}_{3}$ ), 23.62 (1 C, C-17), 21.07 (1 C, C-2 Ac), 18.38 (1 C, Si-C- $\left.\left(\mathrm{CH}_{3}\right)_{3}\right), 16.92$ (1 C, C-16), 15.10 (1 $\mathrm{C}, \mathrm{C}-18), 10.10$ (1 C, C-19), $-6.55\left(2 \mathrm{C}, \mathrm{Si}-\left(\mathrm{CH}_{3}\right)_{2}\right)$.

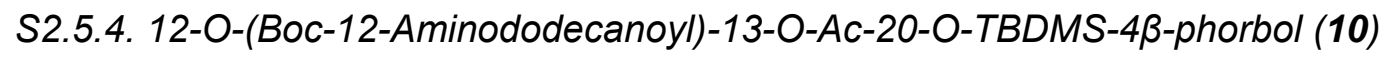

Compound 9 (159 mg; $0.300 \mathrm{mmol}$ ) was dissolved in DCM (4 mL) and then DMAP (56 mg; $0.46 \mathrm{mmol}$ ), EDC (86 mg; $0.45 \mathrm{mmol}$ ) and Boc-12-aminododecanoate (142 mg; $0.45 \mathrm{mmol}$ ) were added. The mixture was stirred for $20 \mathrm{~h}$ at $23{ }^{\circ} \mathrm{C}$, the solvent was evaporated, and the residue purified on a silica column (heptane-EtOAc 3:1) to give product 10 as a yellow powder (250 mg; 94\%). ${ }^{1} \mathrm{H}$ NMR (600 MHz, $\left.\mathrm{CDCl}_{3}\right) \delta \mathrm{ppm} 7.60(\mathrm{dd}, J=2.1,1.3 \mathrm{~Hz}, 1 \mathrm{H}, \mathrm{H}-$ 1), 5.63 (d, J = 4.4 Hz, $1 \mathrm{H}, \mathrm{H}-7$ ), 5.42 (d, J = $10.0 \mathrm{~Hz}, 1 \mathrm{H}, \mathrm{H}-12$ ), 4.02 (s, $2 \mathrm{H}, \mathrm{H}-20), 3.25$ (t, $J=2.7 \mathrm{~Hz}, 1 \mathrm{H}, \mathrm{H}-10), 3.19(\mathrm{t}, J=5.5 \mathrm{~Hz}, 1 \mathrm{H}, \mathrm{H}-8), 3.10\left(\mathrm{~d}, J=5.9 \mathrm{~Hz}, 2 \mathrm{H}, \mathrm{H}^{\prime}-12\right), 2.50$ (d, $\left.J=19.1 \mathrm{~Hz}, 1 \mathrm{H}, \mathrm{H}_{\mathrm{a}}-5\right), 2.41\left(\mathrm{~d}, J=19.1 \mathrm{~Hz}, 1 \mathrm{H}, \mathrm{H}_{\mathrm{b}}-5\right), 2.32\left(\mathrm{~m}, 2 \mathrm{H}, \mathrm{H}^{\prime}-2\right), 2.18-2.13(\mathrm{~m}$, $1 \mathrm{H}, \mathrm{H}-11$ ), 2.10 (s, $3 \mathrm{H}, \mathrm{H}-2 \mathrm{Ac}$ ), 1.77 (dd, $J=2.8,1.3 \mathrm{~Hz}, 3 \mathrm{H}, \mathrm{H}-19$ ), 1.64 (quin, $J=7.3,2$ $\left.\mathrm{H}, \mathrm{H}^{\prime}-3\right), 1.47\left(\mathrm{~m}, 2 \mathrm{H}, \mathrm{H}^{\prime}-11\right), 1.45$ (s, $\left.9 \mathrm{H}, \mathrm{Boc}\right), 1.35-1.26\left(\mathrm{~m}, 14 \mathrm{H}, \mathrm{H}^{\prime}-10 \rightarrow \mathrm{H}^{\prime}-4\right), 1.24$ (s, $3 \mathrm{H}, \mathrm{H}-16), 1.21(\mathrm{~s}, 3 \mathrm{H}, \mathrm{H}-17), 1.07$ (d, J = 5.4 Hz, $1 \mathrm{H}, \mathrm{H}-14), 0.90$ (d, J = 6.6 Hz, $3 \mathrm{H}, \mathrm{H}-$ 18), $0.89\left(\mathrm{~s}, 9 \mathrm{H}\right.$, TBDMS $\left.3 \times \mathrm{CH}_{3}\right), 0.07\left(\mathrm{~s}, 3 \mathrm{H}, \mathrm{Si}-\mathrm{CH}_{3}\right), 0.06\left(\mathrm{~s}, 3 \mathrm{H}, \mathrm{Si}-\mathrm{CH}_{3}\right) .{ }^{13} \mathrm{C} \mathrm{NMR}$ (150 MHz, CDCl 3 ) $\delta$ ppm 208.97 (1 C, C-3), 173.69 (1 C, C'-1), 173.58 (1 C, C-1 Ac), 160.77 (1 C, C-1), 155.97 (1 C, Boc carbonyl) 140.08 (1 C, C-6), 132.61 (1 C, C-2), 128.05 (1 C, C7), 77.97 (1 C, C-9), 76.80 (1 C, Boc C- $\left.\left(\mathrm{CH}_{3}\right)_{3}\right) 76.68$ (1 C, C-12), 73.80 (1 C, C-4), 68.01 (1 C, C-20), 65.71 (1 C, C-13), 56.13 (1 C, C-10), 42.91 (1 C, C-11), 40.61 (1 C, C'-12), 39.10 (1 C, C-8), 38.29 (1 C, C-5), 36.26 (1 C, C-14), 34.57 (1 C, C'-2), 30.05 (1 C, C'-11), 29.5028.43 (7 C, C'4 - C'10), $28.43\left(3 \mathrm{C}\right.$, Boc $3 \times \mathrm{CH}_{3}$ ), $25.94\left(3 \mathrm{C}\right.$, TBDMS $\left.3 \times \mathrm{CH}_{3}\right), 25.54(1 \mathrm{C}$, C-15), 25.16 (1 C, C'-3), 23.85 (1 C, C-17), 21.10 (1C, C-2 Ac), 18.38 (1 C, Si-C-( $\left.\left(\mathrm{CH}_{3}\right)_{3}\right)$, 16.77 (1 C, C-16), 14.38 (1 C, C-18), 10.08 (1 C, C-19), -6.27 (2 C, Si- $\left.\left(\mathrm{CH}_{3}\right)_{2}\right)$.

\section{S2.5.5. 12-O-(12-Aminododecanoyl)-13-O-Ac-4ß-phorbol (8)}

To a solution of compound 10 (170 $\mathrm{mg} ; 0.21 \mathrm{mmol})$ in DCM $(3 \mathrm{~mL})$ was added TFA $(3 \mathrm{~mL})$ under stirring on ice. Then the reaction mixture was allowed to warm to room temperature during $2 \mathrm{~h}$. On TLC the product was visualized by spraying with ninhydrin in $n$-butanol and visualized by heating with a heat gun. The reaction mixture was concentrated, and the resulting residue was fractionated on a silica column (DCM-MeOH 9:1) to give the free 
amine 8 as a yellow amorphous powder (114 mg; 91\%). Analytical UHPLC with the gradient $20 \% \rightarrow 100 \%$ B during $10 \mathrm{~min}$ : retention time of $5.7 \mathrm{~min}$; revealed a purity of $>96 \%$. ${ }^{1} \mathrm{H}$ NMR $\left(600 \mathrm{MHz}\right.$, methanol- $\left.d_{4}\right) \delta \mathrm{ppm} 7.56(\mathrm{dd}, J=2.1,1.3 \mathrm{~Hz}, 1 \mathrm{H}, \mathrm{H}-1), 5.64(\mathrm{~d}, J=4.4 \mathrm{~Hz}, 1 \mathrm{H}$, $\mathrm{H}-7$ ), 5.46 (d, $J=10.0 \mathrm{~Hz}, 1 \mathrm{H}, \mathrm{H}-12), 3.99-3.92$ (dd, $J=12.8,9.8 \mathrm{~Hz}, 2 \mathrm{H}, \mathrm{H}-20), 3.31$ (t, $J=$ $5.5 \mathrm{~Hz}, 1 \mathrm{H}, \mathrm{H}-8), 3.18(\mathrm{t}, J=2.7 \mathrm{~Hz}, 1 \mathrm{H}, \mathrm{H}-10), 2.9$, (t, J = 7.7 Hz, $\left.2 \mathrm{H}, \mathrm{H}^{\prime}-12\right), 2.56(\mathrm{~d}, J=$ $\left.19.1 \mathrm{~Hz}, 1 \mathrm{H}, \mathrm{H}_{\mathrm{a}}-5\right), 2.50\left(\mathrm{~d}, J=19.1 \mathrm{~Hz}, 1 \mathrm{H}, \mathrm{H}_{\mathrm{b}}-5\right), 2.42-2.32\left(\mathrm{~m}, 2 \mathrm{H}, \mathrm{H}^{\prime}-2\right), 2.26-2.20(\mathrm{~m}$, $1 \mathrm{H}, \mathrm{H}-11$ ), 2.08 (s, $3 \mathrm{H}, \mathrm{H}-2 \mathrm{Ac}$ ), 1.76 (dd, $J=2.8,1.3 \mathrm{~Hz}, 3 \mathrm{H}, \mathrm{H}-19), 1.69-1.63(\mathrm{~m}, 4 \mathrm{H}$, $\left.\mathrm{H}^{\prime}-3, \mathrm{H}^{\prime}-11\right), 1.44-1.31,\left(\mathrm{~m}, 14 \mathrm{H}, \mathrm{H}^{\prime}-10 \rightarrow \mathrm{H}^{\prime}-4\right), 1.27$ (s, $\left.3 \mathrm{H}, \mathrm{H}-16\right), 1.23(\mathrm{~s}, 3 \mathrm{H}, \mathrm{H}-17)$, $1.17(\mathrm{~d}, J=5.4 \mathrm{~Hz}, 1 \mathrm{H}, \mathrm{H}-14), 0.91(\mathrm{~d}, J=6.6 \mathrm{~Hz}, 3 \mathrm{H}, \mathrm{H}-18) .{ }^{13} \mathrm{C}$ NMR $(150 \mathrm{MHz}$, methanol- $\left.d_{4}\right) \delta$ ppm 208.90 (1 C, C-3), 174.21 (1 C, C'-1), 173.69 (1 C, C-1 Ac), 159.13 (1 C, C-1), 141.14 (1 C, C-6), 133.18 (1 C, C-2), 127.90 (1 C, C-7), 78.38 (1 C, C-9), 76.83 (1 C, C-12), 73.32 (1 C, C-4), 66.58 (1 C, C-20), 65.73 (1 C, C-13), 55.94 (1 C, C-10), 53.41 (1 C, C-13), 42.85 (1 C, C-11), 39.36 (1 C, C'-12), 38.61 (1 C, C-8), 37.07 (1 C, C-5), 35.64 (1 C, C-14), 33.95 (1 C, C'-2), 29.20-28.43 (7 C, C'4 - C'10), 27.17 (1 C, C'-3), 26.05 (1 C, C-15), 24.84 (1 C, C'-11), 22.72 (1 C, C-17), 19.68 (1C, C-2 Ac), 15.96 (1 C, C-16), 13.45 (1 C, C18), 8.64 (1 C, C-19). HRMS-ESI: $\left[\mathrm{C}_{34} \mathrm{H}_{53} \mathrm{NO}_{8}+\mathrm{H}\right]^{+} \mathrm{m} / \mathrm{z}: 604.3849$. Found 604.3845.

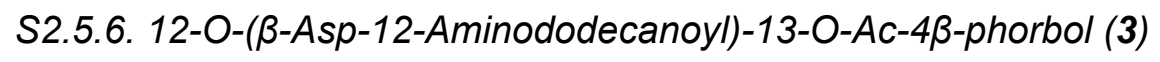

To a solution of 12-Aminododecanoic acid $(4.71 \mathrm{~g} ; 21.9 \mathrm{mmol})$ in $90 \mathrm{~mL}$ acetone and $90 \mathrm{~mL}$ $\mathrm{H}_{2} \mathrm{O}$ were added Fmoc-OSu (6.55 g; $\left.21.9 \mathrm{mmol}\right)$ and $\mathrm{NaHCO}_{3}(2.39 \mathrm{~g} ; 28.5 \mathrm{mmol})$ and the reaction was stirred at $23{ }^{\circ} \mathrm{C}$ for $20 \mathrm{~h}$. The reaction mixture was acidified with conc. $\mathrm{HCl}$ until $\mathrm{pH} 4-5$, and the resulting precipitate was extracted with EtOAc $(3 \times 50 \mathrm{~mL})$. The combined organic phases were dried with $\mathrm{Na}_{2} \mathrm{SO}_{4}$, filtered, and concentrated. The crude product was purified on a silica column (hexane-EtOAc 3:1) to provide Fmoc-12-aminododecanoic acid (4.20 g; 43\%) as a white solid. ${ }^{1} \mathrm{H}$ NMR and ${ }^{13} \mathrm{C}$ NMR were as reported ${ }^{7}$. 2-CTC resin (2.58 g; loading: $1.6 \mathrm{mmol} / \mathrm{g})$ was swelled in $\mathrm{DCM}(5 \mathrm{~mL})$ in a teflon reaction vessel fitted with a polypropylene filter, and a solution of Fmoc-12-aminododecanoic acid (0.60 g; $1.37 \mathrm{mmol})$ and DIPEA (2.38 $\mathrm{mL} ; 13.7 \mathrm{mmol})$ in DCM $(3 \mathrm{~mL})$ was added to the resin. The mixture was shaken for $3 \mathrm{~h}$ at $23{ }^{\circ} \mathrm{C}$. The resin was drained and washed twice with DCM followed by capping with DIPEA-MeOH-DCM 5:15:80 (8 mL; $2 \times 5 \mathrm{~min}$ ). The resin was washed successively with DMF, MeOH and DCM (each 3 times with $8 \mathrm{~mL}$ for $3 \mathrm{~min}$ ), and then residual solvent was removed on a freeze-dryer. Test cleavage of the dry preloaded resin with a $20 \%$ solution of HFIP in DCM showed a loading of approx. $0.48 \mathrm{mmol} / \mathrm{g}$.

The Fmoc protecting group was removed with a $20 \%$ solution of piperidine in DMF ( $8 \mathrm{~mL} ; 2 \times$ $20 \mathrm{~min}$ ) followed by washing with DMF, MeOH and DCM (each 3 times as above). A solution of Fmoc-Asp-OtBu (587 mg; $1.42 \mathrm{mmol}$ ), PyBOP (743 mg; $1.42 \mathrm{mmol}$ ) and DIPEA (0.25 mL; 
$2.62 \mathrm{mmol})$ dissolved in DMF $(6 \mathrm{~mL})$ was added to the resin-bound 12-Aminododecanoic acid $\left(1.00 \mathrm{~g}, 0.48 \mathrm{mmol}\right.$ loading). The mixture was shaken for $4 \mathrm{~h}$ at $23{ }^{\circ} \mathrm{C}$, an then a final standard washing (as above) of the resin performed, and finally the product was cleaved from the resin with a $20 \%$ solution of HFIP in DCM $(3 \times 6 \mathrm{~mL}$; each time for $30 \mathrm{~min})$. The eluate was concentrated to give Fmoc-Asp-OtBu-12-aminododecanoate (140 mg; 0.23 mmol; 93\%) as colorless amorphous solid.

To a solution of Fmoc-Asp-OtBu-12-aminododecanoic acid (140 mg; $0.23 \mathrm{mmol}$ ) in DCM (3 $\mathrm{mL}$ ) was added 13-O-Ac-20-O-TBDMS-4ß-phorbol (9; $103 \mathrm{mg} ; 0.20 \mathrm{mmol}$ ), $10 \mathrm{~mol} \%$ DMAP (2.5 mg; $0.02 \mathrm{mmol}$ ) and EDC (56 mg; $0.29 \mathrm{mmol})$. To avoid loss of the Fmoc group DMAP ( $5 \mathrm{mg} ; 0.04 \mathrm{mmol}$ ) was added four times with $1 \mathrm{~h}$ intervals. The reaction was stopped after $25 \mathrm{~h}$. The reaction mixture was concentrated, and the residue purified on silica column (toluene-EtOAc 4:1) to provide 12-O-(Fmoc-Asp-OtBu-12-aminododecanoyl)-13-O-Ac-20TBDMS-4ß-phorbol (14; 92 mg; 42\%).

To a solution of compound 14 (92 $\mathrm{mg} ; 0.08 \mathrm{mmol})$ in DCM (2 mL) and THF (3 mL) added a few drops of $\mathrm{H}_{2} \mathrm{O}$ were added, the and the reaction was stirred at $23^{\circ} \mathrm{C}$ for $1 \mathrm{~h}$. and TFA and DCM were removed by evaporation and DCM $(4 \mathrm{~mL})$ was added followed by addition of $\mathrm{Et}_{2} \mathrm{NH}(1 \mathrm{~mL})$. The reaction was stirred at $23{ }^{\circ} \mathrm{C}$ for $1 \mathrm{~h}$. The reaction mixture was then concentrated. The residue was purified by preparative HPLC with the gradient $50 \% \rightarrow 100 \%$ B during $20 \mathrm{~min}$ to give 12-O-(Asp-12-aminododecanoyl)-13-O-Ac-20-TBDMS-4ß-phorbol 3 as white powder (37 mg; 62\%). Analytical UHPLC with gradient $50 \% \rightarrow 100 \%$ B during 10 min: retention time $2.2 \mathrm{~min}$; purity $\geq 99 \%$. ${ }^{1} \mathrm{H}$ NMR $\left(600 \mathrm{MHz}\right.$, methanol- $\left.d_{4}\right) \delta \mathrm{ppm} 7.57$ (s, 1 $\mathrm{H}, \mathrm{C}-3$ ), 5.64 (d, J = 4.4 Hz, $1 \mathrm{H}, \mathrm{H}-7$ ), 5.47 (d, $J=10.0 \mathrm{~Hz}, 1 \mathrm{H}, \mathrm{H}-12$ ), 4.23 (dd, $J=7.1,4.4$ $\mathrm{Hz}, 1 \mathrm{H}, \alpha-\mathrm{H}$ Asp), 3.96 (dd, J = 12.8, $9.8 \mathrm{~Hz}, 2 \mathrm{H}, \mathrm{H}-20), 3.31(\mathrm{~m}, 1 \mathrm{H}, \mathrm{H}-8), 3.22(\mathrm{~m}, 1 \mathrm{H}, \mathrm{H}-$ 10), $3.19-3.16$ (m, $\left.2 \mathrm{H}, \mathrm{H}^{\prime}-12\right), 2.96-2.81$ (m, $2 \mathrm{H}, \beta-\mathrm{H}$ Asp), $2.54\left(\mathrm{~d}, J=19.1 \mathrm{~Hz}, 1 \mathrm{H}, \mathrm{H}_{\mathrm{a}^{-}}\right.$ 5), $2.50\left(\mathrm{~d}, J=19.1 \mathrm{~Hz}, 1 \mathrm{H}, \mathrm{H}_{\mathrm{b}}-5\right), 2.44-2.30\left(\mathrm{~m}, 2 \mathrm{H}, \mathrm{H}^{\prime}-2\right), 2.24(\mathrm{~m}, 1 \mathrm{H}, \mathrm{H}-11), 2.08$ (s, 3 $\mathrm{H}, \mathrm{H}-2 \mathrm{Ac}), 1.76(\mathrm{dd}, \mathrm{J}=2.8,1.3 \mathrm{~Hz}, 3 \mathrm{H}, \mathrm{H}-19), 1.70-1.62\left(\mathrm{~m}, 2 \mathrm{H}, \mathrm{H}^{\prime}-3\right), 1.52\left(\mathrm{~m}, 2 \mathrm{H}, \mathrm{H}^{\prime}-\right.$ 11), $1.42-1.30\left(\mathrm{~m}, 14 \mathrm{H}, \mathrm{H}^{\prime}-10 \rightarrow \mathrm{H}^{\prime}-4\right), 1.27(\mathrm{~s}, 3 \mathrm{H}, \mathrm{H}-16), 1.23(\mathrm{~s}, 3 \mathrm{H}, \mathrm{H}-17), 1.17$ (d, $\mathrm{J}=$ $5.4 \mathrm{~Hz}, 1 \mathrm{H}, \mathrm{H}-14), 0.91(\mathrm{~d}, J=6.6 \mathrm{~Hz}, 3 \mathrm{H}, \mathrm{H}-18) .{ }^{13} \mathrm{C}$ NMR $\left(150 \mathrm{MHz}\right.$, methanol- $\left.d_{4}\right) \delta \mathrm{ppm}$ 208.91 (1 C, C-3), 174.23 (1 C, C'-1), 173.89 (1 C, C-1 Ac), 169.65 (1 C, C-4 Asp), 169.49 (1 C, C-1 Asp) 159.13 (1 C, C-1), 141.44 (1 C, C-6), 133.19 (1 C, C-2), 127.89 (1 C, C-7), 78.37 (1 C, C-9), 76.85 (1 C, C-12), 73.32 (1 C, C-4), 66.57 (1 C, C-20), 65.73 (1 C, C-13), 55.94 (1 C, C-10), 49.69 (1 C, C-3 Asp), 42.85 (1 C, C-11), 39.14 (1 C, C'-12), 38.61 (1 C, C-8), 37.07 (1 C, C-5), 35.63 (1 C, C-14), 33.95 (1 C, C'-2), 33.81 (1 C, C-2 Asp), 29.24-28.65 (7 C, C'-4 - C'-9 + C'-11), 26.59 (1 C, C'-10), 25.78 (1 C, C-15) 24.83 (1 C, C'-3), 22.70 (1 C, C-17), 19.66 (1C, C-2 AC), 15.98 (1 C, C-16), 13.43 (1 C, C-18), 8.81 (1 C, C-19). HRMS-ESI: $\left[\mathrm{C}_{38} \mathrm{H}_{58} \mathrm{~N}_{2} \mathrm{O}_{11}+\mathrm{H}\right]^{+} \mathrm{m} / \mathrm{z}: 719.4119$. Found 719.4112. 
Sample ID

Data Filename

TZ41 2preplargescale.Icd

Method Filename $501 \overline{00 B} 10 \mathrm{~min}$ crude2014.Icm

Batch Filename : 2017_06_08_4.Iç

Vial \#

$1-63$

njection Volume : 5 ul

Date Acquired : 6/8/2017

\section{Complete Chromatogram}

mAU

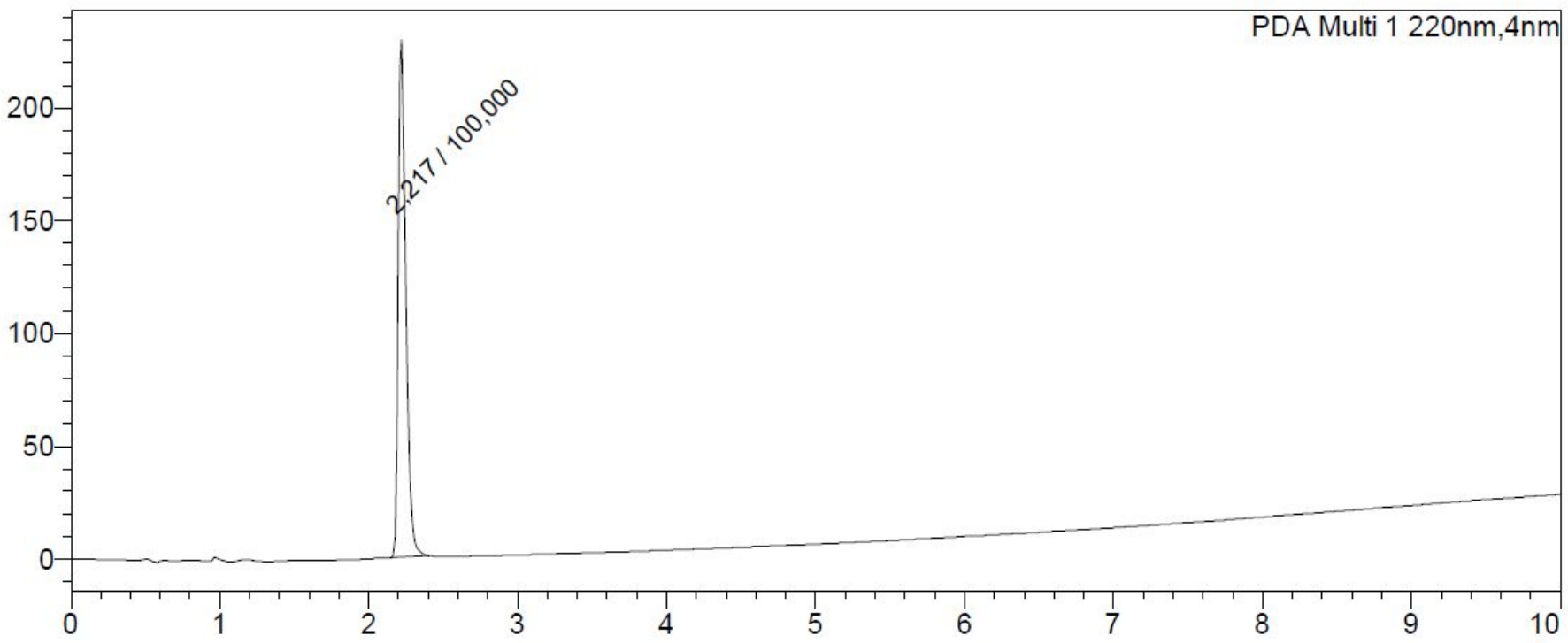

PDA Ch1 220nm

\begin{tabular}{|r|r|r|r|r|}
\hline Peak\# & Ret. Time & \multicolumn{1}{c|}{ Area\% } & Height & \multicolumn{1}{c|}{ Area } \\
\hline 1 & 2,217 & 100,000 & 229389 & 839410 \\
\hline Total & & 100,000 & 229389 & 839410 \\
\hline
\end{tabular}

Fig.S6: Compound 3 analytical HPLC 


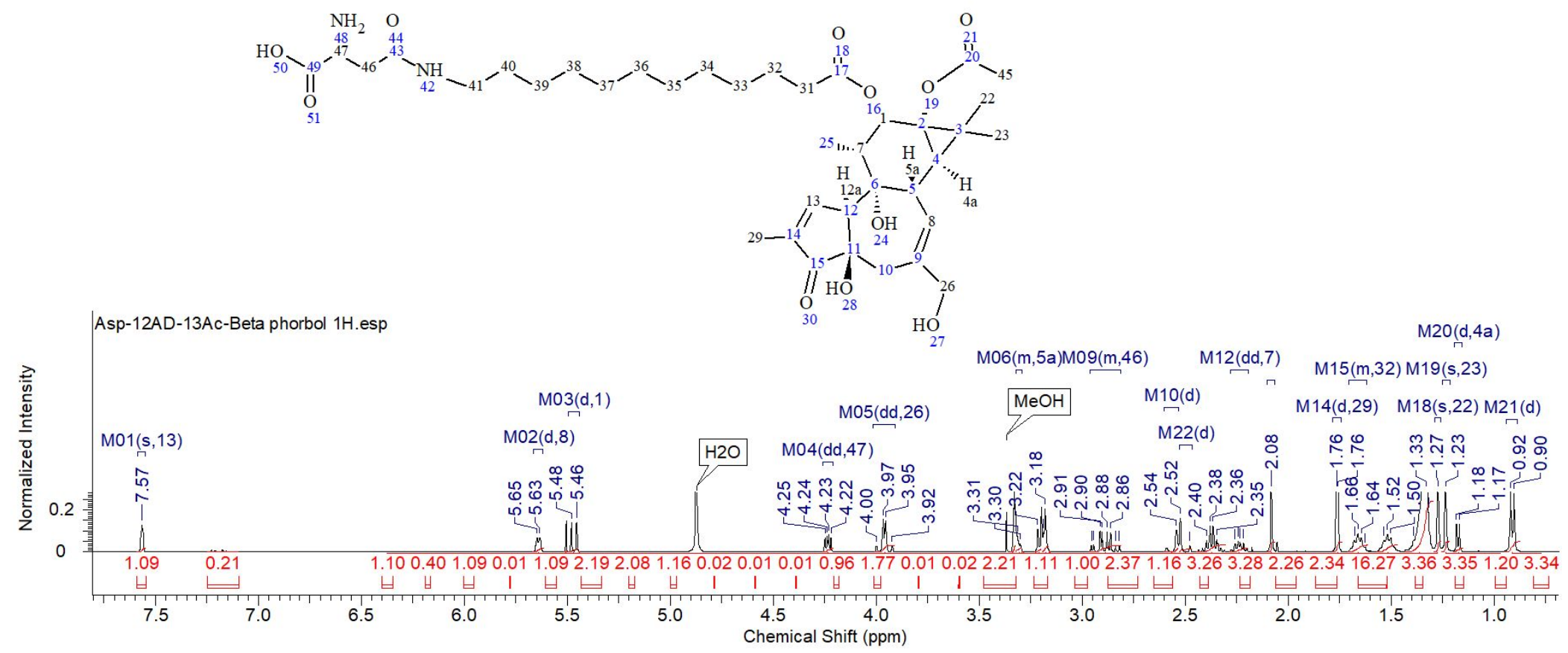

Fig.S7: Compound $3^{1} \mathrm{H}$ NMR 


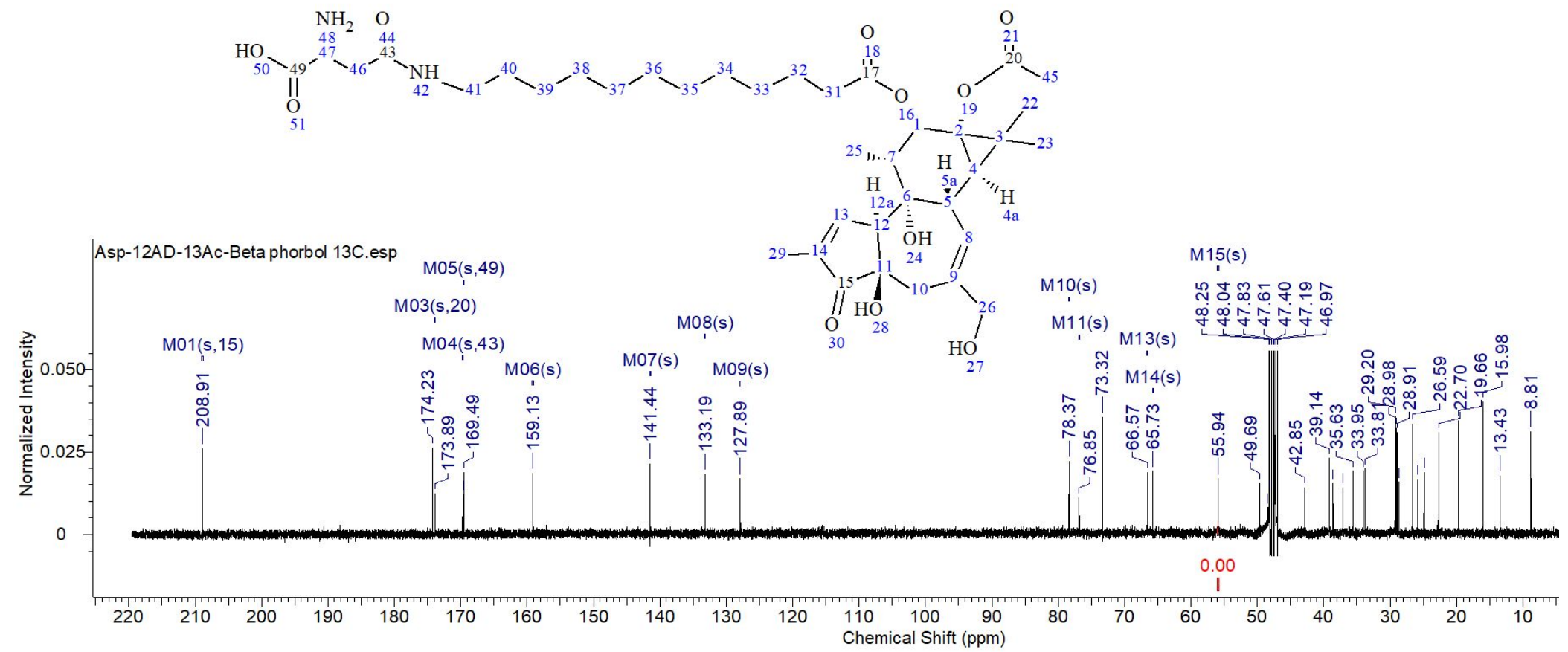

Fig.S8: Compound $3{ }^{13} \mathrm{C}$ NMR 


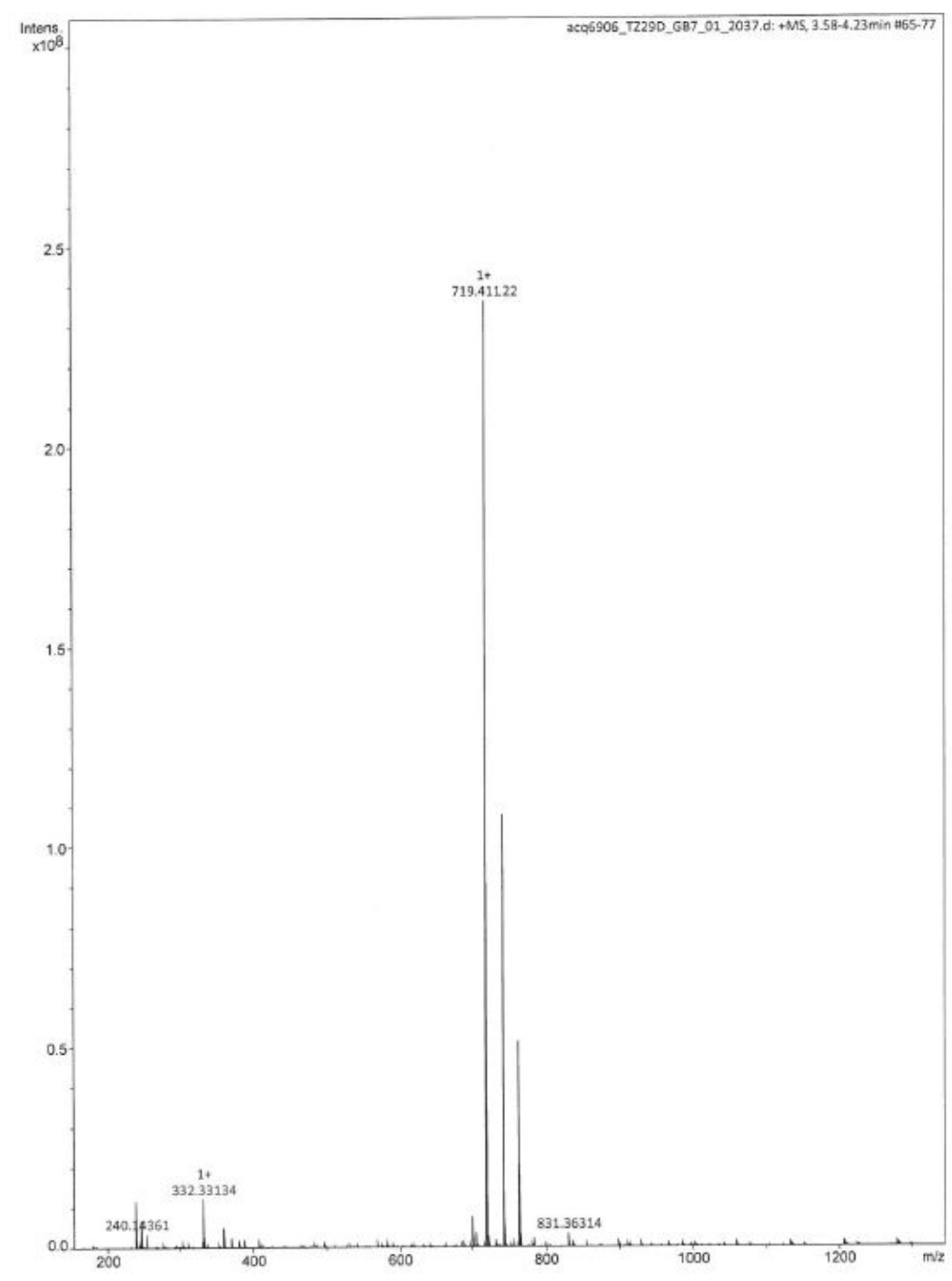

Fig.S9: Compound 3 HRMS 


\section{S2.5.7. 12-O-(Leu-12-Aminododecanoyl)-13-O-Ac- $\beta-$ phorbol (2)}

Fmoc-12-aminododecanoic loaded on 2-CTC resin $(0.5 \mathrm{~g}, 0.48 \mathrm{mmol}$ loading) was deprotected as described in the synthesis of 3 , then a solution of Boc-Leu-OH (170 mg; 0.71 mmol), PyBOP (372 mg; $0.71 \mathrm{mmol}$ ) and DIPEA (0.12 mL; $1.31 \mathrm{mmol})$ dissolved in DMF (5 $\mathrm{mL}$ ) were added. The mixture was shaken for $4 \mathrm{~h}$ at $23^{\circ} \mathrm{C}$, and after a standard wash of the resin, cleavage was performed with a $20 \%$ solution of HFIP in DCM $(3 \times 6 \mathrm{~mL}$; each time for $30 \mathrm{~min}$ ). The eluate was concentrated to give $\mathrm{N}$-Boc-Leu-12-aminododecanoate (90 mg; $88 \%)$ as a transparent thick amorphous solid. To a solution of Boc-Leu-12-aminododecanoic acid $(0.090 \mathrm{~g} ; 0.21 \mathrm{mmol})$ in DCM (3 mL) was added 13-O-Ac-20-O-TBDMS-4ß-phorbol (9; $0.090 \mathrm{~g} ; 0.17 \mathrm{mmol})$, DMAP (32 $\mathrm{mg} ; 0.26 \mathrm{mmol})$ and EDC (0.050 g; $0.26 \mathrm{mmol})$ under stirring at $23{ }^{\circ} \mathrm{C}$. After $15 \mathrm{~h}$ the reaction mixture was concentrated, and the residue purified on a silica column (heptane-EtOAc 1:1) to provide 12-O-(Boc-Leu-12-aminododecanoyl)-13O-Ac-20-TBDMS-4ß-phorbol (13) as white powder (140 mg; 94\%).

A portion of the product 13 (74 $\mathrm{mg} ; 0.09 \mathrm{mmol})$ was dissolved in DCM (3 mL), and then the Boc group was removed by addition of TFA $(3 \mathrm{~mL})$ and leaving the solution at $23^{\circ} \mathrm{C}$ for $3 \mathrm{~h}$. The reaction mixture was concentrated, and the residue fractionated by preparative HPLC with the gradient $30 \% \rightarrow 100 \%$ B during 20 min to give 2 as a white powder $(19.5 \mathrm{mg} ; 30 \%)$. Analytical UHPLC with gradient $20 \% \rightarrow 80 \%$ B during 10 min: retention time 7.8 min; purity $\geq 99 \%$. ${ }^{1} \mathrm{H}$ NMR $\left(600 \mathrm{MHz}\right.$, methanol- $\left.d_{4}\right) \delta \mathrm{ppm} 7.56(\mathrm{dd}, J=2.1,1.3 \mathrm{~Hz}, 1 \mathrm{H}, \mathrm{H}-1), 5.64(\mathrm{~d}, J$ $=4.4 \mathrm{~Hz}, 1 \mathrm{H}, \mathrm{H}-7), 5.47(\mathrm{~d}, J=10.0 \mathrm{~Hz}, 1 \mathrm{H}, \mathrm{H}-12), 3.96(\mathrm{dd}, J=12.8,9.8 \mathrm{~Hz}, 2 \mathrm{H}, \mathrm{H}-20)$, $3.81\left(\mathrm{t}, J=6.8 \mathrm{~Hz}, 1 \mathrm{H}, \alpha-\mathrm{H}\right.$ Leu), $3.31(\mathrm{~m}, 1 \mathrm{H}, \mathrm{H}-8), 3.29$ (t, $J=7.3 \mathrm{~Hz}, 1 \mathrm{H}, \mathrm{H}_{\mathrm{a}}-12$ 12AD), 3.20 (t, J = 7.0 Hz, $1 \mathrm{H}, \mathrm{H}_{\mathrm{b}}-12$ 12AD), $3.17(\mathrm{~m}, 1 \mathrm{H}, \mathrm{H}-10), 2.58-2.482 .57$ (d, J = $19.1 \mathrm{~Hz}, 1$ $\left.\mathrm{H}, \mathrm{H}_{\mathrm{a}}-5\right), 2.50$ (d, J = $\left.19.1 \mathrm{~Hz}, 1 \mathrm{H}, \mathrm{H}_{\mathrm{b}}-5\right), 2.42$ - 2.32 (m, $2 \mathrm{H}, \mathrm{H}-2$ 12AD), $2.23(\mathrm{~m}, 1 \mathrm{H}, \mathrm{H}-$ 11), 2.08 (s, $3 \mathrm{H}, \mathrm{H}-2 \mathrm{Ac}$ ), 1.76 (dd, $J=2.8,1.3 \mathrm{~Hz}, 3 \mathrm{H}, \mathrm{H}-19), 1.73-1.70$ (m, $1 \mathrm{H}, \mathrm{y}-\mathrm{H}$ Leu), $1.70-1.67$ (m, $2 \mathrm{H}, \beta-\mathrm{H}$ Leu), $1.67-1.63$ (m, $2 \mathrm{H}, \mathrm{H}-11$ 12AD), 1.55 (quin, $J=7.2 \mathrm{~Hz}, 2 \mathrm{H}$, $\mathrm{H}-3$ 12AD), $1.40-1.32\left(\mathrm{~m}, 14 \mathrm{H}, \mathrm{H}^{\prime}-10 \rightarrow \mathrm{H}^{\prime}-4\right), 1.27$ (s, $\left.3 \mathrm{H}, \mathrm{H}-16\right), 1.23(\mathrm{~s}, 3 \mathrm{H}, \mathrm{H}-17), 1.17$ (d, $J=5.4 \mathrm{~Hz}, 1 \mathrm{H}, \mathrm{H}-14), 1.03-1.00(\mathrm{~m}, 6 \mathrm{H}), 0.91(\mathrm{~d}, J=6.6 \mathrm{~Hz}, 3 \mathrm{H}, \mathrm{H}-18) .{ }^{13} \mathrm{C}$ NMR (150 MHz, methanol- $\left.d_{4}\right) \delta$ ppm 208.87 (1 C, C-3), 174.19 (1 C, C'-1), 173.85 (1 C, C-1 Ac), 169.01 (1 C, C-1 Leu), 159.09 (1 C, C-1), 141.43 (1 C, C-6), 133.17 (1 C, C-2), 127.86 (1 C, C-7), 78.36 (1 C, C-9), 76.84 (1 C, C-12), 73.31 (1 C, C-4), 66.56 (1 C, C-20), 65.71 (1 C, C13), 55.93 (1 C, C-10), 51.74 (1 C, C-2 Leu), 42.85 (1 C, C-11), 40.44 (1 C, C-3 Leu), 39.27 (1 C, C'-12), 38.59 (1 C, C-8), 37.06 (1 C, C-5), 35.63 (1 C, C-14), 33.93 (1 C, C'-2), 29.2428.64 (7 C, C'-4 - C'-9 + C'-11), 26.57 (1 C, C'-10), 25.78 (1 C, C-15) 24.82 (1 C, C'-3), 24.12 (1C , C-4 Leu), 22.69 (1 C, C-17), 21.53 (1 C, C-5 a Leu), 20.87 (1 C, C-5b Leu), 19.68 (1C, C-2 Ac), 15.96 (1 C, C-16), 13.42 (1 C, C-18), 8.80 (1 C, C-19). HRMS-ESI: $\left[\mathrm{C}_{40} \mathrm{H}_{64} \mathrm{~N}_{2} \mathrm{O}_{9}+\mathrm{H}\right]^{+} \mathrm{m} / \mathrm{z}:$ 717.4690. Found 717.4679. 
Sample ID

Data Filename : TZ27D_20_80afterprep.lcd

Method Filename : $2080 \overline{\mathrm{B}} 10 \overline{\mathrm{min}}$ purified $2014 . \mathrm{lcm}$

Batch Filename

Vial \#

Injection Volume : 103

Date Acquired $\quad: 5 / 23 / 2017$

Complete Chromatogram

$\mathrm{mAU}$

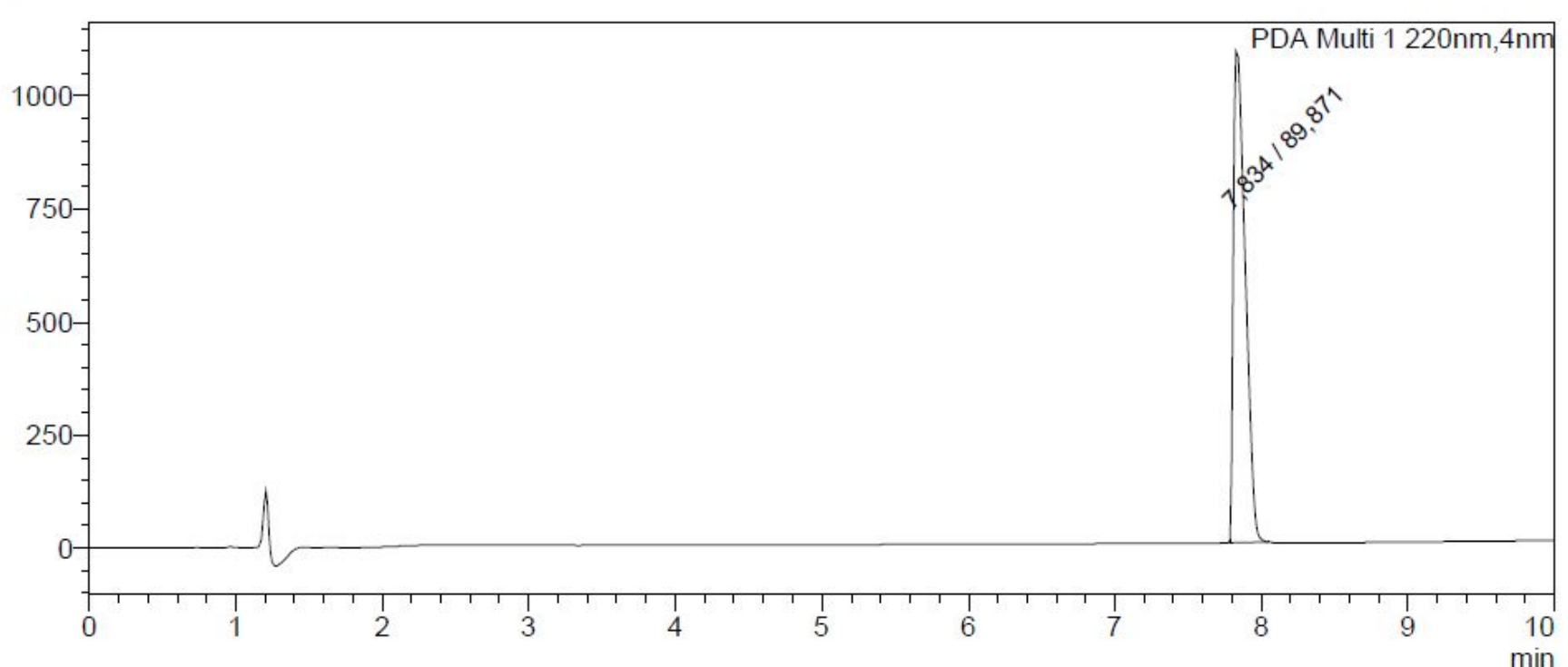

PDA Ch1 220nm

\begin{tabular}{|r|r|r|r|r|}
\hline Peak\# & Ret. Time & \multicolumn{1}{|c|}{ Area\% } & Height & \multicolumn{1}{c|}{ Area } \\
\hline 1 & 7,834 & 89,871 & 1087652 & 5994656 \\
\hline 2 & 18,165 & 10,129 & 5229 & 675597 \\
\hline Total & & 100,000 & 1092881 & 6670253 \\
\hline
\end{tabular}

Fig. S10: Compound 2 analytical HPLC 


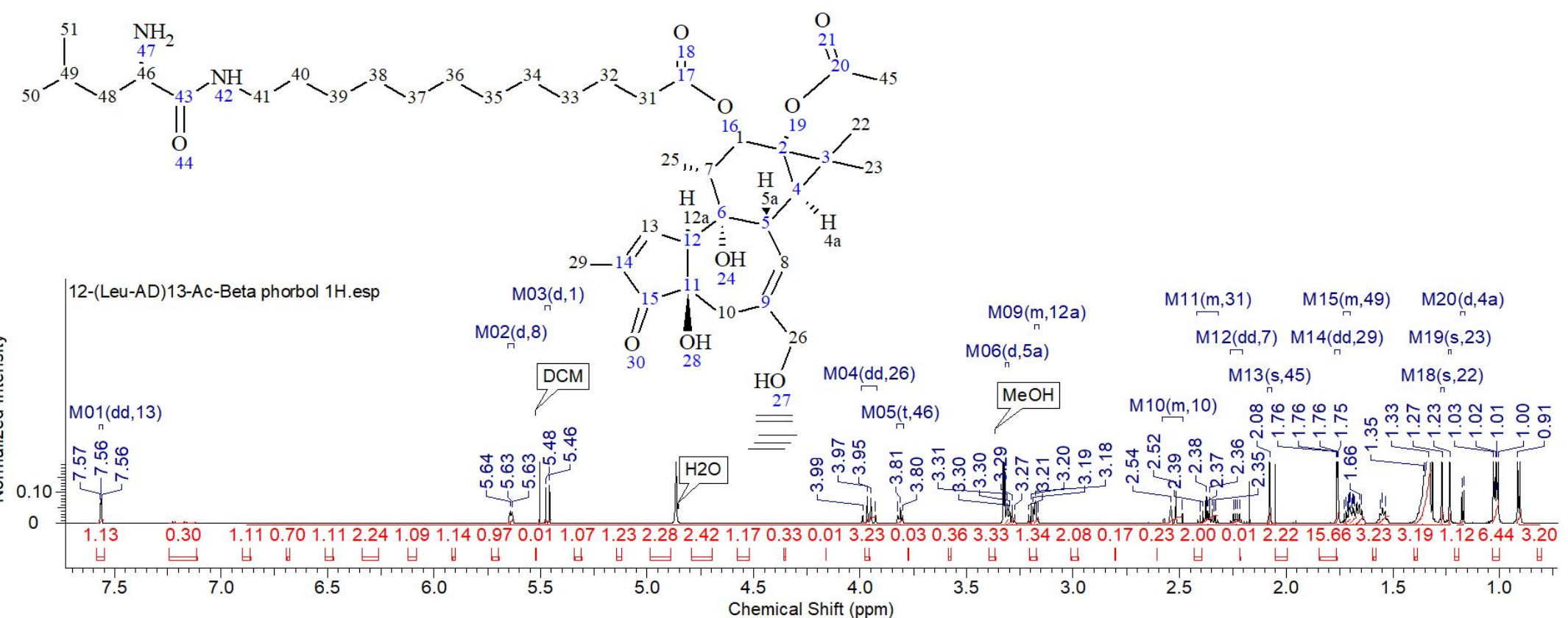

Fig.S11: Compound $2{ }^{1} \mathrm{H}$ NMR 


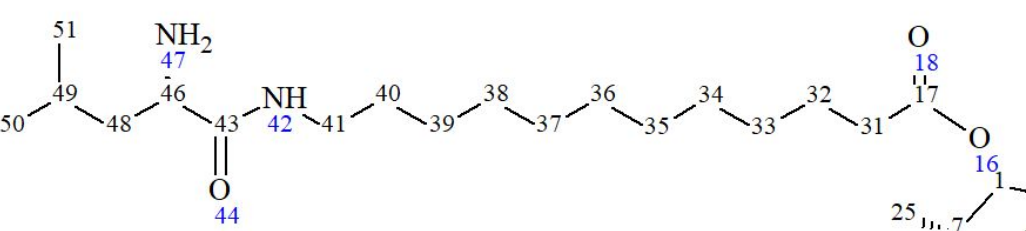

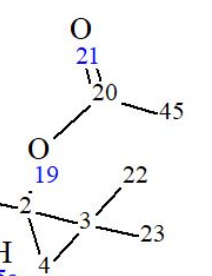

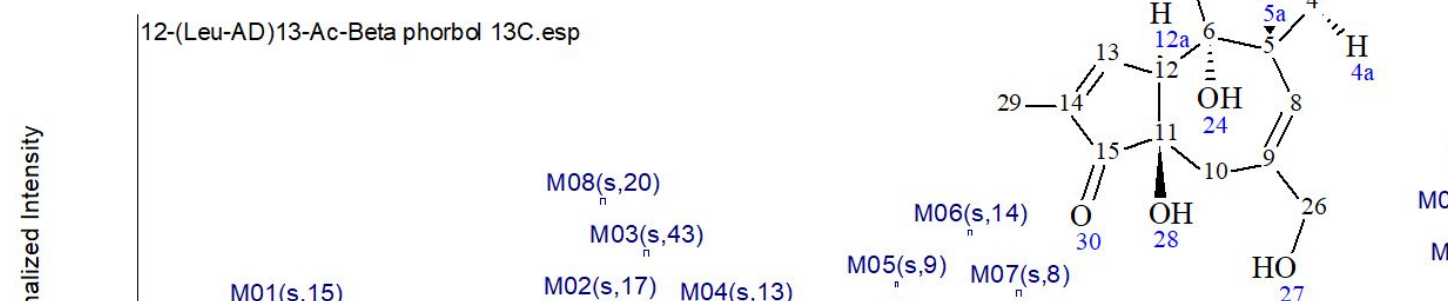

M19(s,5)M29(s,39) M38(s,25)

$$
\text { M13(s,2) M2O(s,10)M31(s,32) }
$$

$\mathrm{M} 11(\mathrm{~s}, 11) \quad \mathrm{M} 14(\mathrm{~s}, 12) \quad \mathrm{M} 22(\mathrm{~s}, 31)^{\mathrm{M} 35(\mathrm{~s}, 50)}$

M09(s,6) M12(s,26) M15(s,46) M21(s,4) M36(s,45)

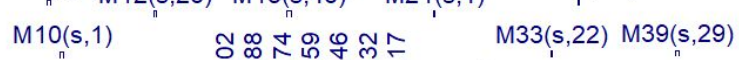

02(s,17) M04(s,13) M05(s,9) M07(s,8)

$\mathrm{HO}_{27}$

贷

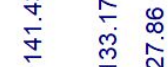

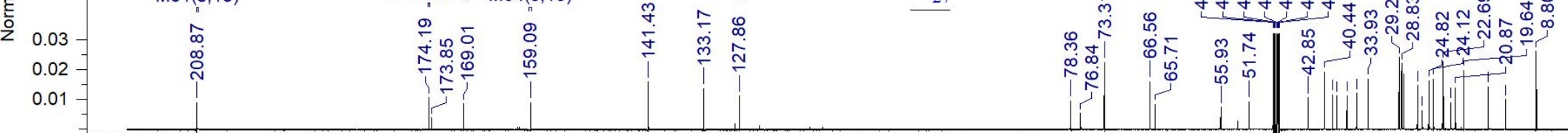

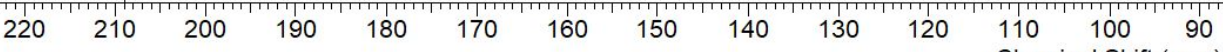

Fig.S12: Compound $2{ }^{13} \mathrm{C}$ NMR 


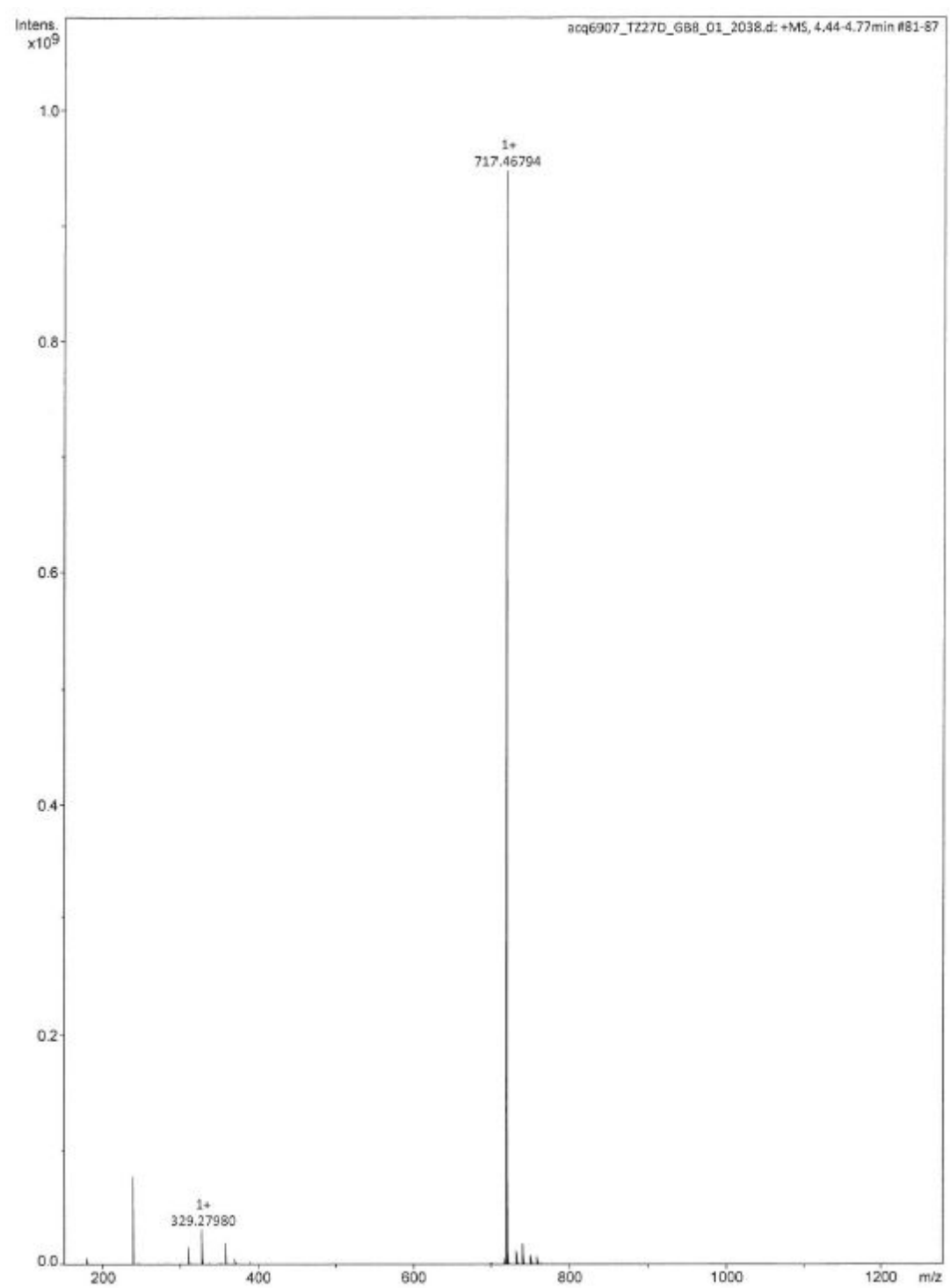

Fig.S13: Compound 2 HRMS 
S2.5.8. 12-O-(Morpholine-4-carbonyl-His-Ser-Ser-Lys-Leu-GIn-Leu-N-aminododecanoyl)-13O-Ac-4ß-phorbol (5)

Synthesis of the peptide His-Ser-Ser-Lys-Leu-GIn-Leu was performed on a Liberty Blue microwave peptide synthesizer starting from preloaded Fmoc-Leu-(Cl-Trt)-resin $(0.9 \mathrm{mmol} / \mathrm{g}$; $110 \mathrm{mg} ; 0.1 \mathrm{mmol})$ swelled in DMF $(5 \mathrm{~mL})$. Calculated amounts of Fmoc protected amino acids in $0.2 \mathrm{M}$ solution (added as volumes corresponding to 5 equivalents): Fmoc-His(Boc)$\mathrm{OH}$ (0.38 g; $6 \mathrm{~mL}$ DMF), Fmoc-Ser(tBu)-OH (0.43 g; $11 \mathrm{~mL}$ DMF), Fmoc-Lys(Boc)-OH (0.29 g; $6 \mathrm{~mL}$ DMF), Fmoc-Leu-OH (0.22 g; $6 \mathrm{~mL}$ DMF), Fmoc-Gln(Trt)-OH (0.37 g; $6 \mathrm{~mL}$ DMF). Conditions for chain elongation: single coupling at $45^{\circ} \mathrm{C}$ during $15 \mathrm{~min}$; Fmoc removal was performed with a $20 \%$ solution of piperidine in DMF at $45^{\circ} \mathrm{C}$ for $30 \mathrm{~s}$ and $180 \mathrm{~s}$.

The protected His-Ser-Ser-Lys-Leu-GIn-Leu-O-(Cl-Trt)-resin was placed in two reaction vessels for swelling. The resin was washed twice with DMF and DCM. A mixture of morpholine-4-carbonyl chloride- $\mathrm{Et}_{3} \mathrm{~N}-\mathrm{NMP}(1: 4: 20 ; 8 \mathrm{~mL})$ were added, and then the mixture was heated to $40{ }^{\circ} \mathrm{C}$ for $2 \mathrm{~h}$. The resin was washed with $\mathrm{DCM}$ and the procedure was repeated for $1 \mathrm{~h}$ with fresh reagents, followed by washing with DMF, MeOH and DCM (each $3 \times 8 \mathrm{~mL}$ for $3 \mathrm{~min}$ ). The product was cleaved from the resin with a $20 \%$ solution of HFIP in $\mathrm{DCM}$, and concentration of the drained cleavage mixture gave the protected peptide as an amorphous solid $(220 \mathrm{mg})$. To a solution of the residue $(134 \mathrm{mg})$ in DCM $(1 \mathrm{~mL})$ and THF (1 $\mathrm{mL}$ ) was added PyBOP (57 mg; $0.11 \mathrm{mmol}$ ) and DIPEA (0.030 mL; $0.29 \mathrm{mmol})$. The mixture was stirred for $20 \mathrm{~min}$, and then 11 (55 mg; $0.091 \mathrm{mmol})$ dissolved in DCM (1 mL) was added. The mixture was stirred under argon for $27 \mathrm{~h}$ at $23^{\circ} \mathrm{C}$. The resulting reaction mixture was concentrated, and the residue was dissolved in DCM $(1.5 \mathrm{~mL})$ and deprotected with TFA ( $1.5 \mathrm{~mL}$; added four drops of $\mathrm{H}_{2} \mathrm{O}$ ) for $1 \mathrm{~h}$ at $23^{\circ} \mathrm{C}$. The cleavage mixture was concentrated, and the residue fractionated by preparative HPLC using the gradient $20 \% \rightarrow 70 \%$ B over 20 min. The purity of the product was determined by analytical UHPLC (> 99\%) by using the gradient $20 \% \rightarrow 100 \%$ B during $10 \mathrm{~min}$ (retention time: $6.2 \mathrm{~min}$ ). Upon concentration the resulting residue was dissolved in 1,4-dioxane- $\mathrm{H}_{2} \mathrm{O}$ and freeze-dried to provide prodrug 5 (14 mg; 10\%) as a white powder. ${ }^{1} \mathrm{H}$ NMR $\left(600 \mathrm{MHz}\right.$, methanol- $\left.d_{4}\right) \delta \mathrm{ppm} 8.70\left(\mathrm{~s}, 1 \mathrm{H}, \mathrm{H}-\varepsilon_{1}\right.$ His), 7.45 (s, $1 \mathrm{H}, \mathrm{C}-3$ ), 7.27 (s, $1 \mathrm{H}, \mathrm{H}-\delta_{2} \mathrm{His}$ ), 5.52 (d, J = $4.4 \mathrm{~Hz}, 1 \mathrm{H}, \mathrm{H}-7$ ), 5.35 (d, J = $10.0 \mathrm{~Hz}, 1 \mathrm{H}, \mathrm{H}-12), 4.48$ (m, $1 \mathrm{H}, \mathrm{\alpha}-\mathrm{H}$ His), 4.39 - 4.34 (m, $2 \mathrm{H}, 2 \mathrm{\alpha}-\mathrm{H}$ Ser), , 4.21 (m, $1 \mathrm{H}$,

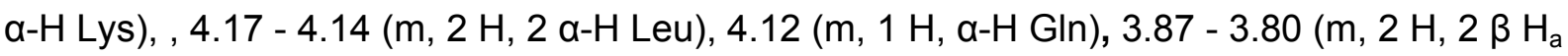
Ser), 3.85 - 3.82 (m, 2H, H-20), 3.74 - $3.69\left(\mathrm{~m}, 2 \mathrm{H}, 2 \beta \mathrm{H}_{\mathrm{b}}\right.$ Ser), 3.57 - 3.51 (t, J = $4.4 \mathrm{~Hz}, 4$ $\mathrm{H}, \mathrm{H}-2$ and $\mathrm{H}-6$ morpholine), $3.31-3.27$ (t, $J=5.1 \mathrm{~Hz}, 4 \mathrm{H}, \mathrm{H}-3$ and $\mathrm{H}-5$ morpholine), 3.20 (m, $\left.1 \mathrm{H}, \beta-\mathrm{H}_{\mathrm{a}} \mathrm{His}\right), 3.19(\mathrm{~m}, 1 \mathrm{H}, \mathrm{H}-8), 3.11$ ( $\left.\mathrm{m}, 1 \mathrm{H}, \beta-\mathrm{H}_{\mathrm{b}} \mathrm{His}\right), 3.06$ (m, $2 \mathrm{H}, \mathrm{H}-12$ 12AD), 3.03 (m, $1 \mathrm{H}, \mathrm{H}-10), 2.83$ (t, J = 7.5 Hz, $2 \mathrm{H}, \varepsilon-\mathrm{H}$ Lys), 2.43 (d, J = $\left.19.1 \mathrm{~Hz}, 1 \mathrm{H}, \mathrm{H}_{\mathrm{a}}-5\right), 2.40$ (d, $J=19.1 \mathrm{~Hz}, 1 \mathrm{H}, \mathrm{H}_{\mathrm{b}}-5$ ), $2.30-2.25$ (m, $2 \mathrm{H}, \mathrm{y}-\mathrm{H}$ Gln), 2.25-2.19 (m, $2 \mathrm{H}, \mathrm{H}-2$ 12AD), 2.12 
(m, $1 \mathrm{H}, \mathrm{H}-11$ ), 2.05 - 1.97 (m, $2 \mathrm{H}, \beta-\mathrm{H} \mathrm{Gln}), 1.96$ (s, $3 \mathrm{H}, \mathrm{H}-2 \mathrm{Ac}), 1.79$ (m, $1 \mathrm{H}, \beta-\mathrm{H}_{\mathrm{a}}$ Lys), $1.69\left(\mathrm{~m}, 1 \mathrm{H}, \beta-\mathrm{H}_{\mathrm{b}}\right.$ Lys), 1.64 (dd, $\left.J=2.8,1.3 \mathrm{~Hz}, 3 \mathrm{H}, \mathrm{H}-19\right), 1.62$ - 1.59 (m, $2 \mathrm{H}, 2$ y-H Leu), 1.58 (m, 2 H, ס-H Lys), 1.57 - 1.52 (m, 4 H, 2 ß-H Leu), 1.50 (m, 2 H, H-3 12AD), 1.42 (m, 2 $\mathrm{H}, \mathrm{H}-11$ 12AD), 1.40 (m, $2 \mathrm{H}, \mathrm{y}-\mathrm{H}$ Lys), 1.29 - 1.20 (m, $14 \mathrm{H}, \mathrm{H}-10 \rightarrow \mathrm{H}-4$ 12AD), 1.15 (s, 3 $\mathrm{H}, \mathrm{H}-16), 1.12$ (s, 3H, H-17), 1.06 (d, J = 5.4 Hz, $1 \mathrm{H}, \mathrm{H}-14) 0.85$ (m, $6 \mathrm{H}, 2$ ठ- $\mathrm{H}_{\mathrm{a}}$ Leu), $0.82-$ $0.80\left(\mathrm{~m}, 6 \mathrm{H}, 2 \delta-\mathrm{H}_{\mathrm{b}} \mathrm{Leu}\right), 0.79(\mathrm{~d}, J=6.6 \mathrm{~Hz}, 3 \mathrm{H}, \mathrm{H}-18) \cdot{ }^{13} \mathrm{C} \mathrm{NMR}\left(150 \mathrm{MHz}\right.$, methanol- $\left.d_{4}\right) \delta$ ppm 208.94 (1 C, C-3), 176.41 (1 C, C-5 Gln), 174.47 (1 C, C'-1), 174.22 (1 C, C-1 AC), 173.94 (1 C, C-1 Leu $), 173.90$ (1 C, C-1 Leu $), 173.48$ (1 C, C-1 Lys), 173.15 (1 C, C-1 His), 172.39 (1 C, C-1 Gln), 172.21 (1 C, C-1 Ser 2 ), 172.05 (1 C, C-1 Ser 3 ), 159.10 (1 C, C-1), 157.97 (1 C, morpholine carbonyl), 141.45 (1 C, C-6), 133.60 (1 C, C- $\varepsilon_{1} \mathrm{His}$ ), 133.19 (1 C, C2), 129.94 (1 C, H-ү His), 127.89 (1 C, C-7), 117.12 (1 C, C- ${ }_{2}$ His), 78.37 (1 C, C-9), 76.84 (1 C, C-12), 73.32 (1 C, C-4), 66.57 (1 C, C-20), 66.12 (2 C, C-2 and C-6 morpholine), 66.72 (1 C, C-13), 61.46 (1 C, C-3 Ser $)_{3}, 61.32$ (1 C, C-3 Ser 2 ), 55.94 (1 C, C-10) 55.63 (2 C, C-2 Ser), 54.35 (1 C, C-2 Gln), 54.14 (1 C, C-2 His), 53.58 (2 C, C-2 Leu), 52.12 (1 C, C-2 Lys), 43.93 (2 C, C-3 and C-5 morpholine), 42.85 (1 C, C-11), 39.61 (2 C, C-3 Leu), 39.11 (2 C, $C^{\prime}-12$ and C-6 Lys), 38.60 (1 C, C-8), 37.07 (1 C, C-5), 35.63 (1 C, C-14), 33.95 (1 C, C'-2), 31.42 (1 C, C-4 Gln), 30.10 (1 C, C-3 Lys), 29.25-28.66 (7 C, C'-4 - C'-9 + C'-11), 27.00 (1 C, C-3 Gln), 26.73 (1 C, C-3 His), 26.56 (1 C, C-5 Lys), 26.50 (1 C, C'-10), 25.76 (1 C, C15), 24.84 (1 C, C'-3), 24.48 (2 C, 2 C-4 Leu), 24.60 (1 C, C-5 Leu $), 24.51$ (1 C, C-5 Leu $)$ ), 22.81 (1 C, C-17), 22.71 (1 C, C-4 Lys), $22.23+22.00$ (2 C, 2 C-6 Leu), $20.47+20.30$ (2 C, 2 C-6 Leu), 19.67 (1 C, C-2 Ac), 15.98 (1 C, C-16), 13.42 (1 C, C-18), 8.81 (1 C, C-19). HRMS-ESI: $\quad\left[\mathrm{C}_{74} \mathrm{H}_{119} \mathrm{~N}_{13} \mathrm{O}_{20}{ }^{+} \quad 2 \mathrm{H}\right]^{2+} \quad \mathrm{m} / \mathrm{z}:$ 755.9425. Found 755.9406 . 
Sample ID

Data Filename : TZ67againmainprod.Icd

Method Filename : 20 100B_10min_purified $2014 . \mathrm{lcm}$

Batch Filename : 2017_12_15_1.Icb

Vial \#

Injection Volume : :

Date Acquired : 12/20/2017

\section{Complete Chromatogram}

mAU

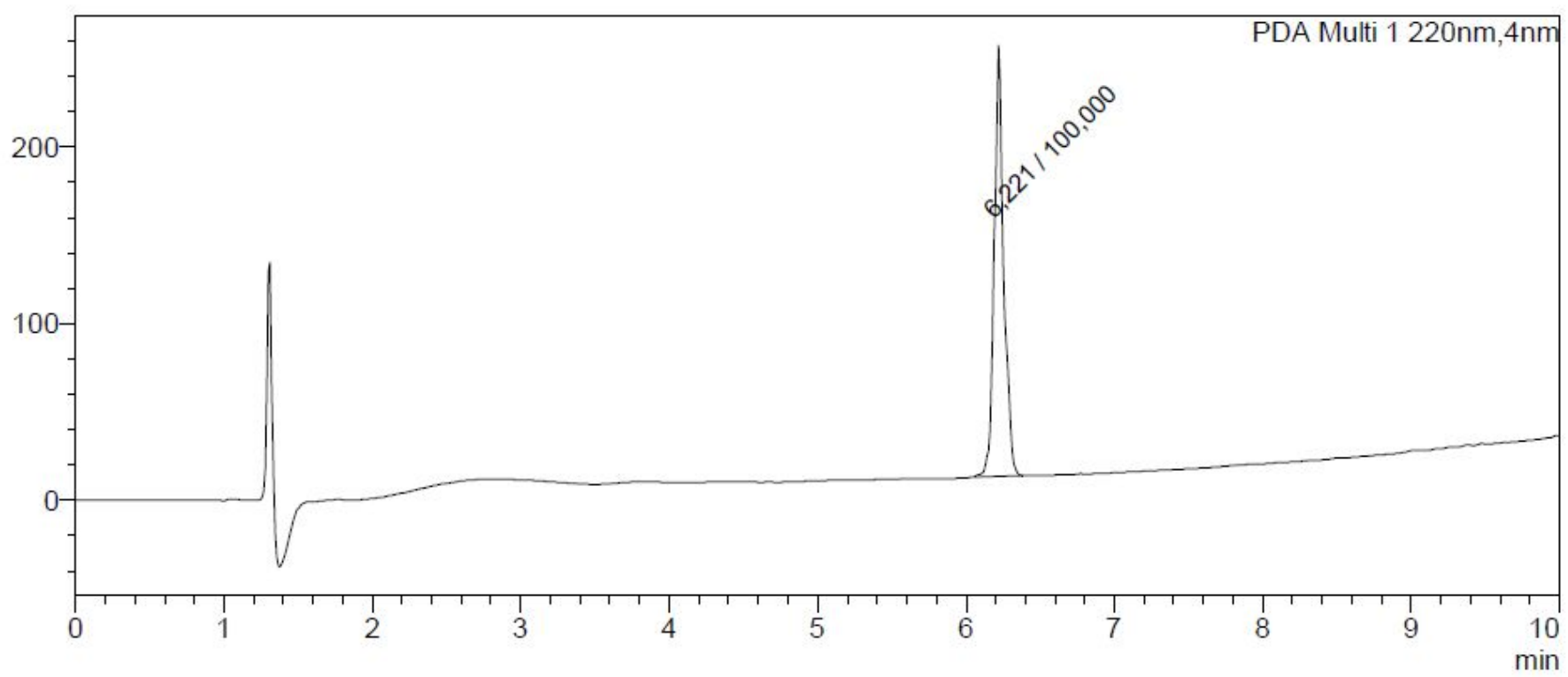

PDA Ch1 220nm

\begin{tabular}{|c|c|c|c|c|}
\hline Peak\# & t. Time & Area \% & Height & Area \\
\hline 1 & 6,221 & 100,000 & 243843 & 1097257 \\
\hline $\mathrm{T}$ & & 100,000 & 243843 & 1097257 \\
\hline
\end{tabular}


Fig.S14: Compound 5 HPLC

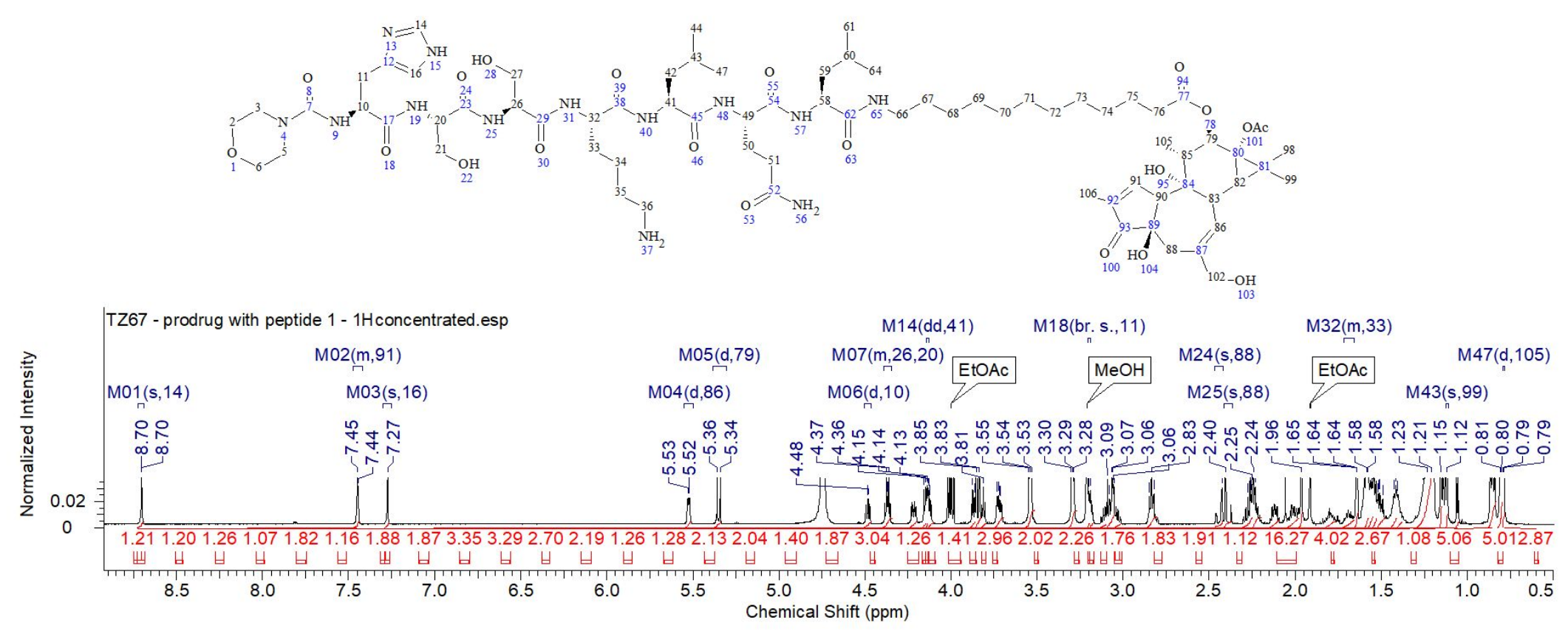

Fig.S15: Compound $5^{1} \mathrm{H}$ NMR 


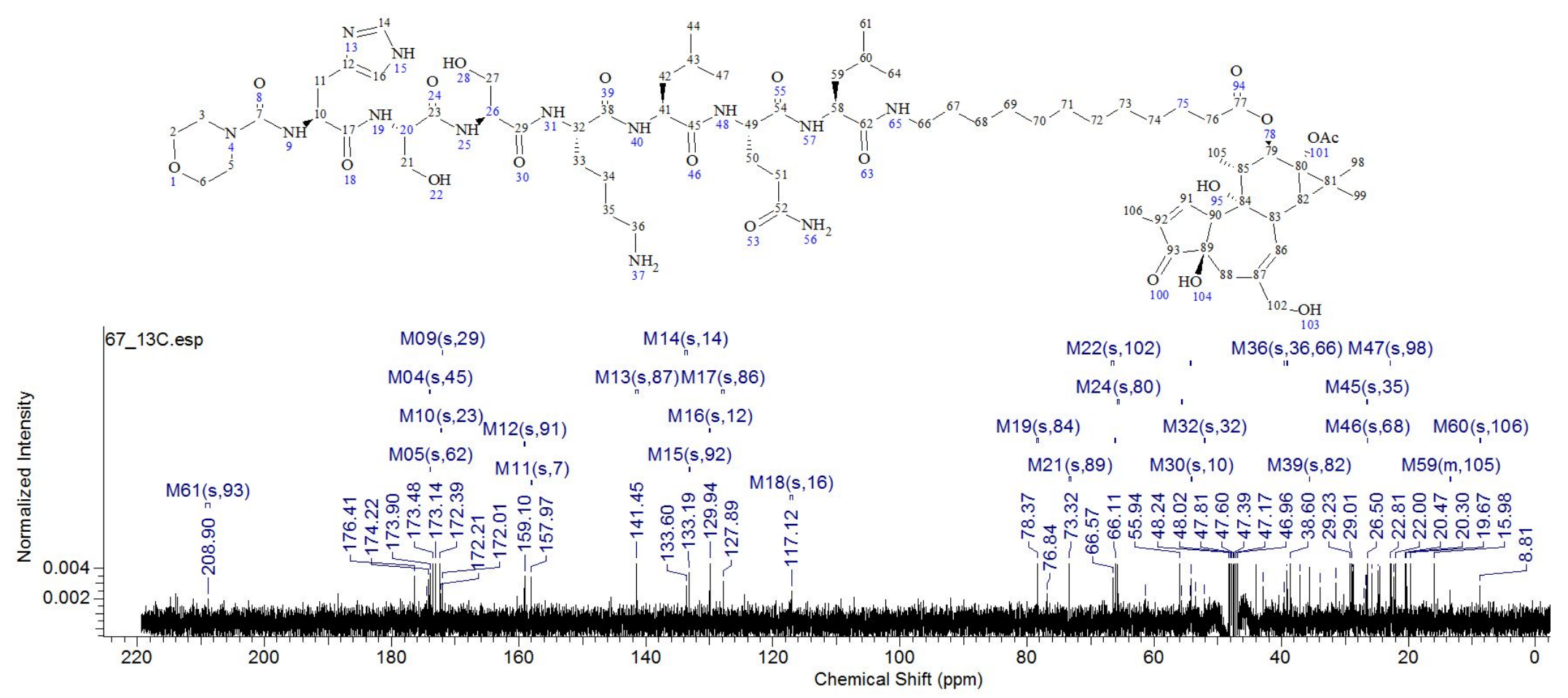

Fig.S16: Compound $5{ }^{13} \mathrm{C}$ NMR 


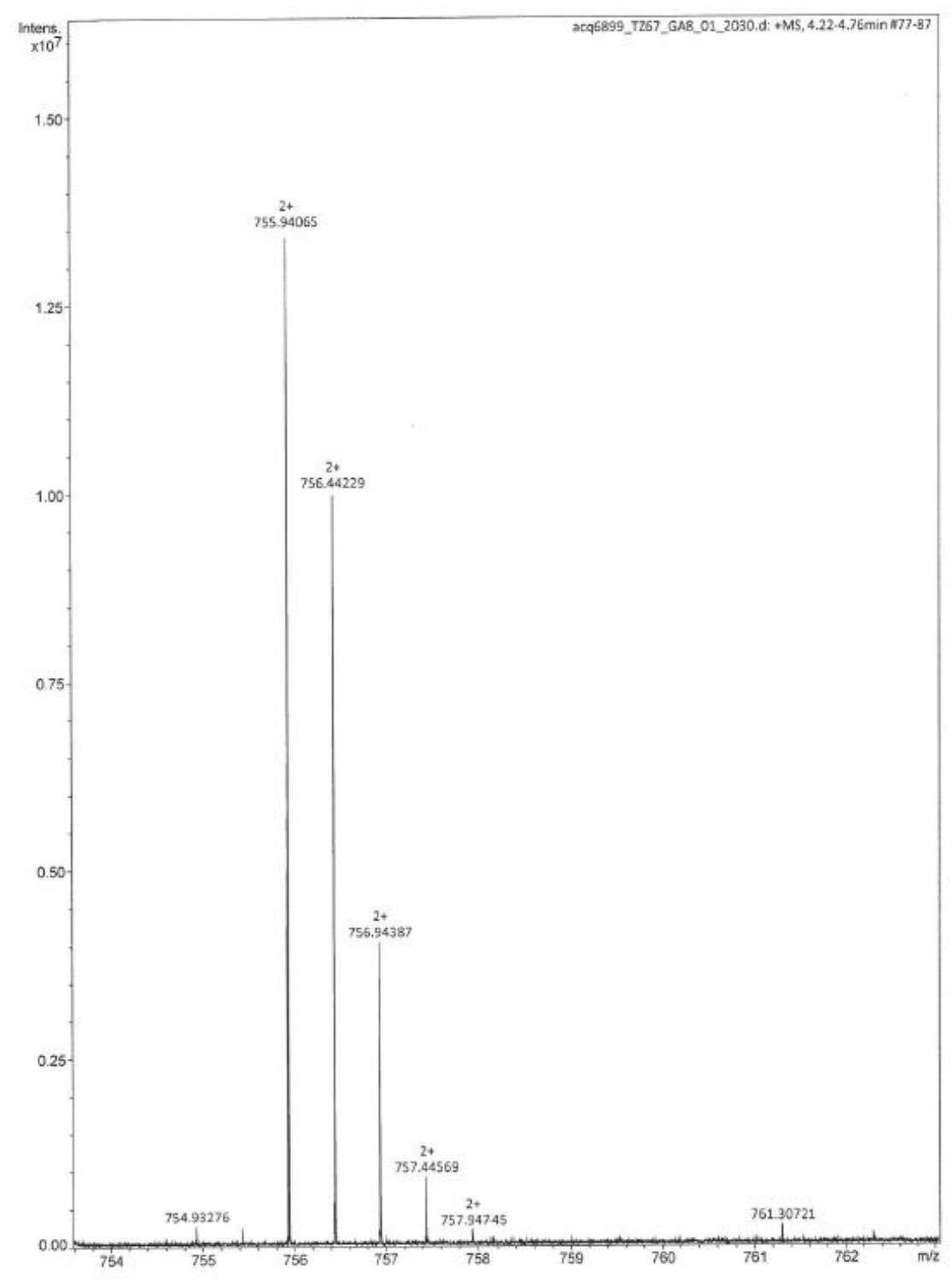

Fig.S17: Compound 5 HRMS 
S2.5.9. 12-O-(Ac-Gly-Lys-Ala-Phe-Arg-Arg-Leu-N-aminododecanoyl)-13-O-Ac-4ß-phorbol (4) First, the C-terminal residue was loaded onto a $2-\mathrm{CTC}$ resin $(1.6 \mathrm{mmol} / \mathrm{g} ; 1.0 \mathrm{~g})$ in DCM (4 $\mathrm{mL}$ ) by addition of Fmoc-Leu-OH (564 mg; $1.60 \mathrm{mmol}$ ) dissolved in DCM (4 mL) with DIPEA $(2.7 \mathrm{~mL} ; 16 \mathrm{mmol})$ added. The mixture was shaken for $3.5 \mathrm{~h}$ at $23{ }^{\circ} \mathrm{C}$, and the resin was washed with DCM, free linker groups were capped by treatment with DIPEA-MeOH-DCM 5:15:80 ( $8 \mathrm{~mL} ; 2 \times 5 \mathrm{~min}$ ), and subsequently the resin was washed with $\mathrm{DMF}, \mathrm{MeOH}$ and DCM (each with $3 \times 10 \mathrm{~mL}$ for $3 \mathrm{~min}$ ). Test cleavage with $20 \%$ HFIP-DCM (2 mL) of a small amount of dry loaded resin was followed by thorough evaporation and weighing the amount of cleaved Fmoc-Leu-OH showed a loading of approx. $0.9 \mathrm{mmol} / \mathrm{g}$.

The peptide sequence Ac-Gly-Lys-Ala-Phe-Arg-Arg-Leu-OH was assembled by using a Liberty Blue microwave peptide synthesizer starting from Fmoc-Leu-O-(2-Cl-Trt)-resin (0.9 $\mathrm{mmol} / \mathrm{g} ; 110 \mathrm{mg} ; 0.1 \mathrm{mmol})$ swelled in DMF $(5 \mathrm{~mL})$ as a starting material. Calculated amounts of Fmoc protected amino acids in $0.2 \mathrm{M}$ solution (added as volumes corresponding to 5 equivalents): Fmoc-Gly-OH (0.33 g; $11 \mathrm{~mL} \mathrm{DMF),} \mathrm{Fmoc-Lys(Boc)-OH} \mathrm{(0.52} \mathrm{g;} 11 \mathrm{~mL}$ DMF), Fmoc-Ala-OH (0.35 g; $11 \mathrm{~mL}$ DMF), Fmoc-Phe-OH (0.43 g; $11 \mathrm{~mL}$ DMF), Fmoc$\operatorname{Arg}(\mathrm{Pbf})-\mathrm{OH}\left(2.08 \mathrm{~g} ; 32 \mathrm{~mL} \mathrm{DMF}\right.$ ). Conditions for chain elongation: double coupling at $45^{\circ} \mathrm{C}$ during $15 \mathrm{~min}$, while triple coupling at $45^{\circ} \mathrm{C}$ during $15 \mathrm{~min}$ was needed for Arg; Fmoc removal was performed with a $20 \%$ solution of piperidine in DMF at $45^{\circ} \mathrm{C}$ for $30 \mathrm{~s}$ and $180 \mathrm{~s}$. The obtained side-chain protected Gly-Lys-Ala-Phe-Arg-Arg-Leu-O-(Cl-Trt)-resin was washed twice with both DMF and DCM followed by acetylation with $\mathrm{Ac}_{2} \mathrm{O}-\mathrm{DIPEA}-\mathrm{NMP}$ $(1: 2: 3,6 \mathrm{~mL} ; 2 \times 5 \mathrm{~min})$. The resin-bound protected peptide was washed with DMF, MeOH and DCM (each $3 \times 8 \mathrm{~mL}$ for $3 \mathrm{~min}$ ), and cleaved from the resin with a $20 \%$ solution of HFIP in DCM. The drained solution was concentrated to give the protected peptide as an amorphous solid. To a solution of the residue (158 $\mathrm{mg} ; 0.11 \mathrm{mmol})$ in DCM $(1 \mathrm{~mL})$ and THF $(1.5 \mathrm{~mL}$ ) was added PyBOP (66 mg; $0.13 \mathrm{mmol}$ ) and DIPEA (27 mg; $0.20 \mathrm{mmol})$ in DCM (0.5 $\mathrm{mL}$ ). The mixture was stirred for $20 \mathrm{~min}$ to pre-activate the carboxylic acid, and then a solution of compound 8 (64 $\mathrm{mg} ; 0.10 \mathrm{mmol})$ in DCM $(1.5 \mathrm{~mL})$ was added. The mixture was stirred under argon for $14 \mathrm{~h}$ at $23{ }^{\circ} \mathrm{C}$, and the resulting reaction mixture was concentrated in vacuo. The obtained residue was deprotected with TFA ( $3 \mathrm{~mL}$ added four drops of $\mathrm{H}_{2} \mathrm{O}$ ) for $18 \mathrm{~h}$ at $23{ }^{\circ} \mathrm{C}$. After this deprotection a by-product with one Pbf-protected Arg residue was still present as judged by MALDI. After a second deprotection with TFA ( $3 \mathrm{~mL}$ added four drops of water) for $3 \mathrm{~h}$. the reaction mixture was concentrated, and the residue subjected to purification by preparative HPLC using the gradient $20 \% \rightarrow 100 \%$ B over 20 min. The purity of the product was estimated by analytical UHPLC to be $>99 \%$ by using the gradient $20 \% \rightarrow$ $100 \%$ B during $10 \mathrm{~min}$ (retention time: $5.3 \mathrm{~min}$ ). Upon concentration the product was dissolved in 1,4-dioxane- $\mathrm{H}_{2} \mathrm{O}$ and freeze-dried to provide prodrug 4 (18 $\mathrm{mg} ; 12 \%$ ) as a white 
solid. ${ }^{1} \mathrm{H}$ NMR (600 MHz, methanol- $\left.d_{4}\right) \delta$ ppm 7.44 (s, $\left.1 \mathrm{H}, \mathrm{C}-3\right), 7.21-7.07$ (s, $5 \mathrm{H}, \mathrm{H}-\mathrm{Phe}$ aromatics), $5.52(\mathrm{~d}, J=4.4 \mathrm{~Hz}, 1 \mathrm{H}, \mathrm{H}-7), 5.35(\mathrm{~d}, J=10.0 \mathrm{~Hz}, 1 \mathrm{H}, \mathrm{H}-12), 4.34(\mathrm{~m}, 1 \mathrm{H}, \alpha-\mathrm{H}$ Phe), 4.23 (m, $1 \mathrm{H}, \alpha-\mathrm{H}$ Lys), , 4.18 (m, $1 \mathrm{H}, \alpha-\mathrm{H} \mathrm{Arg})$, , 4.13 (m, $1 \mathrm{H}, \alpha-\mathrm{H} \mathrm{Arg}), 4.08$ (m, $1 \mathrm{H}$, $\alpha-H$ Leu), 4.04 (m, 1 H, a-H Ala), $3.89-3.81$ (m, 2H, H-20), 3.84 - 3.71 (m, 2 H, $\alpha-H$ Gly), $3.18(\mathrm{~m}, 1 \mathrm{H}, \mathrm{H}-8), 3.14-3.06(\mathrm{~m}, 6 \mathrm{H}, 2 \mathrm{\delta}-\mathrm{H}$ Arg and H-12 12AD), $3.05(\mathrm{~m}, 1 \mathrm{H}, \mathrm{H}-10), 3.03$ - 2.91 (m, $1 \mathrm{H}, \beta-\mathrm{H}$ Phe) 2.84 (t, J = 7.5 Hz, $2 \mathrm{H}, \varepsilon-\mathrm{H}$ Lys), 2.45 (d, J = $19.1 \mathrm{~Hz}, 1 \mathrm{H}, \mathrm{H}_{\mathrm{a}}-5$ ), 2.41 (d, J = $19.1 \mathrm{~Hz}, 1 \mathrm{H}, \mathrm{H}_{\mathrm{b}}-5$ ), 2.30-2.20 (m, $2 \mathrm{H}, \mathrm{H}-2$ 12AD), 2.12 (m, $1 \mathrm{H}, \mathrm{H}-11$ ), 1.96 (s, 3 $\mathrm{H}, \mathrm{H}-2$ phorbol Ac), 1.88 (s, $3 \mathrm{H}, \mathrm{H}-2$ capped Ac), $1.84-1.72$ (m, $4 \mathrm{H}, \beta-\mathrm{H}$ Arg), 1.71 - 1.66 (m, 2H, $\beta-H$ Lys), 1.64 (dd, $J=2.8,1.3 \mathrm{~Hz}, 3 \mathrm{H}, \mathrm{H}-19), 1.61(\mathrm{~m}, 1 \mathrm{H}, \mathrm{y}-\mathrm{H}$ Leu), $1.60-1.57$ (m, $4 \mathrm{H}, \mathrm{y}-\mathrm{H}$ Arg), 1.56 (m, $2 \mathrm{H}, \mathrm{H}-11$ 12AD), 1.54 (m, $2 \mathrm{H}, \beta-\mathrm{H}$ Leu), $1.51-1.45$ (m, $2 \mathrm{H}, \delta-$ H Lys), 1.45 - 1.40 (m, 2 H, H-3 12AD), 1.39 - 1.33 (m, 2 H, y-H Lys), $1.29-1.20$ (m, 14 H, $\mathrm{H}-10 \rightarrow \mathrm{H}-4$ 12AD), 1.16 (s, $3 \mathrm{H}, \mathrm{H}-16), 1.11$ (s, 3H, H-17), 1.06 (d, J = 5.4 Hz, $1 \mathrm{H}, \mathrm{H}-14$ ),

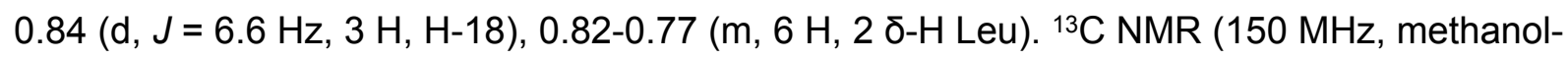
$\left.d_{4}\right) \delta$ ppm 208.90 (1 C, C-3), 174.55 (1 C, C-1 Leu), 174.23 (1 C, C'-1), 173.89 (1 C, C-1 phorbol Ac), 173.64 (1 C, C-1 Ala), 173.19 (2 C, C-1 Arg), 172.98 (1 C, C-1 Phe), 172.87 (1 C, C-1 capped Ac), 172.40 (1 C, C-1 Lys), 171.66 (1 C, C-1 Gly), 159.11 (1 C, C-1), 157.27 + 157.25 (2 C, C-6 Arg), 141.44 (1 C, C-6), 136.90 (1 C, C-4 Phe), 133.19 (1 C, C-2), 128.82 (2 C, C-5 + C-9 Phe), 128.19 (2 C, C-6 + C-8 Phe), 127.89 (1 C, C-7), 126.53 (1 C, C-7 Phe), 78.37 (1 C, C-9), 76.85 (1 C, C-12), 73.32 (1 C, C-4), 66.57 (1 C, C-20), 65.73 (1 C, C-13), 55.94 (1 C, C-10), 55.9 (1 C, C-2 Phe), 54.75 (1 C, C-2 Leu), 53.79 (1 C, C-2 Arg), 53.41 ( C, C-2 Arg), 52.15 (1 C, C-2 Lys), 50.62 (1 C, C-2 Ala), 42.93 (1 C, C-2 Gly), 42.85 (1 C, C-11), 40.68 (1 C, C-3 Leu), 40.55 (2 C, C-5 Arg), 39.07 (2 C, C-12 12AD and C-6 Lys), 38.60 (1 C, C-8), 37.07 (1 C, C-5), 36.53 (1 C, C-Phe), 35.63 (1 C, C-14), 33.95 (1 C, C'-2), 30.33 (1 C, C-3 Lys), 29.29-28.66 (7 C, C'-4 - C'-9 + C'-11), 27.97 (2 C, C-3 Arg), 26.75 (2 C, C-4 Arg), 26.51 (1 C, C'-10), 25.79 (1 C, C-15), 24.97 (1 C, C-5 Lys), 24.84 (1 C, C-3 12AD), 24.48 (2 C, 2 C-4 Leu), 22.82 (1 C, C-17), 22.53 (1 C, C-4 Lys), $22.16+22.40$ (2 C, 2 C-6 Leu), 21.13 (1 C, C-2 capped Ac), 19.67 (1 C, C-2 phorbol Ac), 15.98 (1 C, C-16), 13.43 (1 C, C-18), 8.81 (1 C, C-19). HRMS-ESI $\left.\mathrm{C}_{74} \mathrm{H}_{119} \mathrm{~N}_{15} \mathrm{O}_{16}+2 \mathrm{H}\right]^{2+} \mathrm{m} / \mathrm{z}$ : 737.9550 . Found 737.9546. 
Sample ID

Data Filename :TZ68-4-1lcd.Icd

Method Filename :20_100B_10min_purified2014.lcm

Batch Filename : 2017_09_07_2.Icb

Vial \#

$: 1-20$

$\begin{array}{ll}\text { Injection Volume } & : 10 \mathrm{uL} \\ \text { Date Acquired } & : 9 / 10 / 2017\end{array}$

\section{Complete Chromatogram}

mAU

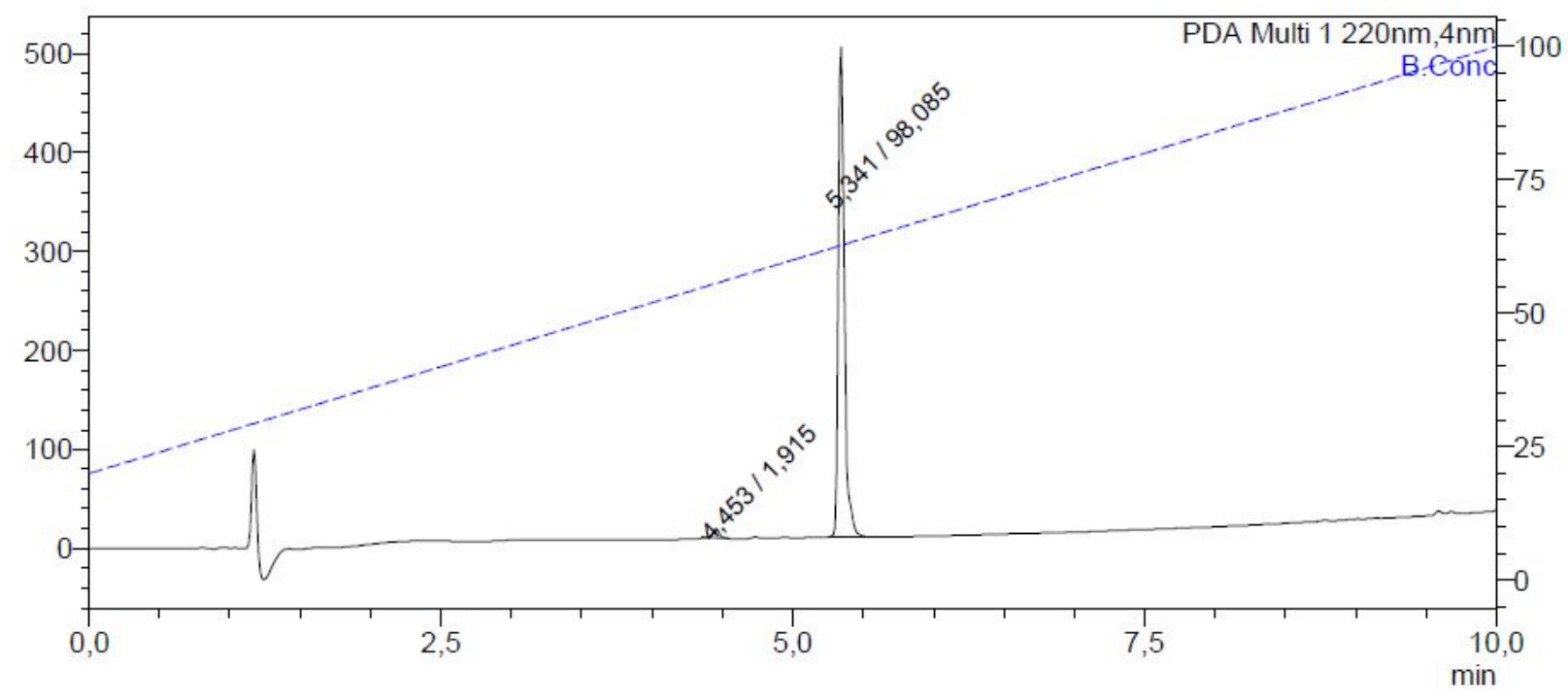

PDA Ch1 220nm

\begin{tabular}{|r|r|r|r|r|}
\hline Peak\# & Ret. Time & \multicolumn{1}{c|}{ Area $\%$} & Height & \multicolumn{1}{c|}{ Area } \\
\hline 1 & 4,453 & 1,915 & 8948 & 28726 \\
\hline 2 & 5,341 & 98,085 & 495231 & 1471601 \\
\hline Total & & 100,000 & 504179 & 1500327 \\
\hline
\end{tabular}

Fig.S18: Compound 4 HPLC 


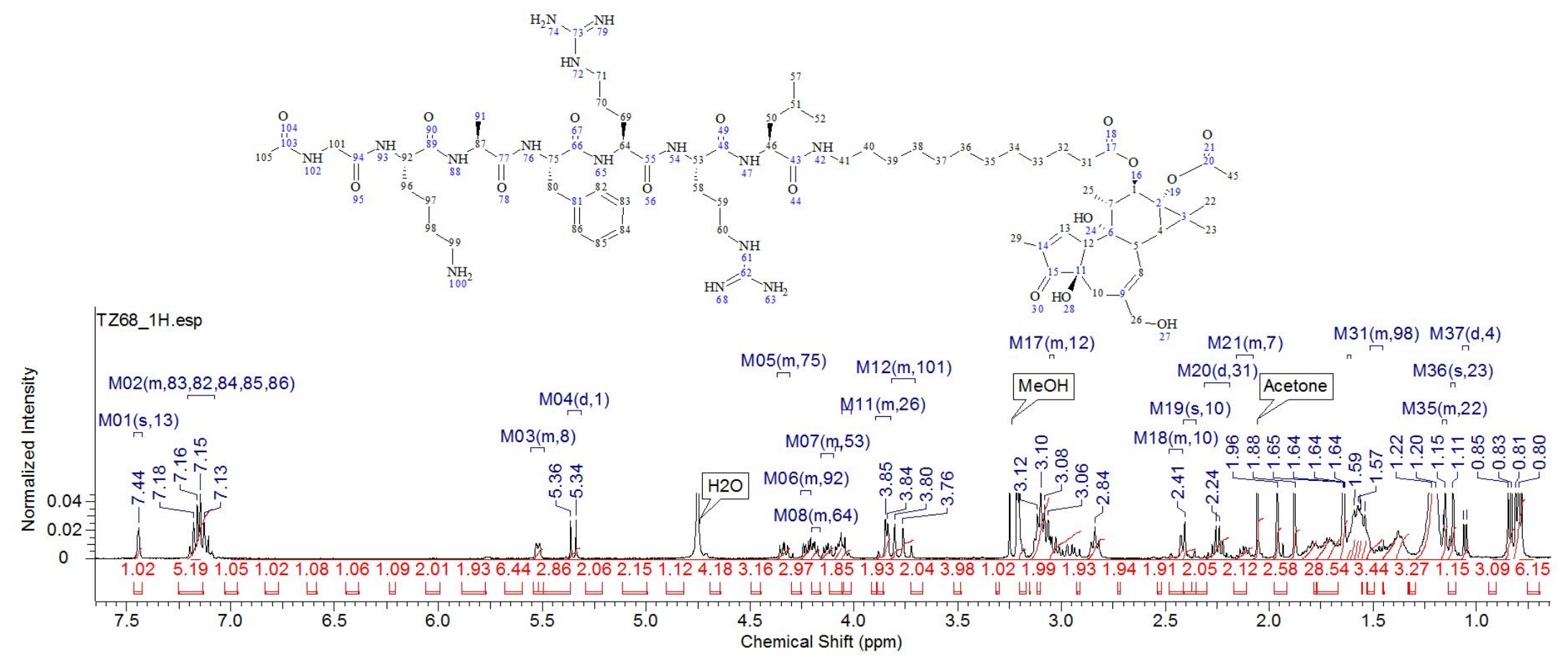

Fig.S19: Compound $4^{1} \mathrm{H}$ NMR 


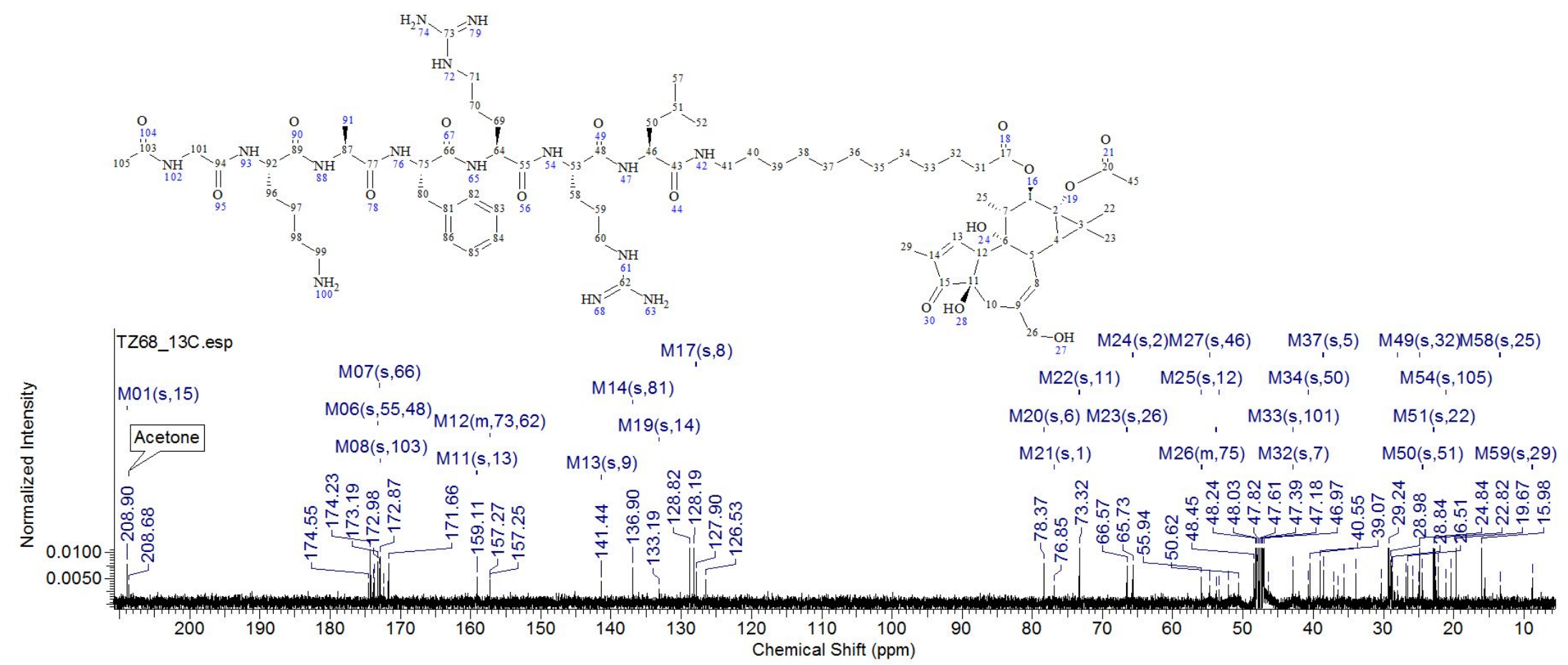

Fig.S20: Compound $4{ }^{13} \mathrm{C}$ NMR 


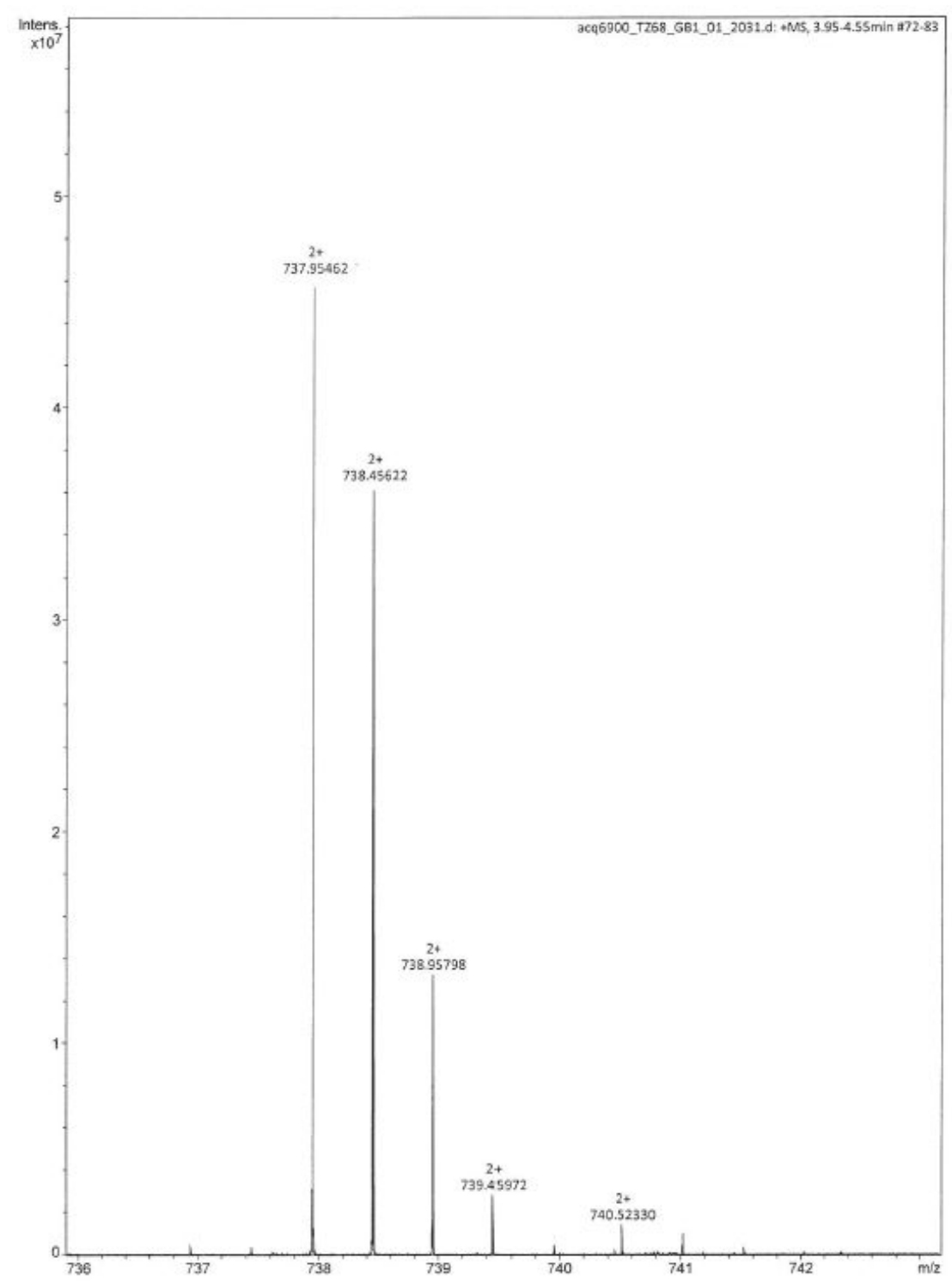

Fig.S21: Compound 4 HRMS 


\section{S2.5.10. 12-O-(( $\gamma$-Glu- $\left.)_{4}-\beta-A s p-N-A m i n o d o d e c a n o y l\right)-13-O-A c-4 \beta-p h o r b o l ~(6)$}

2-CTC resin (1.6 mmol/g; $3.125 \mathrm{~g} ; 5 \mathrm{mmol})$ was swelled in DCM $(8 \mathrm{~mL})$ in a glass filter vessel $(300 \mathrm{~mL})$ for manual SPPS (Peptides International, Louisville, USA). After draining a solution of Fmoc-Glu-OtBu (425 mg; $1.0 \mathrm{mmol}$ ) and DIPEA (2.1 mL; $12 \mathrm{mmol})$ in DCM (15 $\mathrm{mL}$ ) was added to the resin and the mixture was shaken for $3 \mathrm{~h}$ at $23{ }^{\circ} \mathrm{C}$. The resin was drained, washed with DCM, capped with DIPEA-MeOH-DCM 5:15:80 (8 mL; 2 × $5 \mathrm{~min}$ ), and washed with DMF, MeOH and DCM (each 3 times for $3 \mathrm{~min}$ ). The reaction mixture was transferred to glass flask, concentrated in vacuo and residual solvent in the resin was removed on a freeze-dryer. Test cleavage of a dry sample of the loaded resin showed a loading of ca. $0.3 \mathrm{mmol} / \mathrm{g}$.

A large syringe (with a polypropylene filter bottom) was used as reaction vessel for assembly of the peptide on the resin preloaded with Fmoc-Glu-OtBu $(0.30 \mathrm{mmol} / \mathrm{g} ; 1.50 \mathrm{~g})$. Three sequential coupling cycles with addition of a solution of Fmoc-Glu-OtBu (390 mg; 0.95 mmol) pre-activated (10 min) with PyBOP (711 mg; $1.37 \mathrm{mmol}$ ) and DIPEA (0.475 mL; $2.72 \mathrm{mmol}$ ) in DMF (3 mL). Each coupling was followed by Fmoc removal with a $20 \%$ solution of piperidine in DMF ( $8 \mathrm{~mL} ; 2 \times 20 \mathrm{~min}$ ), washing of the resin with DMF, MeOH and DCM (each 3 times for $3 \mathrm{~min})$, addition of DMF (3 $\mathrm{mL})$ and DCM $(2 \mathrm{~mL})$. Each coupling was performed under shaking for $5 \mathrm{~h}$ at $23^{\circ} \mathrm{C}$, and then the resin was washed with DMF, MeOH and DCM (each 3 times for $3 \mathrm{~min}$ ). Boc-Asp(All)-OH $(0.350 \mathrm{~g} ; 1.28 \mathrm{mmol}$ ) was coupled by using the same conditions. On-resin allyl deprotection was performed by adding DCM ( $5 \mathrm{~mL})$ followed by a solution of $\mathrm{Me}_{2} \mathrm{~N} \cdot \mathrm{BH}_{3}$ in $\mathrm{DCM}(2 \mathrm{~mL})$ and a $0.02 \mathrm{M}$ solution of $\mathrm{Pd}\left(\mathrm{PPh}_{3}\right)_{4}(185 \mathrm{mg})$ in $\mathrm{DCM}(8 \mathrm{~mL})$. The mixture was shaken for $6 \mathrm{~h}$ under argon at $23^{\circ} \mathrm{C}$, after which the resin was washed with DMF, MeOH and DCM (each 3 times for 3 min).

DCM $(4 \mathrm{~mL})$ was added to a part of the resin-bound peptide $(1.5 \mathrm{~g})$ and a solution of PyBOP (680 mg; $1.2 \mathrm{mmol})$ and DIPEA $(0.47 \mathrm{~mL} ; 2.7 \mathrm{mmol})$ in DCM $(4 \mathrm{~mL})$ was added to preactivate the carboxylic acid for $20 \mathrm{~min}$. A solution of 8 (340 mg; $0.56 \mathrm{mmol})$ in DCM (4 mL) was added, and the mixture was shaken for $14 \mathrm{~h}$ at $23^{\circ} \mathrm{C}$. Finally, the resin was drained and washed with DMF, MeOH and DCM (each 3 times for $3 \mathrm{~min}$ ), and then the conjugate was cleaved from the resin with simultaneous removal of side-chain protecting groups by treatment with TFA ( $5 \mathrm{~mL}$ with 5 drops of $\mathrm{H}_{2} \mathrm{O}$ added) for $2 \mathrm{~h}$ at $23^{\circ} \mathrm{C}$. Concentration of the reaction mixture afforded a crude product, which was purified by preparative HPLC using a gradient of $20 \% \rightarrow 80 \%$ B (20 min) to give prodrug 6 , which by analytical UHPLC had a purity of $>98 \%$ when using the same gradient $20 \% \rightarrow 60 \%$ B (10 min; retention time $7.4 \mathrm{~min}$ ). This fraction was evaporated to give a residue, which was dissolved in 1,4-dioxane- $\mathrm{H}_{2} \mathrm{O}$ and freeze-dried to give prodrug 6 (55 mg; 12\%) as a white solid. ${ }^{1} \mathrm{H}$ NMR $(600 \mathrm{MHz}$, methanol$\left.d_{4}\right) \delta$ ppm 7.45 (s, $1 \mathrm{H}, \mathrm{C}-3$ ), 5.52 (d, J = 4.4 Hz, $\left.1 \mathrm{H}, \mathrm{H}-7\right), 5.35$ (d, J = $10.0 \mathrm{~Hz}, 1 \mathrm{H}, \mathrm{H}-12$ ), 
$4.38(\mathrm{~m}, 1 \mathrm{H}, \alpha-\mathrm{H} \mathrm{Glu} 4), 4.36-4.31\left(\mathrm{~m}, 3 \mathrm{H}, \mathrm{\alpha}-\mathrm{H} \mathrm{Glu} \mathrm{u}_{1-3}\right), 4.20(\mathrm{~m}, 1 \mathrm{H}, \mathrm{\alpha}-\mathrm{H} \mathrm{Asp}), 3.84$ (dd, $J=$ 12.8, 9.8 Hz, $2 \mathrm{H}, \mathrm{H}-20), 3.20(\mathrm{~m}, 1 \mathrm{H}, \mathrm{H}-8), 3.13-3.07$ (m, $\left.2 \mathrm{H}, \mathrm{H}^{\prime}-12\right), 3.06(\mathrm{~m}, 1 \mathrm{H}, \mathrm{H}-10)$, 2.87 (dd, $J=4.4,16.5 \mathrm{~Hz}, 1 \mathrm{H}, \mathrm{H}_{\mathrm{a}}-\beta$ Asp), 2.71 (dd, $J=9.0,16.7 \mathrm{~Hz}, 1 \mathrm{H}, \mathrm{H}_{\mathrm{b}}-\beta$ Asp), 2.45 (d, $\left.J=19.1 \mathrm{~Hz}, 1 \mathrm{H}, \mathrm{H}_{\mathrm{a}}-5\right), 2.41\left(\mathrm{~d}, J=19.1 \mathrm{~Hz}, 1 \mathrm{H}, \mathrm{H}_{\mathrm{b}}-5\right), 2.36-2.27(\mathrm{~m}, 8 \mathrm{H}, \mathrm{y}-\mathrm{H} \mathrm{Glu}), 2.26$ (m, $2 \mathrm{H}, \mathrm{H}-2$ 12AD), $2.24-2.10\left(\mathrm{~m}, 4 \mathrm{H}, \beta-\mathrm{H} \mathrm{Glu}{ }_{1}+\mathrm{Glu}_{4}\right), 2.08(\mathrm{~m}, 1 \mathrm{H}, \mathrm{H}-11), 1.96(\mathrm{~s}, 3 \mathrm{H}$, $\mathrm{H}-2 \mathrm{Ac}), 1.93-1.80\left(\mathrm{~m}, 4 \mathrm{H}, \beta-\mathrm{H} \mathrm{Glu}{ }_{2}+\mathrm{Glu}_{3}\right), 1.64$ (dd, $\left.J=2.8,1.3 \mathrm{~Hz}, 3 \mathrm{H}, \mathrm{H}-19\right), 1.54$ (quin, $J=7.2 \mathrm{~Hz}, 2 \mathrm{H}, \mathrm{H}^{\prime}-3$ ), 1.40 (quin, $J=6.8 \mathrm{~Hz}, 2 \mathrm{H}, \mathrm{H}^{\prime}-11$ ), $1.28-1.19\left(\mathrm{~m}, 14 \mathrm{H}_{1} \mathrm{H}^{\prime}-10\right.$ $\left.\rightarrow \mathrm{H}^{\prime}-4\right), 1.16(\mathrm{~s}, 3 \mathrm{H}, \mathrm{H}-16), 1.12(\mathrm{~s}, 3 \mathrm{H}, \mathrm{H}-17), 1.06(\mathrm{~d}, J=5.4 \mathrm{~Hz}, 1 \mathrm{H}, \mathrm{H}-14), 0.79(\mathrm{~d}, J=$ $6.6 \mathrm{~Hz}, 3 \mathrm{H}, \mathrm{H}-18) .{ }^{13} \mathrm{C}$ NMR (150 MHz, methanol- $d_{4}$ ) $\delta$ ppm 208.93 (1 C, C-3), 174.99 (1 C, C-5 Glu 1 ) 174.25 (1 C, C'-1), 173.91 (1 C, C-1 AC), 173.61 (4 C, C-1 Glu $1-4$ ), 173.42 (1 C, C-5 $\mathrm{Glu}_{2}$ ), 172.75 (2 C, C-5 Glu 3 ) $), 169.20$ (1 C, C-1 Asp), 168.26 (1 C, C-5 Asp), 159.16 (1 C, C-1), 141.44 (1 C, C-6), 133.19 (1 C, C-2), 127.89 (1 C, C-7), 78.38 (1 C, C-9) 76.86 (1 C, C12), 73.32 (1 C, C-4), 66.57 (1 C, C-20), 65.73 (1 C, C-13), 55.93 (1 C, C-10), 52.00 (1 C, C$2 \mathrm{Glu}_{1}$ ), 51.78 (1 C, C-2 Glu 4$), 51.68$ (2 C, C-2 Glu $2+3$ ), 50.09 (1 C, C-2 Asp) 42.86 (1 C, C11), 39.28 (1 C, C'-12), 38.61 (1 C, C-8), 37.07 (1 C, C-5), 35.63 (1 C, C-14), 35.12 (1 C, C-3 Asp), 33.94 (1 C, C'-2), $31.55-31.50$ (1 C, C-4 Glu $2-4$ ), 29.85 (1 C, C-4 Glu 1 ), 28.60 - 29.29 (7 C, 7 C, C'-4 - C'-9 + C'-11), 27.06 (1 C, C-3 Glu 1 ), $26.90-26.85$ (2 C, C-3 Glu $2+3$ ), 26.64 (1 C, C'-10), 26.46 (1 C, C-3 Glu 2 ), 25.79 (1 C, C-15), 24.83 (1 C, C'-3) 22.70 (1 C, C-17), 19.67 (1 C, C-2 Ac), 15.97 (1 C, C-16), 13.43 (1 C, C-18), 8.81 (1 C, C-19). HRMS-ESI: $\left[\mathrm{C}_{58} \mathrm{H}_{86} \mathrm{~N}_{6} \mathrm{O}_{23}+\mathrm{H}\right]^{+} \mathrm{m} / \mathrm{z}: 1235.5822$ Found 1235.5818 
Sample ID

Data Filename :TZ69sclup3_fr1afterprepmain.Icd

Method Filename : $2060 \mathrm{~B} 10 \overline{\mathrm{m}}$ in purified $2014 . \mathrm{lcm}$

Batch Filename : 2017_11_29_1.Tcb

Vial \#

Injection Volume

me : 10 uL

Date Acquired : :11/29/2017

\section{Complete Chromatogram}

mAU

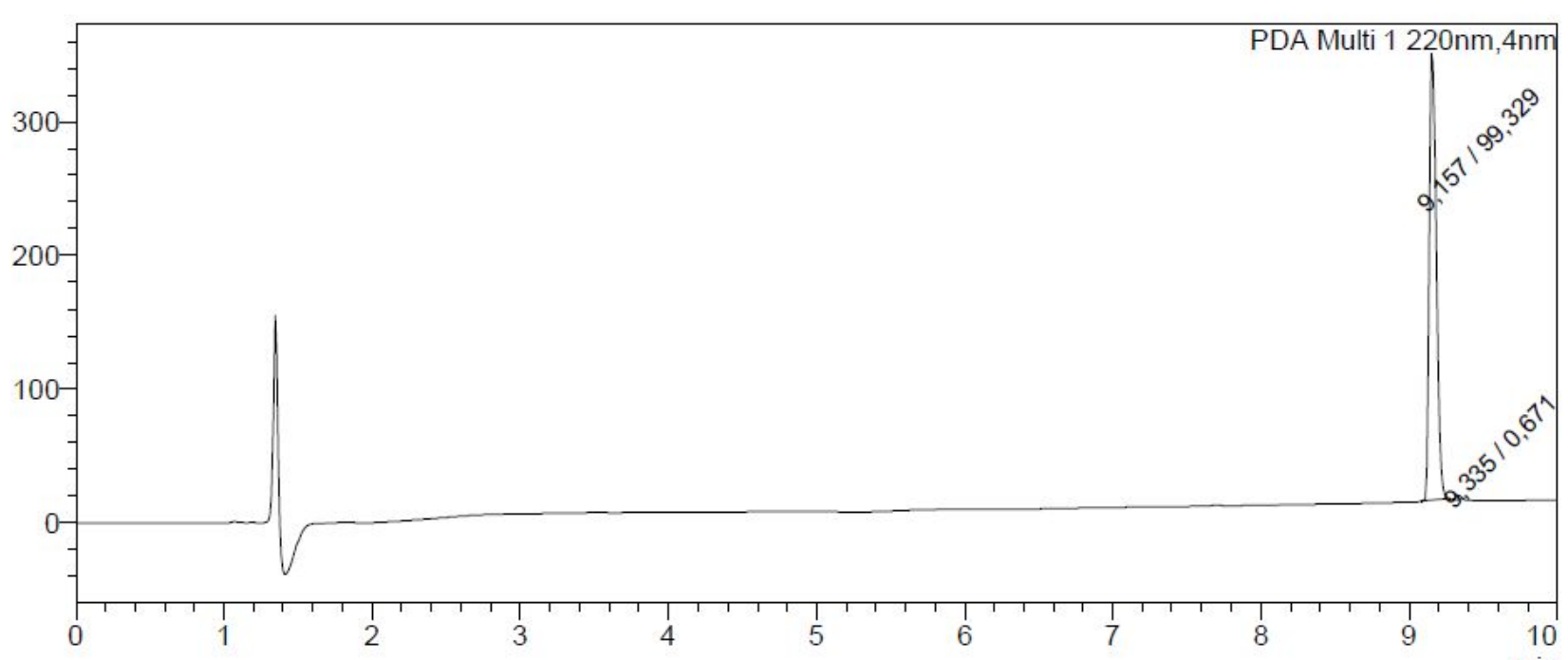

PDA Ch1 220nm
\begin{tabular}{|r|r|r|r|r|}
\hline Peak\# & Ret. Time & Area $\%$ & Height & Area \\
\hline 1 & 9,157 & 99,329 & 334237 & 1054005 \\
\hline 2 & 9,335 & 0,671 & 3021 & 7117 \\
\hline Total & & 100,000 & 337257 & 1061122 \\
\hline
\end{tabular}

Fig.S22: Compound 6 HPLC 


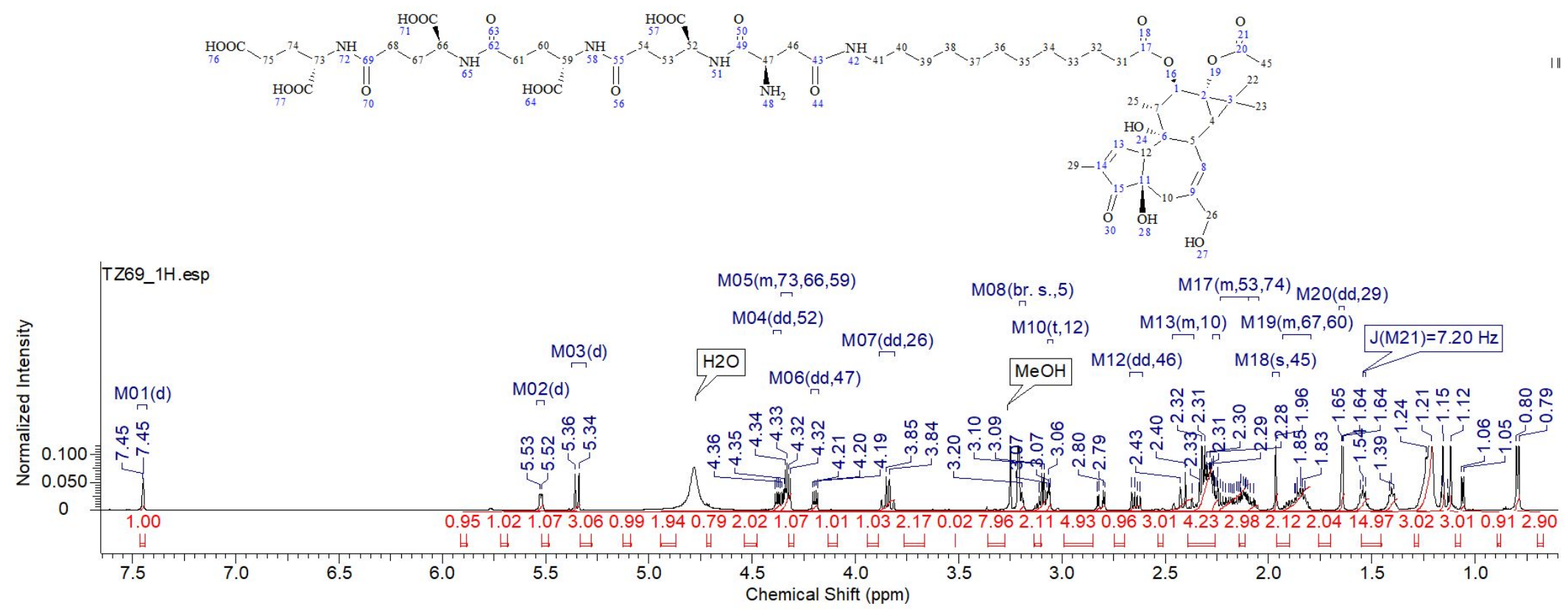

Fig.S23: Compound $6{ }^{1} \mathrm{H}$ NMR 


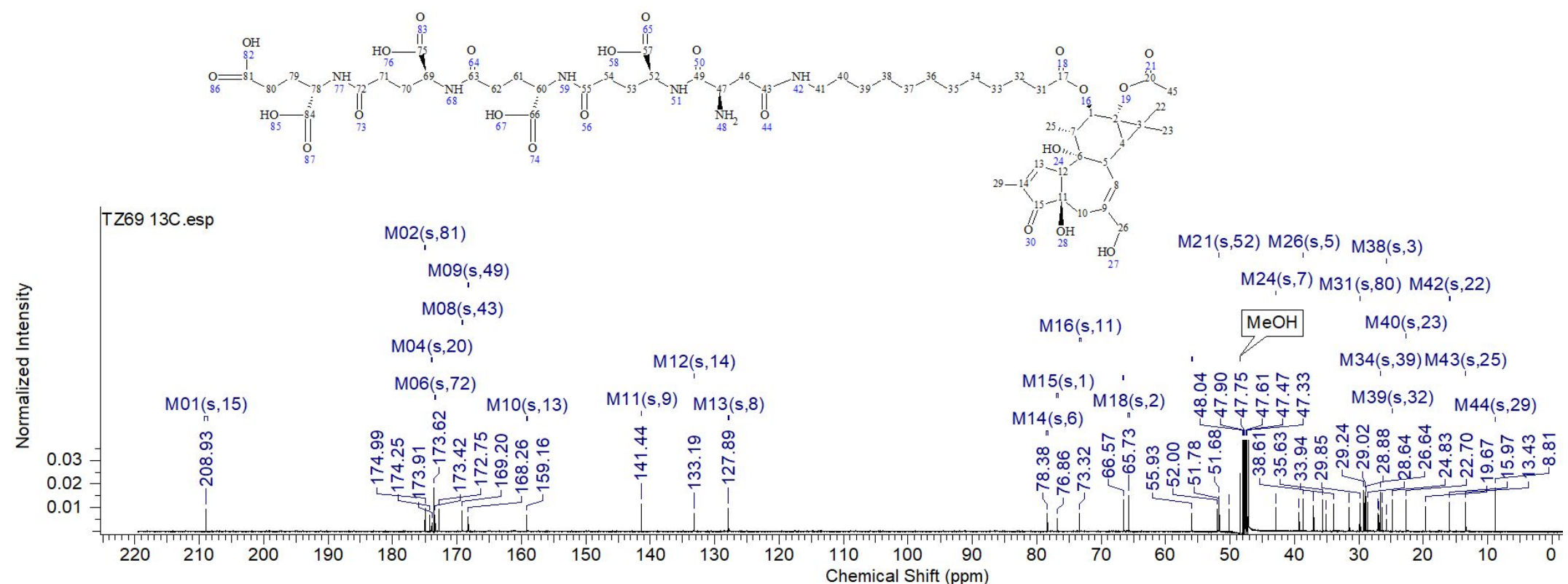

Fig.S24: Compound $6{ }^{13} \mathrm{C}$ NMR 


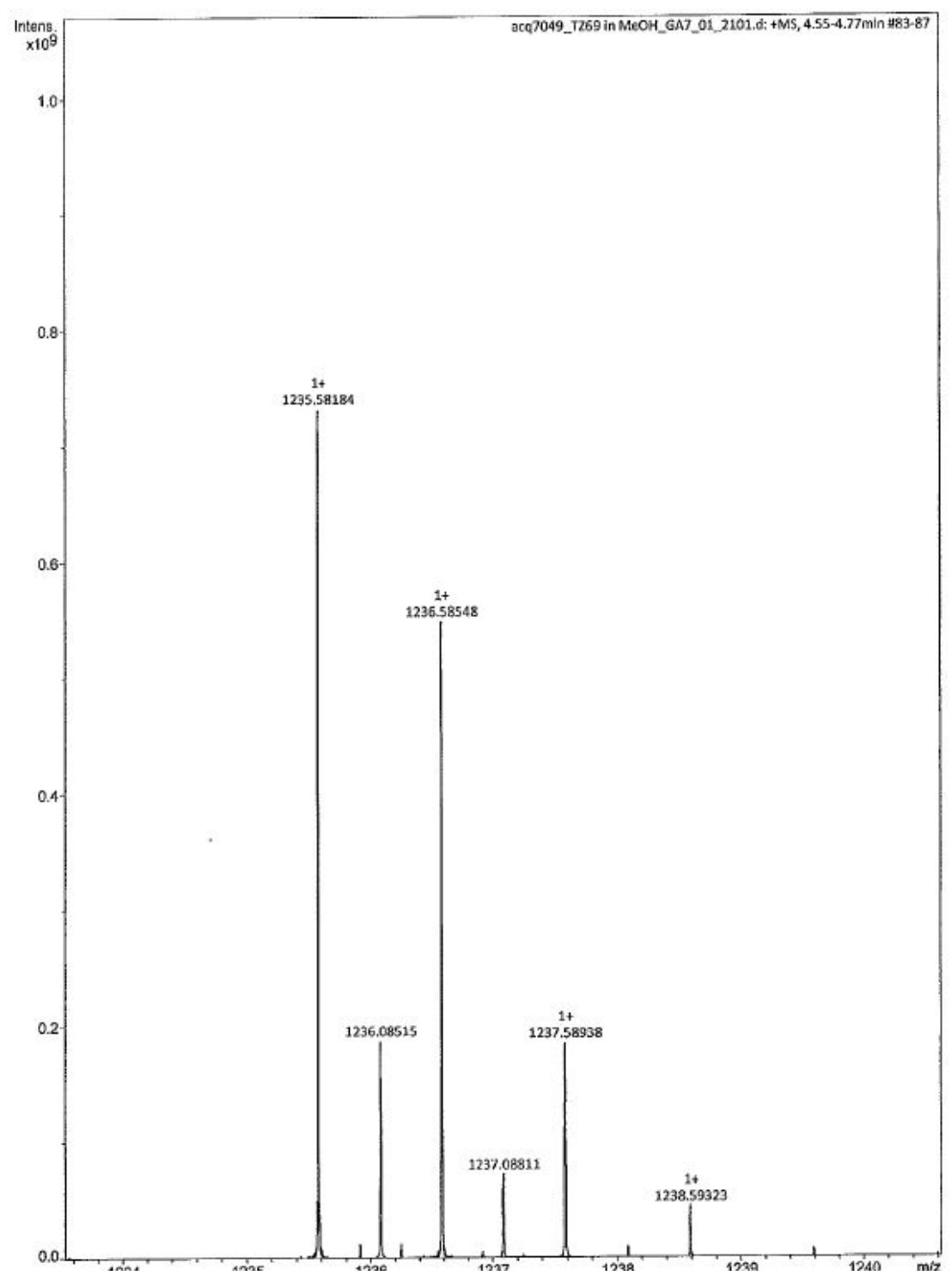

Fig.S25: Compound 6 HRMS 


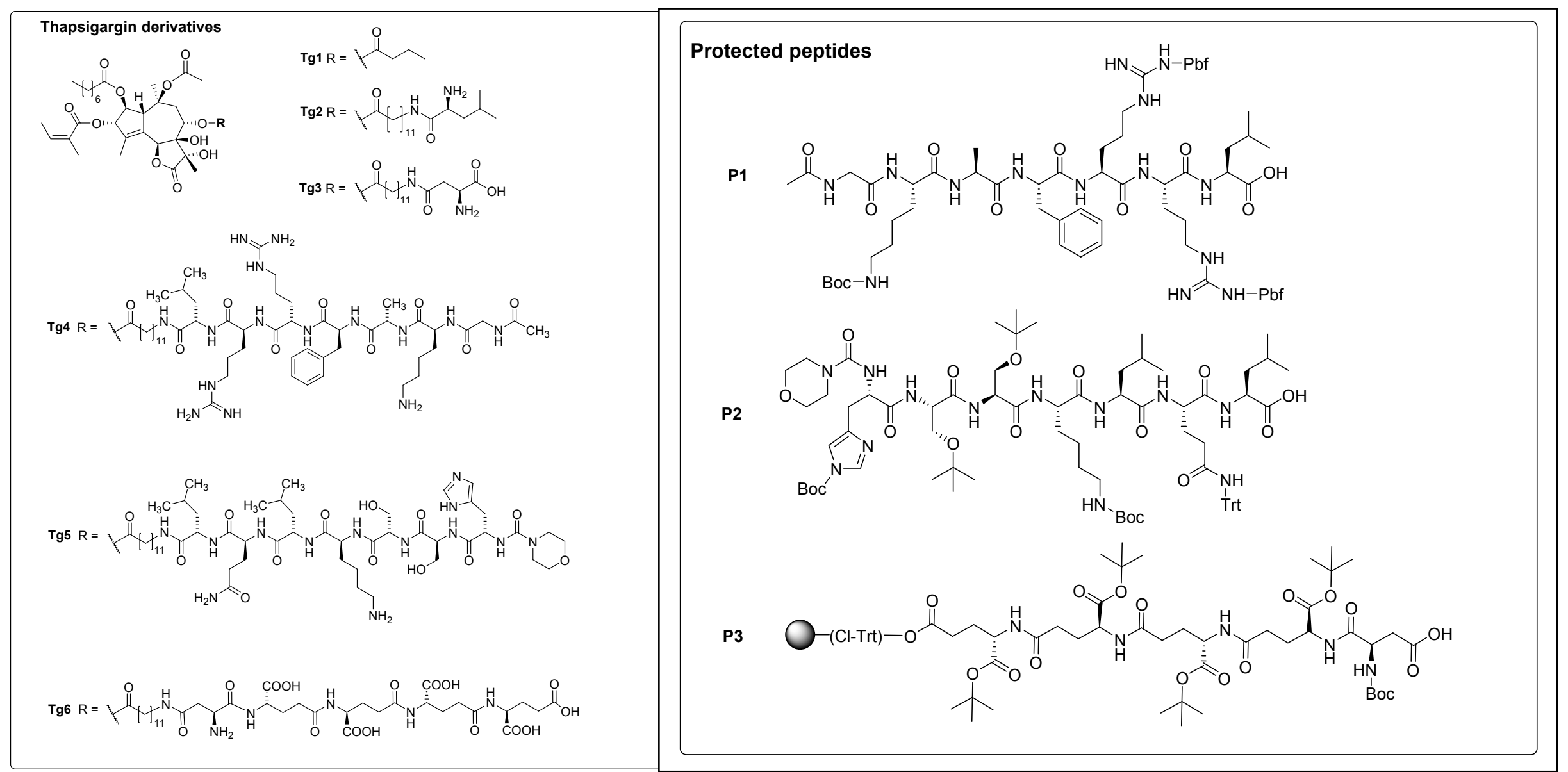

Fig.S26: Prodrugs and drugs of thapsigargin. Tg1 Thapsigargin, Tg2 N-Leu- 0 -8-12-aminododecanoyl-O-8-debutanoylthapsigargin, Tg3 $N$ - $\beta$ Asp-O-8-12-aminododecanoyl-O-8-debutanoylthapsigargin, Tg4 G114, prodrug designed for cleavage by hK2, Tg5 G115, prodrug designed for cleavage by PSA, Tg6 G202, mipsagargin, prodrug designed for cleavage by PSMA, P1 protected peptide substrate for hK2, P2 protected peptide substrates for PSA, P3 protected peptide substrate for PSMA. 


\section{S.3: Design of Prodrugs of Thapsigargin}

In the case of thapsigargin (Tg1, Fig. S26) selectivity toward cancer tissue was obtained by conjugation of the toxin with peptides that are substrates for human glandular kallikrein 2 , hK2, (prodrug Tg4), , 9 PSA (prodrug Tg5) or PSMA (prodrug Tg6, also named mipsagargin). ${ }^{10}$ Replacement of the butanoyl group with a 12-aminododecanoyl moiety enabled introduction of an anchoring point for a peptide. ${ }^{11,12}$ Compound Tg4 contains the peptide Gly-Lys-Ala-Phe-Lys-Arg-Leu, which is a favoured substrate for hK2. ${ }^{8,9}$ The Cterminal Leu is introduced since no cleavage with hK2 was observed in the absence of this amino acid. ${ }^{13}$ The hK2 protease is overexpressed in prostate tumours. ${ }^{8,12}$ The peptide sequence His-Ser-Ser-Lys-Leu-GIn-Leu in compound Tg5 is efficiently cleaved by PSA, ${ }^{12}$ while $\gamma$-Glu- $\gamma$-Glu- $\gamma$-Glu- $\gamma$-Glu- $\beta$-Asp is cleaved by PSMA. ${ }^{10}$ Again, the C-terminal amino acids ( Leu and $\beta$-Asp, respectively) were introduced to make the prodrugs substrates for the enzymes. Enzymatic cleavage of the prodrugs affords the active compounds ( $\operatorname{Tg} 2$ or Tg3). ${ }^{10}$, 12, 14 The peptides in Tg4 and Tg5 are capped with acetyl and morpholine groups, respectively, in order to increase solubility. Mipsagargin has successfully passed clinical trial $2^{15}$

\section{References}

1. Zimmermann, T.; Franzyk, H.; Christensen, S. B. Pborbol Rearrangements. J Nat Prod. 2018, 81.

2. Tammela, P.; Ekokoski, E.; Garcia-Horsman, A.; Talman, V.; Finel, M.; Tuominen, R.; Vuorela, P. Screening of natural compounds and their derivatives as potential protein kinase $C$ inhibitors. Drug Dev. Res. 2004, 63, 76-87.

3. Bradford, M. M. A rapid and sensitive method for the quantitation of microgram quantities of protein utilizing the principle of protein-dye binding. Anal. Biochem. 1976, 72, 248-54.

4. Boije af Gennas, G.; Talman, V.; Aitio, O.; Ekokoski, E.; Finel, M.; Tuominen, R. K.; YliKauhaluoma, J. Design, Synthesis, and Biological Activity of Isophthalic Acid Derivatives Targeted to the C1 Domain of Protein Kinase C. J. Med. Chem. 2009, 52, 3969-3981.

5. Wang, H.-B.; Wang, X.-Y.; Liu, L.-P.; Qin, G.-W.; Kang, T.-G. Tigliane Diterpenoids from the Euphorbiaceae and Thymelaeaceae Families. Chem. Rev. (Washington, DC, U. S.) 2015, 115, 29753011.

6. Shi, Q.-W.; Su, X.-H.; Kiyota, H. Chemical and Pharmacological Research of the Plants in Genus Euphorbia. Chem. Rev. (Washington, DC, U. S.) 2008, 108, 4295-4327.

7. Perlin, L.; MacNeil, S.; Rimmer, S. Cell adhesive hydrogels synthesised by copolymerisation of arg-protected Gly-Arg-Gly-Asp-Ser methacrylate monomers and enzymatic deprotection. Chem. Commun. (Camb.) 2008, 5951-3.

8. Lovgren, J.; Airas, K.; Lilja, H. Enzymatic action of human glandular kallikrein 2 (hK2). Substrate specificity and regulation by $\mathrm{Zn} 2+$ and extracellular protease inhibitors. European Journal of Biochemistry 1999, 262, 781-789.

9. Janssen, S.; Rosen, D. M.; Ricklis, R. M.; Dionne, C. A.; Lilja, H.; Christensen, S. B.; Isaacs, J. T.; Denmeade, S. R. Pharmacokinetics, biodistribution, and antitumor efficacy of a human glandular kallikrein 2 (hK2)-activated thapsigargin prodrug. Prostate 2006, 66, 358-368.

10. Denmeade, S. R.; Mhaka, A. M.; Rosen, D. M.; Brennen, W. N.; Dalrymple, S.; Dach, I.; Olesen, C.; Gurel, B.; DeMarzo, A. M.; Wilding, G.; Carducci, M. A.; Dionne, C. A.; Moeller, J. V.; Nissen, P.; Christensen, S. B.; Isaacs, J. T. Engineering a prostate-specific membrane antigen-activated tumor endothelial cell prodrug for cancer therapy. Sci. Transl. Med. 2012, 4, 140ra86, 13 pp.

11. Zimmermann, T.; Christensen, S. B.; Franzyk, H. Preparation of Enzyme-Activated Thapsigargin Prodrugs by Solid-Phase Synthesis. Molecules 2018, 23, 1463. 
12. Denmeade, S. R.; Jakobsen, C. M.; Janssen, S.; Khan, S. R.; Garrett, E. S.; Lilja, H.; Christensen, S. B.; Isaacs, J. T. Prostate-Specific Antigen-Activated Thapsigargin Prodrug as Targeted Therapy for Prostate Cancer. J. Natl. Cancer Inst. 2003, 95, 990-1000.

13. Akinboye, E. S.; Brennen, W. N.; Denmeade, S. R.; Isaacs, J. T. Albumin-linked prostatespecific antigen-activated thapsigargin- and niclosamide-based molecular grenades targeting the microenvironment in metastatic castration-resistant prostate cancer. Asian J Urol 2019, 6, 99-108.

14. Janssen, S.; Jakobsen, C. M.; Rosen, D. M.; Ricklis, R. M.; Reineke, U.; Christensen, S. B.; Lilja, H.; Denmeade, S. R. Screening a combinatorial peptide library to develop a human glandular kallikrein 2-activated prodrug as targeted therapy for prostate cancer. Mol. Cancer Ther. 2004, 3, 1439-1450.

15. Mahalingam, D.; Mahalingam, D.; Arora, S. P.; Sarantopoulos, J.; Peguero, J.; Campos, L.; Cen, P.; Rowe, J.; Allgood, V.; Tubb, B. A Phase II, Multicenter, Single-Arm Study of Mipsagargin (G-202) as a Second-Line Therapy Following Sorafenib for Adult Patients with Progressive Advanced Hepatocellular Carcinoma. Cancers (Basel) 2019, 11. 